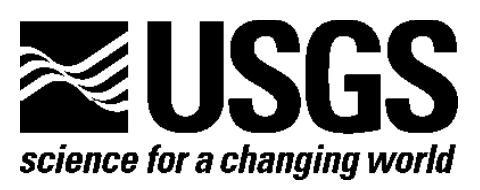

\title{
Incorporating Induced Seismicity in the 2014 United States National Seismic Hazard Model-Results of 2014 Workshop and Sensitivity Studies
}

By Mark D. Petersen, Charles S. Mueller, Morgan P. Moschetti, Susan M. Hoover, Justin L. Rubinstein, Andrea L. Llenos, Andrew J. Michael, William L. Ellsworth, Arthur F. McGarr, Austin A. Holland, and John G. Anderson

Open-File Report 2015-1070 


\section{U.S. Department of the Interior \\ SALLY JEWELL, Secretary}

\section{U.S. Geological Survey \\ Suzette M. Kimball, Acting Director}

U.S. Geological Survey, Reston, Virginia: 2015

For more information on the USGS-the Federal source for science about the Earth, its natural and living resources, natural hazards, and the environment-visit http://www.usgs.gov/ or call 1-888-ASK-USGS (1-888-275-8747).

For an overview of USGS information products, including maps, imagery, and publications, visit http://www.usgs.gov/pubprod/.

Any use of trade, firm, or product names is for descriptive purposes only and does not imply endorsement by the U.S. Government.

Although this information product, for the most part, is in the public domain, it also may contain copyrighted materials as noted in the text. Permission to reproduce copyrighted items must be secured from the copyright owner.

Suggested citation:

Petersen, M.D., Mueller, C.S., Moschetti, M.P., Hoover, S.M., Rubinstein, J.L., Llenos, A.L., Michael, A.J., Ellsworth, W.L., McGarr, A.F., Holland, A.A., and Anderson, J.G., 2015, Incorporating induced seismicity in the 2014 United States National Seismic Hazard Model-Results of 2014 workshop and sensitivity studies: U.S. Geological Survey Open-File Report 2015-1070, 69 p., http://dx.doi.org/10.3133/ofr20151070.

ISSN 2331-1258 (online) 


\section{Acknowledgments}

We wish to thank the workshop participants who made valuable suggestions for revising the 2014 U.S. Geological Survey (USGS) National Seismic Hazard Modeling Project maps and models to incorporate induced seismicity. We also thank the Oklahoma Geological Survey for cohosting the workshop with the USGS. We especially thank members of the National Seismic Hazard and Risk Assessment Steering Committee: Norm Abrahamson, Ken Campbell, Martin Chapman, Michael Hamburger, William Lettis, Nilesh Shome, Ray Weldon, Chris Wills, who reviewed the documentation, data, methods, and models, and provided excellent feedback that helped us to improve the quality of this product. We thank the National Earthquake Hazard Reduction Program (NEHRP) for funding the development of the maps. We also thank Teri Losano, Jill McCarthy, and Janet Slate for editing the manuscript. 


\section{Contents}

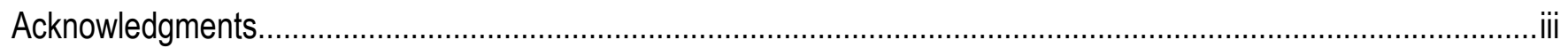

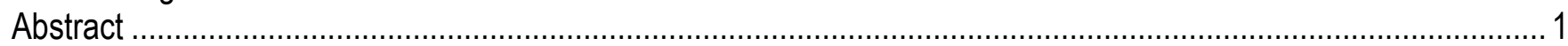

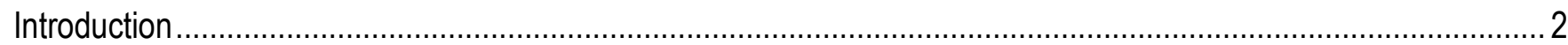

Hazard Models for Induced Seismicity .....................................................................................................

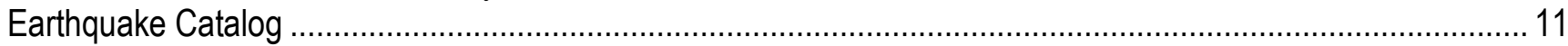

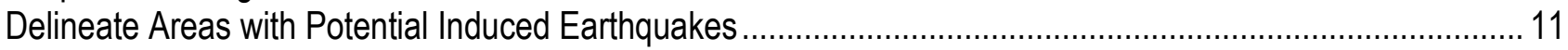

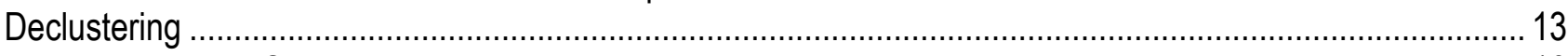

Relation Between Small and Large Earthquakes_b-Value .................................................................... 16

Magnitudes Used to Predict Future Earthquakes ………………......................................................... 18

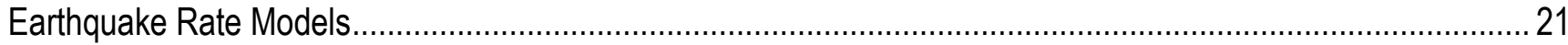

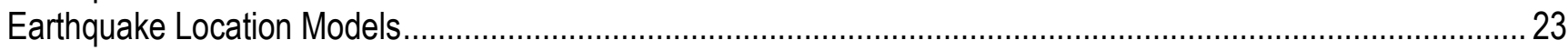

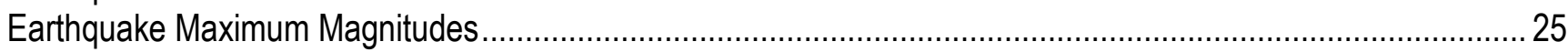

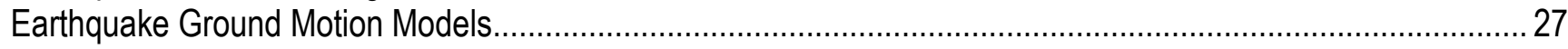

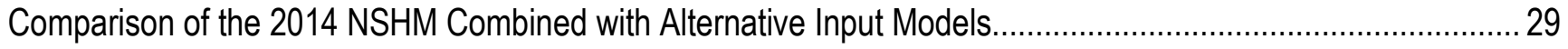

Seismic Hazard Products Suggested at the Workshop .............................................................................. 36

USGS Research Agenda for Induced Seismicity Hazard Studies.................................................................. 39

Short-Term Hazard Agenda for Induced Earthquakes (2015-16) ................................................................ 39

Long-Term Research Directions for Understanding Hazard from Induced Earthquakes (2015-20) .................... 40

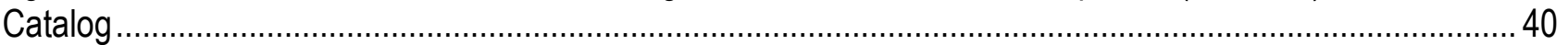

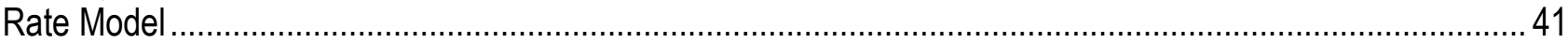

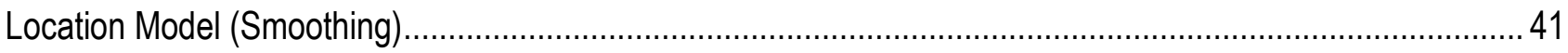

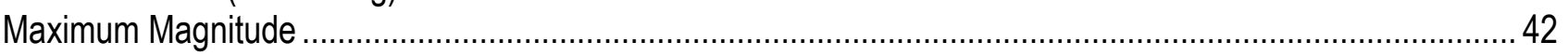

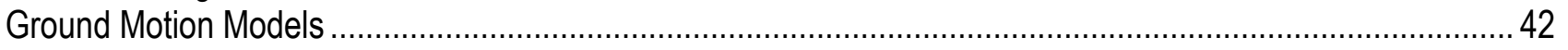

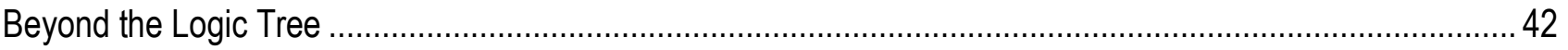

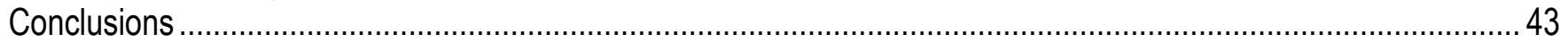

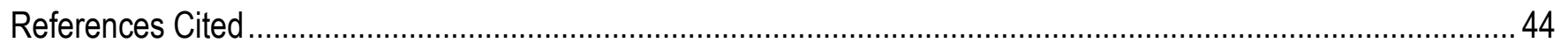

Appendix 1: Initial Likelihood Tests of Potential Seismicity-Rate Models for Induced Seismicity in Oklahoma,

Southern Kansas and North-Central Texas .......................................................................................... 49

Appendix 2: Recurrence Analysis in Recent (2001-14) Oklahoma Earthquakes .................................................58

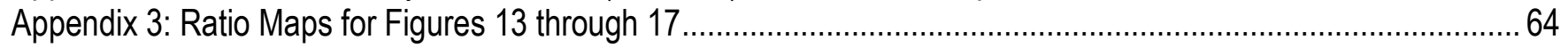

\section{Figures}

1. 2014 United States National Seismic Hazard Maps, 5-Hz spectral acceleration, 2-percent probability of exceedance in 50 years or 0.04 -percent probability of exceedance in 1 year on firm rock site condition. Areas where suspected induced seismicity because of fluid injection, mining, and conventional oil and gas production have been intentionally removed from the hazard model, and are shown as polygons.......... 3

2. Workshop participants' affiliations................................................................................................. 4

3. Polygons showing where potential induced earthquakes have been extracted for the following: $A$, Central and Eastern United States, $B$, Induced seismicity showing area near Oklahoma. C, Time histories of seismicity for 17 zones shown in in $3 A$....................................................................... 5

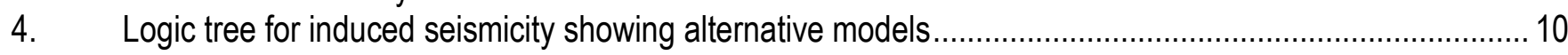

5. Sensitivity study comparing base model to declustered catalog model ................................................. 15 
6. Sensitivity study comparing a b-value (the slope of the curve that relates the numbers of small and large earthquakes) of 1.0 and 1.5 .

7. Sensitivity study comparing earthquake catalogs with minimum magnitude set at moment magnitude

(M) 2.5 and M2.7

8. Sensitivity study comparing earthquake catalogs with minimum magnitude set at moment magnitude

(M) 2.5 and M3.0

9. Sensitivity study comparing hazard calculated from 2014 and 2013 catalogs. The 2014 catalog is from November 1, 2013, to October 31, 2014. The 2013 catalog is from November 1, 2012, to October 31, 2013.

10. Sensitivity study comparing earthquake location models based on smoothing parameters with

5-kilometer (km) and 50-km width.

11. Sensitivity study comparing the NSHM craton maximum magnitude (Mmax) model (mean moment magnitude [M] 7), and an M6.0 maximum magnitude 26

12. Sensitivity study comparing low and high ground motion model...... 28

13. 2014 NSHM combined with induced seismicity hazard. Uniform hazard maps for 1-percent (top) and 0.04-percent (bottom) probability of exceedance in 1 year. This base case model uses a 2014 nondeclustered catalog with magnitudes greater than minimum magnitude (Mmin) 2.5, b-value equal to 1.0, 5 kilometers $(\mathrm{km})$ smoothing, 8 National Seismic Hazard Model (NSHM) ground motion models (GMM), and NSHM craton maximum magnitude (Mmax) model (mean M7)...

14. 2014 NSHM combined with induced seismicity hazard. Uniform hazard maps for 1-percent (top) and 0.04-percent (bottom) probability of exceedance in 1 year. This model uses a 2014 nondeclustered catalog with magnitudes greater than minimum magnitude (Mmin) 3.0, b-value equal to 1.0, 5 kilometers $(\mathrm{km})$ smoothing, 8 National Seismic Hazard Model (NSHM) ground motion models (GMM), and NSHM craton maximum magnitude (Mmax) model (mean M7)

15. 2014 NSHM combined with induced seismicity hazard. Uniform hazard maps for 1-percent (top) and 0.04-percent (bottom) probability of exceedance in 1 year. This model uses a 2014 declustered catalog with magnitudes greater than minimum magnitude (Mmin) 2.5, b-value equal to 1.0, 5 kilometers $(\mathrm{km})$ smoothing, 8 National Seismic Hazard Model (NSHM) ground motion models (GMM), and NSHM craton maximum magnitude (Mmax) model (mean M7) ....

16. 2014 NSHM combined with induced seismicity hazard. Uniform hazard maps for 1-percent (top) and 0.04-percent (bottom) probability of exceedance in 1 year. This model uses a 2014 nondeclustered catalog with magnitudes greater than minimum magnitude (Mmin) 2.5, b-value equal to 1.5, 5 kilometers $(\mathrm{km})$ smoothing, 8 National Seismic Hazard Model (NSHM) ground motion models (GMM), and NSHM craton maximum magnitude (Mmax) model (mean M7)

17. 2014 NSHM combined with induced seismicity hazard. Uniform hazard maps for 1-percent (top) and 0.04-percent (bottom) probability of exceedance in 1 year. This model uses a 2014 declustered catalog with magnitudes greater than minimum magnitude (Mmin) 2.5, b-value equal to 1.0, $50 \mathrm{~km}$ smoothing, 8 National Seismic Hazard Model (NSHM) ground motion models (GMM), and NSHM craton maximum magnitude (Mmax) model (mean M7).

18. Hazard curves for Fort Worth, Texas and Oklahoma City, Oklahoma for the 2014 National Seismic Hazard Model (black) and adding the induced seismicity component using the full nondeclustered or declustered catalogs with a b-value (the slope of the curve that relates the numbers of small and large earthquakes) of 1.0 or 1.5 , and for smoothing parameters of 5 kilometers $(\mathrm{km})$ or $50 \mathrm{~km}$..... 


\section{Tables}

1. Seventeen induced seismicity zones, Central and Eastern United States ............................................ 13

2. Central and Eastern United States ground motion models and weights in the 2014 hazard models ...........29

3. Median and 84th percentile ground motions for firm rock site condition (NEHRP BC) from Frankel and others (1996) 


\title{
Incorporating Induced Seismicity in the 2014 United States National Seismic Hazard Model-Results of 2014 Workshop and Sensitivity Studies
}

By Mark D. Petersen, Charles S. Mueller, Morgan P. Moschetti, Susan M. Hoover, Justin L. Rubinstein, Andrea L. Llenos, Andrew J. Michael, William L. Ellsworth, Arthur F. McGarr, Austin A. Holland, and John G. Anderson

\begin{abstract}
The U.S. Geological Survey (USGS) National Seismic Hazard Model (NSHM) for the conterminous United States was updated in 2014 to account for new methods, input models, and data necessary for assessing the seismic ground shaking hazard from natural (tectonic) earthquakes. The USGS NSHM project uses probabilistic seismic hazard analysis to quantify the rate of exceedance for earthquake ground shaking (ground motion). For the 2014 NSHM assessment, the seismic hazard from potentially induced earthquakes was intentionally not considered because we had not determined how to properly treat these earthquakes for the seismic hazard analysis. The phrases "potentially induced" and "induced" are used interchangeably in this report, however it is acknowledged that this classification is based on circumstantial evidence and scientific judgment. For the 2014 NSHM update, the potentially induced earthquakes were removed from the NSHM's earthquake catalog, and the documentation states that we would consider alternative models for including induced seismicity in a future version of the NSHM. As part of the process of incorporating induced seismicity into the seismic hazard model, we evaluate the sensitivity of the seismic hazard from induced seismicity to five parts of the hazard model: (1) the earthquake catalog, (2) earthquake rates, (3) earthquake locations, (4) earthquake Mmax (maximum magnitude), and (5) earthquake ground motions. We describe alternative input models for each of the five parts that represent differences in scientific opinions on induced seismicity characteristics. In this report, however, we do not weight these input models to come up with a preferred final model. Instead, we present a sensitivity study showing uniform seismic hazard maps obtained by applying the alternative input models for induced seismicity. The final model will be released after further consideration of the reliability and scientific acceptability of each alternative input model. Forecasting the seismic hazard from induced earthquakes is fundamentally different from forecasting the seismic hazard for natural, tectonic earthquakes. This is because the spatio-temporal patterns of induced earthquakes are reliant on economic forces and public policy decisions regarding extraction and injection of fluids. As such, the rates of induced earthquakes are inherently variable and nonstationary. Therefore, we only make maps based on an annual rate of exceedance rather than the 50-year rates calculated for previous USGS hazard maps.

To discuss the latest research on induced seismic activity, and to obtain feedback on products that will be useful for decision makers, the USGS and the Oklahoma Geological Survey cohosted a workshop that included about 150 participants from academia, industry, and government on 17-19 November 2014 in Midwest City, Oklahoma. In this report we summarize the discussions from this
\end{abstract}


workshop, show alternative input models and corresponding uniform hazard maps, and describe a research agenda for improving future seismic hazard assessment products. Probabilistic ground motions are calculated at 1-percent and 0.04-percent probability of exceedance in 1 year. The annual frequencies of the 0.04-percent probability of exceedance in a 1-year uniform hazard map and the 2-percent probability of exceedance in a 50-year uniform hazard map are equivalent. The sensitivity studies are developed for peak horizontal ground acceleration, 5-Hertz $(\mathrm{Hz})$, and 1-Hz spectral acceleration on a uniform firm rock site condition; only $5-\mathrm{Hz}$ spectral acceleration ground motions are shown in the report. Preliminary results indicate very large changes in probabilistic ground motion depending on the following: range of earthquake magnitudes applied in the forecast model, whether or not clustered earthquakes (foreshocks, aftershocks, and swarms) are included, the slope (b-value) of the curve that relates the numbers of small and large earthquakes, efficacy of using seismicity from one year to predict the following year's activity, degree of spatial smoothing, assumed maximum magnitude of future earthquakes, and the ground motion models applied in the analysis. Regardless of the choice of the alternative input models examined in this study, we find that potentially induced seismicity greatly increases the seismic hazard in Oklahoma and in the other induced seismicity zones compared to seismic hazard assessed for the 2014 update of the National Seismic Hazard Model.

\section{Introduction}

During the past several decades, the U.S. Geological Survey (USGS) has provided the National Seismic Hazard Model (NSHM) which is applied in earthquake mitigation strategies, risk assessments, insurance rate structures, and seismic-design regulations for buildings, bridges, highways, railroads, and other structures (Algermissen and Perkins, 1976; Frankel and others, 1996, 2002; Petersen and others, 2008, 2012, 2014). The NSHM considers where future earthquakes will occur, how often they will occur, and how strong the ground shaking will be. The final model, for the contiguous 48 States, is updated every 6 years based on new data, input models, and methods that have become available since the last update. The final probabilistic seismic hazard model is constructed using the best available science, allowing for variability in the input seismic model parameters and for alternative input models proposed by the scientific community. Products resulting from the model can be displayed as uniform probabilistic seismic hazard maps with a 2-percent probability of exceedance in 50 years (fig. 1), or as hazard curves that show the probability of exceedance in 50 years for each given ground shaking level. The NSHM affects economic and safety decisions across the United States. 


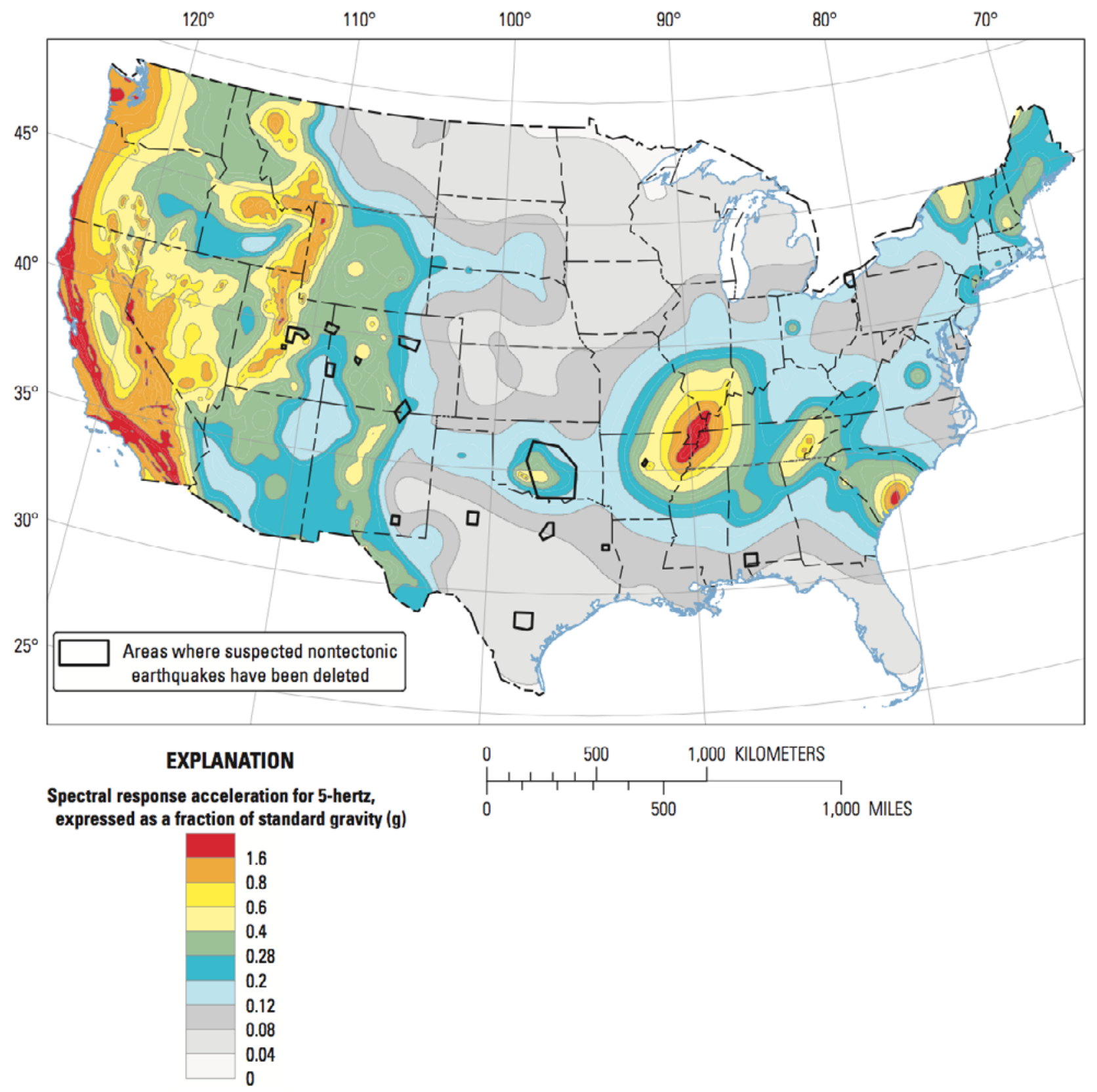

Figure 1. 2014 United States National Seismic Hazard Maps, 5-Hz spectral acceleration, 2-percent probability of exceedance in 50 years or 0.04 -percent probability of exceedance in 1 year on firm rock site condition. Areas where suspected induced seismicity because of fluid injection, mining, and conventional oil and gas production have been intentionally removed from the hazard model, and are shown as polygons. Three of the polygons contain seismicity associated with coal production (one zone is near Paonia, Colorado, and two zones are related to coal fields in central Utah).

Nontectonic earthquakes were deleted in earlier National Seismic Hazard Model versions, either because the causative industrial process had been suspended or because the earthquakes did not appear to pose a significant hazard. However, dramatic increases in seismicity rates have been observed in the Central United States in the past 5 to 7 years. This increase is reported to be stimulated by injection of wastewater or other fluids in deep disposal wells (Healy and others, 1968; Raleigh and others, 1976; 
Seeber and others, 2004; Frohlich and others, 2011; Horton, 2012; Ellsworth, 2013; Keranen and others, 2013; Llenos and Michael, 2013; Block and others, 2014; Rubinstein and others, 2014a, b; Sumy and others, 2014). In addition, scientists studying the $2011 \mathrm{M}_{\mathrm{W}}$ (moment magnitude) 5.6 Prague, Oklahoma earthquake suggested that deep injection of wastewater could trigger earthquakes with enough strength to damage nearby structures (Keranen and others, 2013). The increased rate of earthquakes (including potentially induced earthquakes) translates into an increased earthquake hazard. The phrases "potentially induced seismicity," "induced seismicity," "potentially induced earthquakes" or "induced earthquakes" are used interchangeably in this report, and indicate that the seismicity in a given region has shown an increased earthquake rate that can be attributed to human activities, such as fluid injection or extraction. We acknowledge that this classification is based on circumstantial evidence and scientific judgment. Difficulties in assessing seismic hazard arise from a lack of relevant technical information on human industrial activity (that is, pumping data for injection wells). Thus, in this report we do not explore the causes of the increased seismicity, but rather try to find a way to quantify the associated hazard. Also, this report does not address the seismic hazard from induced earthquakes because of mining activities, for example, rock bursts or coal bumps.

For the 2014 hazard models (Petersen and others, 2014) we delineated and removed suspected induced seismicity. We advised users that the seismic hazard would be higher in these areas from the additional induced seismicity than the seismic hazard depicted on the 2014 NSHM. To better assess the seismic hazard contributed by these induced earthquakes, the USGS and the Oklahoma Geological Survey cohosted a workshop focused on the seismic hazard from induced seismicity November 17-19, 2014 in Midwest City, Oklahoma. The purpose of the workshop was to seek feedback from the scientific and user communities on how to best assess the hazard and what products would be most useful for those who need to make business and public safety decisions. The workshop included about 150 in-person and webcast participants from academia, government, and industry (fig. 2), including the USGS National Seismic Hazard and Risk Assessment Steering Committee. The Steering Committee provides external advice, guidance, and review of the data, input models, and methods used in the seismic hazard analysis.

\section{Workshop Attendee Affiliation}

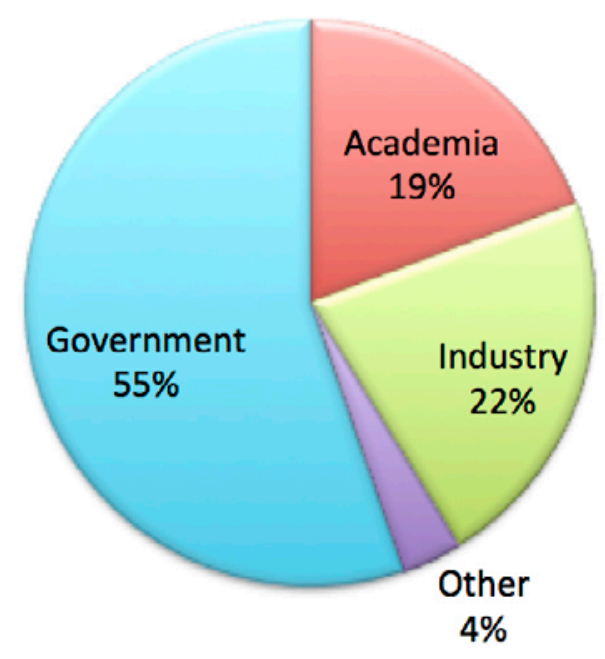

Figure 2. Workshop participants' affiliations. 
Conclusions of the workshop and meeting indicated that induced earthquakes are difficult to include in probabilistic seismic hazard analysis because the hazard is (1) highly variable spatially and temporally, (2) dependent on human economic or societal decisions regarding when to initiate or terminate wastewater disposal and how much fluid (volume) would be injected or extracted, (3) conditional on understanding differences between source and ground shaking characteristics of induced and natural earthquakes, and (4) dependent on the length and depth extent of the causative faults, which are generally unknown. For this 2015 sensitivity study, we redefine the 2014 zones based on locations of earthquakes that have been attributed to human activities such as wastewater injection and hydraulic fracturing.

Induced seismicity patterns and rates vary across the Central United States. The locations and rates of earthquakes for the past 50 years at each of the 17 induced seismicity zones are shown in figure 3. Patterns of increased seismicity vary considerably between the different areas. Some areas show pulses of increased activity interspersed between periods with little or no activity (for example, Cogdell, Texas, and Rangely, Colorado). Other areas (such as central Oklahoma and southern Kansas) show exponential growth patterns of seismicity that are continuing today (2015). In a few places, seismic activity increased as pumping began but diminished or ceased when the pumping stopped, sometimes with a lag time before the earthquake activity terminated (for example, Rocky Mountain Arsenal, Colorado). It is important to recognize that the induced seismicity behavior differs substantially between zones, so these rate characteristics need to be evaluated for each zone separately.

$A$

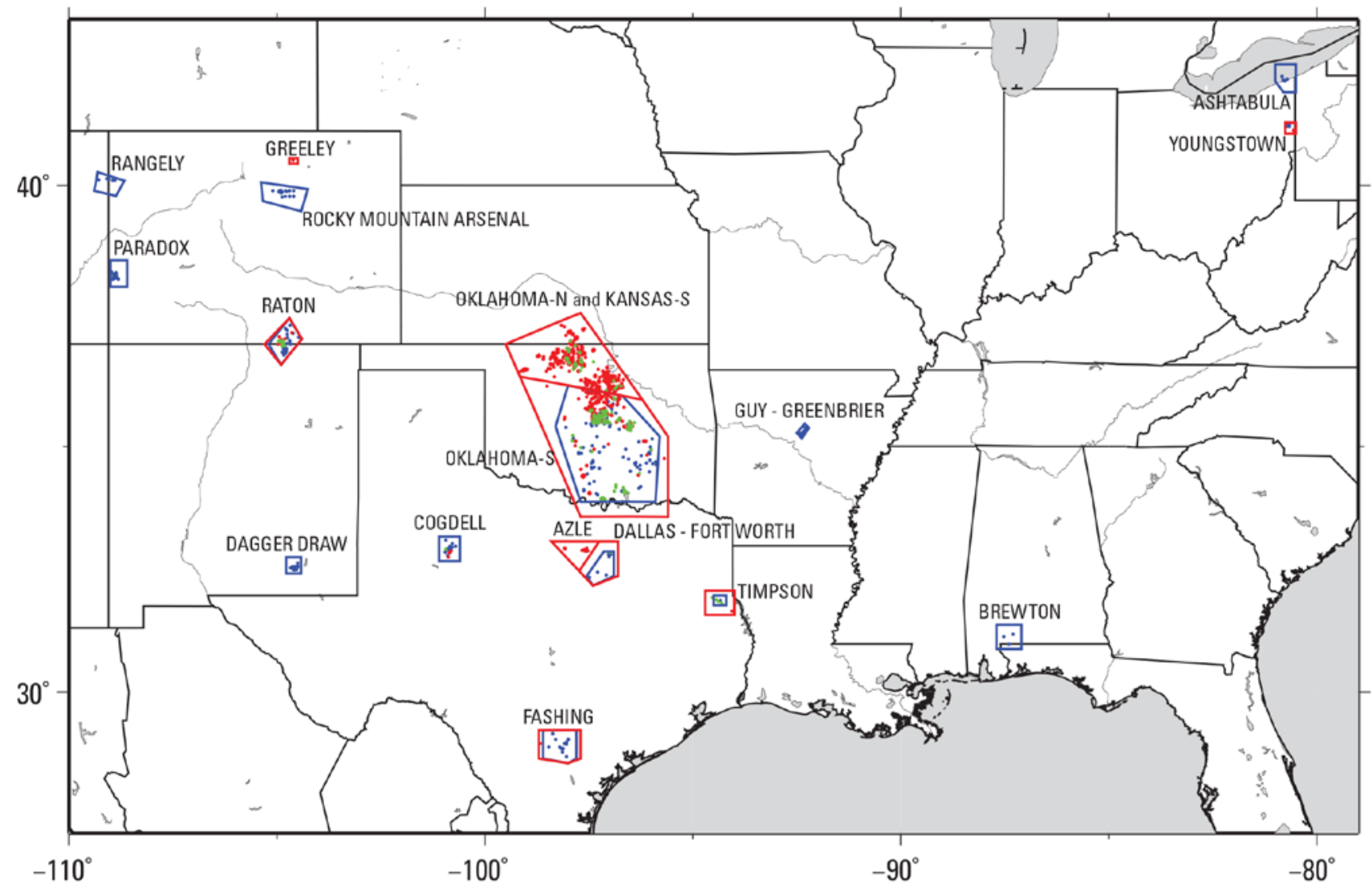

Figure 3. Polygons showing where potential induced earthquakes have been extracted for the following: $A$, Central and Eastern United States, $B$, Induced seismicity showing area near Oklahoma. For $3 A$ and $3 B$ 
Red $=2014$ nondeclustered catalog, Green $=2013$ nondeclustered catalog, Blue $=2012$ and previous using a declustered catalog. C, Time histories of seismicity for 17 zones shown in in $3 A$, blue lines represent nondeclustered catalog and red lines represent declustered catalog. The minimum magnitude (Mmin) used in these plots is M2.7.

$B$

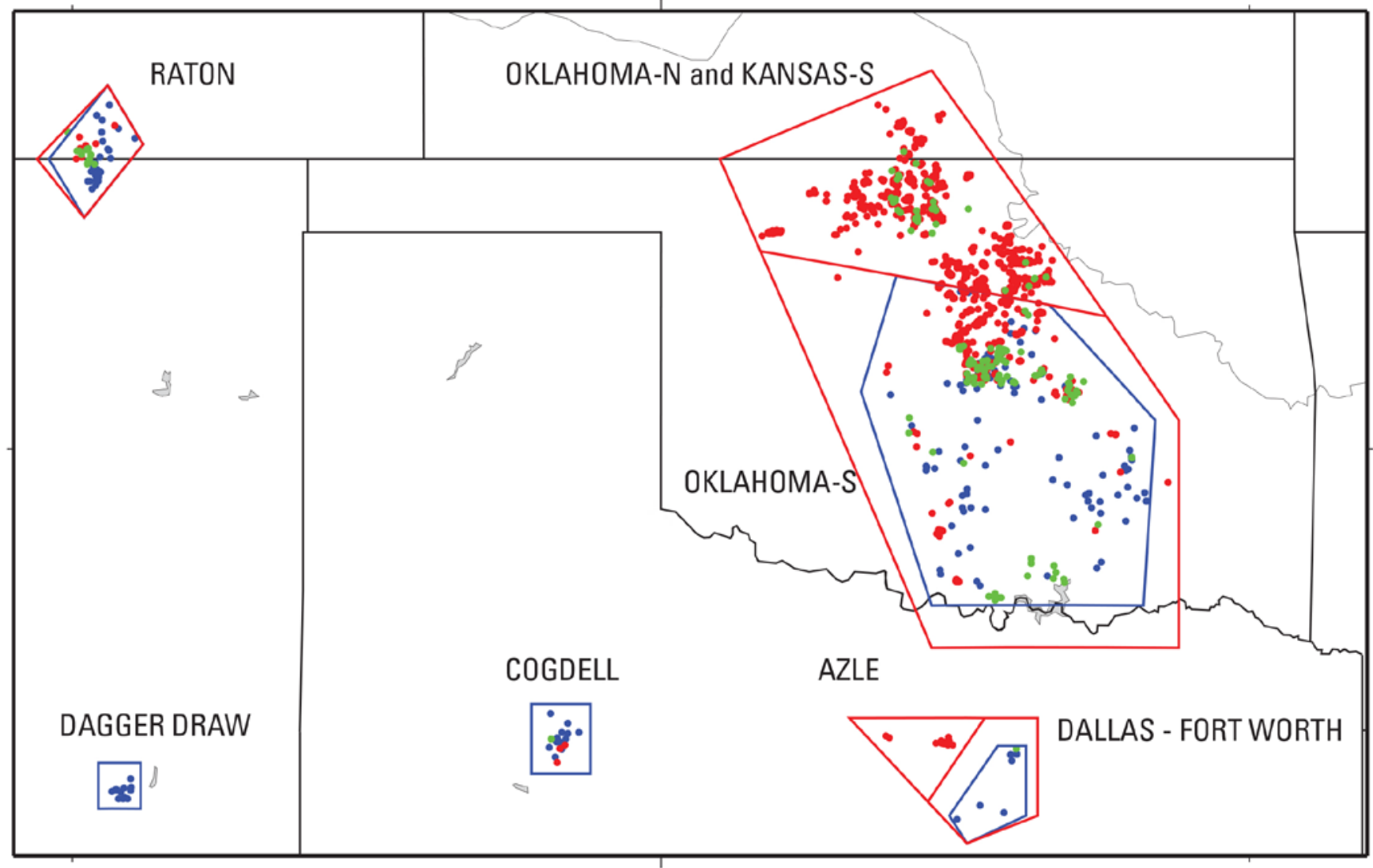

$-100^{\circ}$

Figure 3. Polygons showing where potential induced earthquakes have been extracted for the following: $A$, Central and Eastern United States, $B$, Induced seismicity showing area near Oklahoma. For $3 A$ and $3 B$ Red $=$ 2014 nondeclustered catalog, Green $=2013$ nondeclustered catalog, Blue $=2012$ and previous using a declustered catalog. C, Time histories of seismicity for 17 zones shown in in $3 A$, blue lines represent nondeclustered catalog and red lines represent declustered catalog. The minimum magnitude (Mmin) used in these plots is M2.7.-Continued 

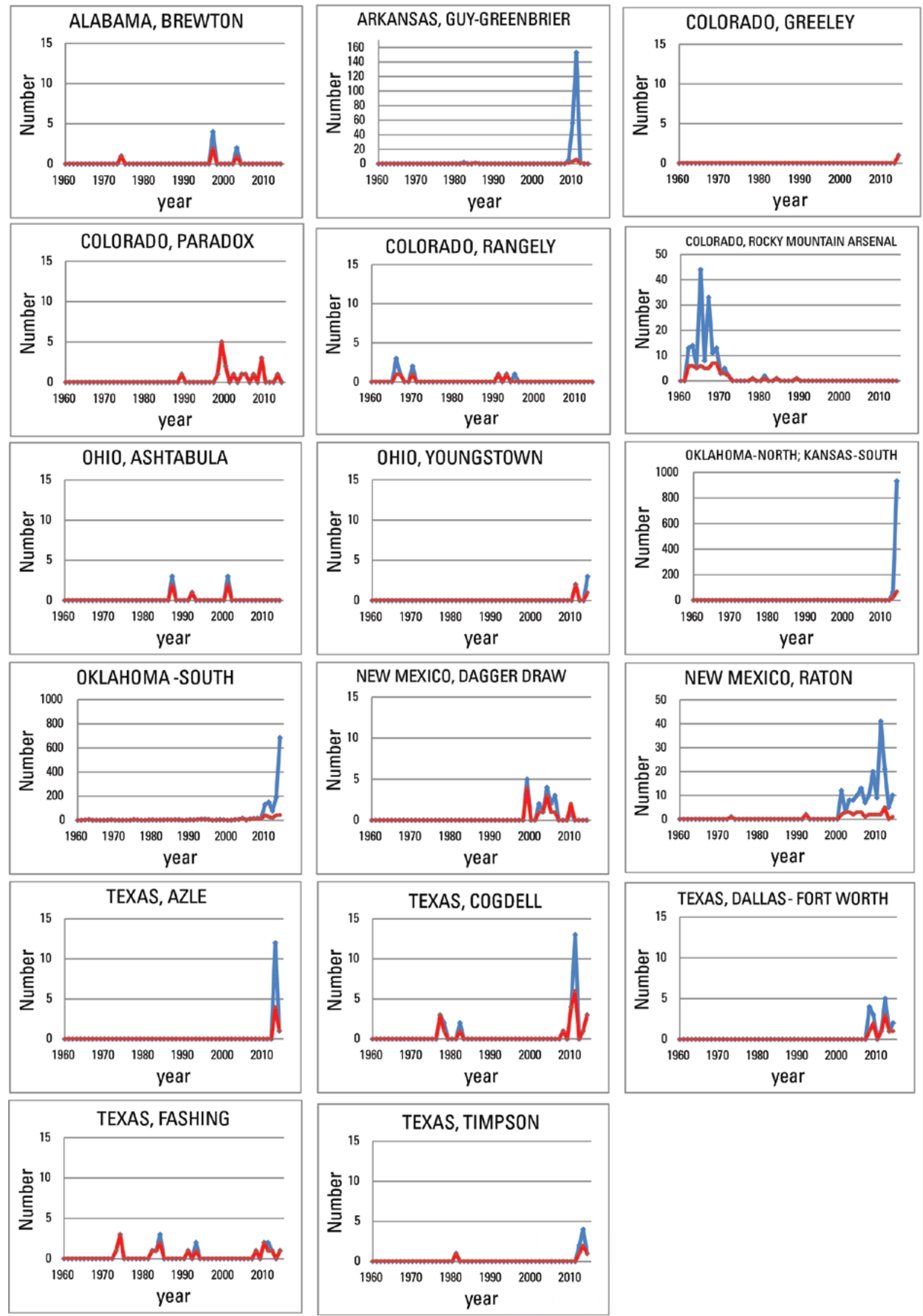
Figure 3. Polygons showing where potential induced earthquakes have been extracted for the following: $A$, Central and Eastern United States, $B$, Induced seismicity showing area near Oklahoma. For $3 A$ and $3 B$ Red $=$ 2014 nondeclustered catalog, Green $=2013$ nondeclustered catalog, Blue $=2012$ and previous using a declustered catalog. C, Time histories of seismicity for 17 zones shown in in $3 A$, blue lines represent nondeclustered catalog and red lines represent declustered catalog. The minimum magnitude (Mmin) used in these plots is M2.7.-Previous page 
In this report, we describe the workshop discussions pertaining to the inputs necessary for seismic hazard evaluation, show how the hazard varies depending on different modeling choices within 17 areas of increased seismic activity, and submit a research agenda that will be critical for developing new input models that consider this activity. The main objective of this report is to show results from sensitivity studies that will guide future model development. This report is organized into three primary sections. First, technical suggestions from participants are discussed and results of the sensitivity tests are presented in the section "Hazard Models for Induced Seismicity." Second, product suggestions and attendee questions are outlined in the section on "Seismic Hazard Products Suggested at the Workshop." Finally, potential research directions are described at the end of the report in a section entitled "USGS Research Agenda for Induced Seismicity Hazard Studies." Three appendices also are included that describe the results of studies on induced seismic hazard.

\section{Hazard Models for Induced Seismicity}

Seismic hazard analyses provide information about the expected ground shaking from future, damaging earthquakes. Probabilistic Seismic Hazard Analysis (PSHA) (Cornell, 1968) provides the framework for computing the rate of exceeding a particular ground shaking level caused by these earthquakes. The analysis is based on where and how often future earthquakes will occur and how strongly the ground will shake. While there are many hazards associated with earthquakes, including liquefaction, tsunamis, and landslides, for the purpose of this report, we only address one: the ground shaking (or ground motion). As such, the induced seismicity PSHA sensitivity tests that we carry out for this report provide rates of exceeding a set of ground motion at sites across the United States. We use the standard assumption of Poissonian earthquake occurrences, $P(\lambda, t)=1-e^{-\lambda t}$ to compute probabilities of exceedance, $\mathrm{P}$, from rates of exceedance, $\lambda$, within specified time periods, $t$. This distribution implies that the probabilities are time-independent.

In this report, we refer to the probabilities or rates of exceedance as the 'hazard' or as the 'hazard level,' and we refer to the ground motions as the 'probabilistic ground motions,' indicating that the computed ground motions are derived from a probabilistic distribution. The sensitivity results

presented in this report examine the impact of the probabilistic ground motions at a fixed hazard level to the seismic source and ground motion models developed for the induced seismicity.

The hazard calculations depend on five inputs that are well established in the probabilistic hazard methodology: the earthquake catalog, the earthquake rate model, the earthquake location model, the maximum magnitude model, and the ground motion model. The earthquake catalog is used to statistically assess where and how often future earthquakes may occur. We use $\mathrm{M}$ or $\mathrm{M}_{\mathrm{W}}$ to represent moment magnitude in this report. The earthquake rate model assumes that the rate of smaller earthquakes near a site can be used to predict the rate of larger earthquakes (by assuming that earthquake magnitude follows a truncated exponential distribution). The earthquake location model assumes that future moderate to large earthquakes will occur in the vicinity of past smaller earthquakes. The maximum magnitude model assumes alternatives for the magnitude at which the probability density function of earthquake magnitude is truncated. The ground motion model relates earthquake magnitudes and distances to the strength of ground shaking at a site. We implement these five inputs using a logic tree approach (Petersen and others, 2014) that formally accounts for a range of alternative interpretations of data, models, and methods. A logic tree for the induced seismicity portion of the hazard is shown in figure 4 . In the text that follows, we discuss each branch of the logic tree and the sensitivity of hazard models to the different input choices. 


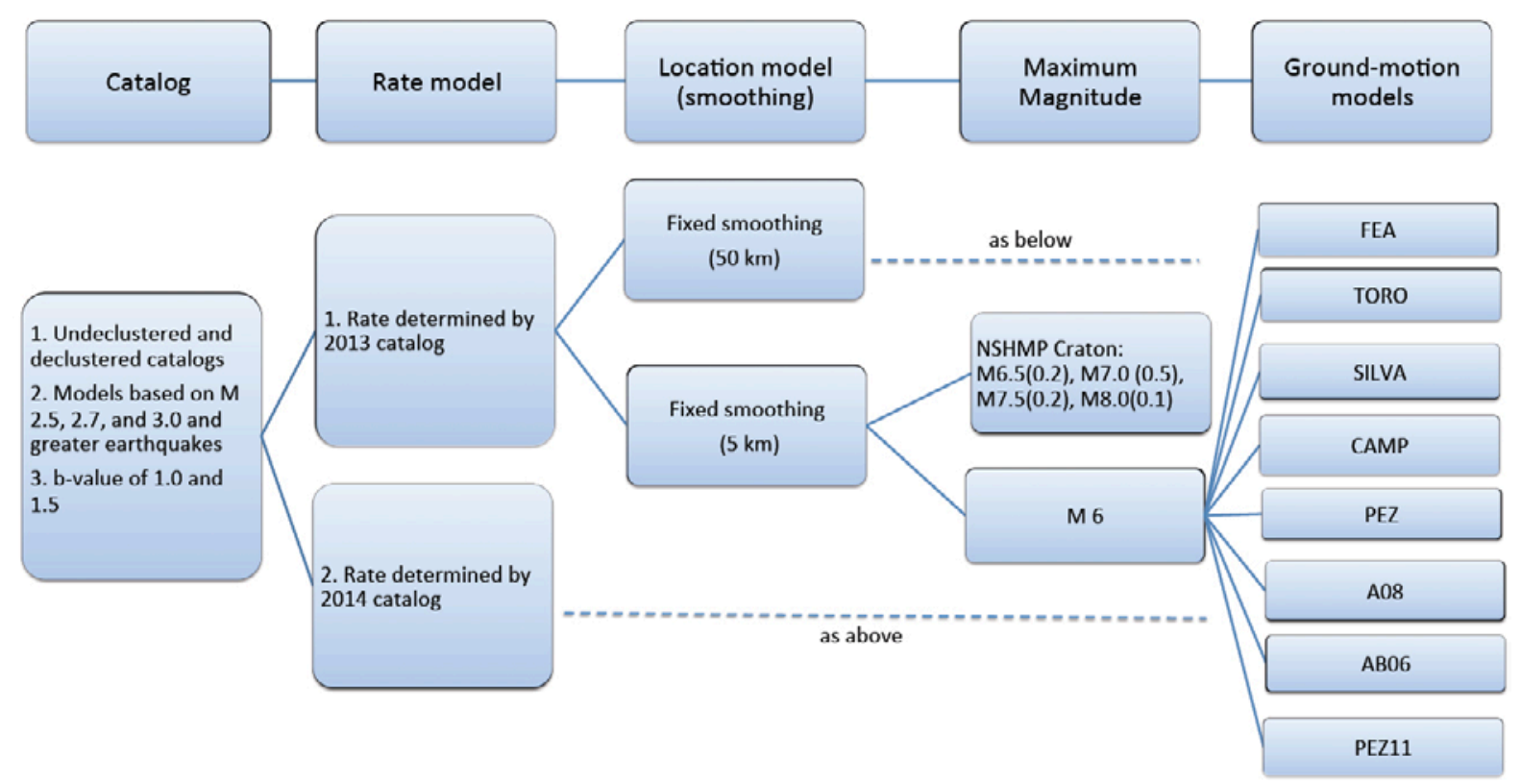

Figure 4. Logic tree for induced seismicity showing alternative models. $M$ is moment magnitude, b-value is the slope of the curve that relates the numbers of small and large earthquakes, km is kilometers, NSHMP is National Seismic Hazard Modeling Project, FEA is Frankel and others (1996), TORO is Toro and others (1997) and Toro (2002), SILVA is Silva and others (2002), CAMP is Campbell (2003), PEZ is Tavakoli and Pezeshk (2005), A08 is Atkinson (2008), AB06 is Atkinson and Boore (2006), and PEZ11 is Pezeshk and others (2011).

For the sensitivity study, we use the parameters that were favored by many participants at the workshop. These choices, however, do not constitute our final model, and impacts and science are still being analyzed. For the base model, which is used to compare all the alternative models, we consider the 17 areas and associated seismicity catalogs shown in figure 3. For this model we incorporate the nondeclustered catalog (which contains some statistically dependent events), we extrapolate from small to large earthquakes using a slope (b-value) of 1.0, we use earthquakes greater than M2.5 minimum magnitude (Mmin) to predict larger earthquakes, we apply a 1-year catalog (11/1/2013 to $10 / 31 / 2014)$ to predict the activity for the following year, we apply a 5-kilometer $(\mathrm{km})$ fixed length smoothing parameter to assess the locations of future earthquakes, we model earthquakes from magnitude 4.7 to as much as the maximum magnitudes considered in the 2014 NSHM (with a mean of M7, but with a distribution extending down to M6.5 and as much as M7.9), and we apply the 8 ground motion models that were considered in the 2014 NSHMs. Each of these decisions will be reevaluated in developing the final models. Primary results of the sensitivity studies are presented as uniform hazard maps and difference maps with respect to the base model. Probabilistic ground motions are calculated at 1-percent and 0.04-percent probability of exceedance in 1 year (rather than the typical 50-year period) for 5-Hz spectral acceleration, on a uniform firm rock site. The ground motion models have been modified from the hard-rock site condition (soil type A) to the firm-rock site condition (BC, which is the boundary between soil types B and C). For this study, we apply a National Earthquake Hazards Reduction Program (NEHRP, Building Seismic Safety Council, 2009) shear wave velocity (time-average) in the upper 30 meters $\left(\mathrm{V}_{\mathrm{S} 30}\right)$ of 760 meters per second $(\mathrm{m} / \mathrm{s})$. In this report we focus on the 5-Hz spectral acceleration ground motions, but have calculated peak horizontal ground acceleration (PGA) and 1-Hz spectral accelerations that are typically lower than the 5-Hz motions by factors of 1.7 and 3.4, respectively. 


\section{Earthquake Catalog}

The earthquake catalog contains the locations and magnitudes of recorded past earthquakes and can be used to assess rates and locations of future earthquakes (appendix 1). The earthquake catalog used in this analysis is based on the USGS Advanced National Seismic System (ANSS) Comprehensive Catalog (ComCat: http://earthquake.usgs.gov/earthquakes/map/doc_aboutdata.php), which should include all of the Central and Eastern United States earthquakes greater than or equal to moment magnitude (M) 3.0 since the year 2000 (http://earthquake.usgs.gov/monitoring/anss/docs/ANSS_Perf_Standards.pdf). Various magnitude types are reported by ComCat, thus for our purposes, all earthquake magnitudes are converted to a moment magnitude (M) as is consistent practice with the 2014 NSHMs catalog.

For a given region, the Gutenberg-Richter magnitude-frequency relation, $\log \mathrm{N}=\mathrm{a}-\mathrm{bM}$ provides a good fit to the magnitude distribution, where $N$ is the number or earthquakes above a certain magnitude, $M$; $a$ is the parameter that defines the rate of earthquakes; $b$ (b-value) is a parameter that defines the slope of the distribution. This relation depends on a magnitude of completeness $\left(\mathrm{M}_{\mathrm{c}}\right)$ for which all earthquakes above that level are considered completely represented in the catalog. A more accurate $\mathrm{M}_{\mathrm{c}}$ increases the likelihood of determining the actual b-value of the distribution.

Four tasks are required to develop the seismicity model from an earthquake catalog: (1) delineate areas with potentially induced seismicity using information available in scientific publications, seismicity patterns, and information on industrial activity; (2) determine whether or not to decluster the catalog, which removes foreshocks, aftershocks, and swarm events leaving only independent events;

(3) assess the annual parameters of the exponential magnitude-frequency (Gutenberg and Richter, 1944) distribution that relates the number or rate of small and large earthquakes (b-value); and (4) evaluate the minimum magnitudes (Mmin) of the earthquakes in the catalog that will best predict the future large earthquakes, considering local completeness levels of the catalog.

\section{Delineate Areas with Potential Induced Earthquakes}

In developing the 2014 National Seismic Hazard Models (Petersen and others, 2014), we initially identified 14 areas in the Central and Eastern United States (fig. 1) that contained seismicity that was suspected to have been induced by fluid injection or fluid removal. Three additional areas outlined in figure 1 will not be addressed in this report. These three additional areas contain nontectonic seismicity associated with coal production. One zone is near Paonia, Colorado, and two zones are related to coal fields in central Utah.

At the workshop, participants recommended that we update the catalog through October 2014 to include activity since 2012 that was not included in the previous model. We updated the catalog and identified three new areas of enhanced seismicity (Oklahoma-north and Kansas-south; Greeley, Colorado; and Azle, Texas). Seismicity maps and time histories of the 17 regions are shown in figure 3. Table 1 shows the names and seismicity parameters (location, largest associated earthquake, and time window) for each of the zones that are discussed in this report. For this update, we also expanded the zone boundaries shown on the NSHM in places where recent (2013 and 2014) seismicity was located outside the earlier boundaries (Fashing, Texas; Dallas - Fort Worth, Texas; Oklahoma; Raton Basin (Raton in figures), New Mexico - Colorado; Youngstown, Ohio; and Timpson, Texas). We acknowledge that natural earthquakes could occur within the defined zones during the stated time windows; however, we treat the seismicity as induced for this study because the earthquakes are all located near deep fluid injection wells or other industrial activities capable of inducing earthquakes. 
Scientific publications also proved useful for suggesting causal relations between industrial activities and seismicity (table 1).

The Guy-Greenbrier, Arkansas zone was established for the 2014 NSHM (Petersen and others, 2014) and took into account seismicity through 2012. Indeed, the injection wells that were considered to be the cause of the Guy-Greenbrier earthquakes stopped injecting in March 2011, and the seismicity decayed to background levels not long thereafter. However, during 2013 and 2014 about 25 earthquakes between M2.7 and M3.8 occurred in an area just outside of the defined Guy-Greenbrier zone. The area of seismicity for 2013 and 2014 is about 20 kilometers by $60 \mathrm{~km}$, and extends to the north and to the west of the defined Guy-Greenbrier zone; no earthquakes of this size occurred within the zone. Experts believe that the 2013 and 2014 seismicity in central Arkansas includes natural clusters and induced clusters (Horton and others, 2013). At this time we do not define this seismicity in 2013 and 2014 to be induced because the clusters do not occur exclusively near the well locations, and the experts believe that there are natural clusters in close proximity to the potentially induced clusters (Horton and others, 2013). Hence, for this study, we do not expand the Guy-Greenbrier zone to include this recent seismicity. This example near Guy-Greenbrier illustrates the complexity of the task at hand and highlights one of the main challenges to developing separate hazard models for natural and induced seismicity, especially in regions where both types of earthquakes have been detected. Whereas for earthquakes induced by mining and oil and gas production from conventional reservoirs the relation between the earthquakes and the causative industrial operation is reasonably obvious, this is often not the case in areas where there are many injection wells and broadly distributed seismicity.

Relating earthquakes to specific injection activities can be difficult, partly because, given enough time, the pore pressure perturbations caused by injection may have traveled substantial distances from the injection site. 
Table 1. Seventeen induced seismicity zones, Central and Eastern United States.

\begin{tabular}{|c|c|c|c|c|}
\hline $\begin{array}{l}\text { Induced Seismicity Zone } \\
\text { (this report) }\end{array}$ & Location & $\begin{array}{l}\text { Largest } \\
\text { Earthquake } \\
\text { (moment } \\
\text { magnitude) }\end{array}$ & Time Window & Reference \\
\hline Rocky Mountain Arsenal & Environs of Denver, Colorado & 4.8, Aug. 1967 & $1962-1979$ & Evans (1966), Healy and others (1968) \\
\hline Rangely & Northwestern Colorado & 4.3, Apr. 1970 & $1957-2014$ & Raleigh and others (1976) \\
\hline Paradox & Southwestern Colorado & 3.9, Jan. 2013 & 1991-2014 & Ake and others (2005), Block and others (2014) \\
\hline Greeley & In the Denver Basin, Colorado & 3.2, Jun. 2014 & $2013-2014$ & Yeck and others (2014) \\
\hline Raton Basin & New Mexico-Colorado border & 5.2 Aug. 2011 & $2001-2014$ & $\begin{array}{l}\text { Meremonte and others (2001), Rubinstein and } \\
\text { others (2014a) }\end{array}$ \\
\hline Dagger Draw & Southeastern New Mexico & 4.1, Dec. 2005 & 1998-2014 & $\begin{array}{l}\text { Sanford and others (2006), Pursley and others } \\
\text { (2013) }\end{array}$ \\
\hline Guy-Greenbrier & Central Arkansas & 4.7, Feb. 2011 & 2009-2014 & Horton (2012) \\
\hline Oklahoma & Central Oklahoma & 5.6, Nov. 2011 & 2006-2014 & Keranen and others $(2013,2014)$ \\
\hline Oklahoma-N; Kansas-S & Oklahoma-Kansas border & 4.8, Nov. 2014 & $2013-2014$ & Rubinstein and others (2014b) \\
\hline Cogdell & West-central Texas & 4.5, Jun. 1978 & $1976-2014$ & Davis and Pennington (1989) \\
\hline Fashing & $\begin{array}{l}\text { Conventional natural gas field in } \\
\text { southern Texas }\end{array}$ & 4.6, Oct. 2011 & 1973-2014 & Pennington and others (1986) \\
\hline Timpson & Eastern Texas & 4.8, May 2012 & 2011-2014 & Brown and Frohlich (2013) \\
\hline Dallas-Fort Worth & Near Dallas-Fort Worth, Texas & 3.2, Jun. 2012 & 2008-2014 & Frohlich and others (2011) \\
\hline Azle & Northwest of Fort Worth, Texas & 3.4, Nov. 2013 & $2013-2014$ & DeShon and others (2014) \\
\hline Ashtabula & Northeastern Ohio & 3.9, Jan. 2001 & 1987-2007 & Seeber and others (2004) \\
\hline Youngstown & Northeastern Ohio & 3.7, Dec. 2011 & 2010-2014 & Kim (2013) \\
\hline Brewton & Alabama-Florida border & 4.9, Oct. 1997 & 1997-2014 & Gomberg and Wolf (1999) \\
\hline
\end{tabular}

Declustering

Hazard analysis is usually computed using declustered earthquake catalogs to remove statistically dependent events such as foreshocks and aftershocks (Petersen and others, 2014). This is because the statistical model commonly used in probabilistic seismic hazard assessment assumes that the earthquakes are independent. The 2014 NSHM used the Gardner and Knopoff (1974) declustering method to remove dependent earthquakes. Declustering, however, can remove earthquakes that may not be dependent events. For example, for about 9 months following the M5.6 Prague earthquake, declustering removes dependent earthquakes within about a 50-km radius. We know, however, that independent earthquakes (not aftershocks or foreshocks) occurred before and after this 9-month window, and we might expect some to occur during this time interval. Another example is the 2010 Guy-Greenbrier sequence in Arkansas, in which approximately 90 percent of the earthquakes in the sequence are removed by standard Gardner-Knopoff declustering (fig. $3 C$ ). This issue was discussed at the workshop, and the general consensus was that the hazard from all of the induced earthquakes (independent and dependent) should be included by using catalogs for the induced seismicity that are not declustered. Nevertheless, use of the declustered catalog is more consistent with standard practice in hazard analysis (Petersen and others, 2014). Participants recommended that more research be done to develop new models for declustering induced seismicity. Recent research focusing on several 
earthquake sequences in Oklahoma indicates that induced earthquake sequences tend to die out faster than typical decay patterns from natural earthquakes, however the aftershocks are distributed spatially across a larger area than would be expected (McNamara and others, 2015). For this sensitivity analysis, we calculated the hazard using the declustered and nondeclustered catalogs to show the effect of this decision. Figure 5 shows that ground motions can be 0.5 to $1.0 \mathrm{~g}$ (acceleration of gravity) greater when using the nondeclustered catalog (corresponding ratios over a broad region of the Central United States can be more than a factor of 2 larger). Appendix 1 shows a preliminary analysis of how declustering influences the predictive power of the model. 
A) $1 \% / y r$ base model, full catalog

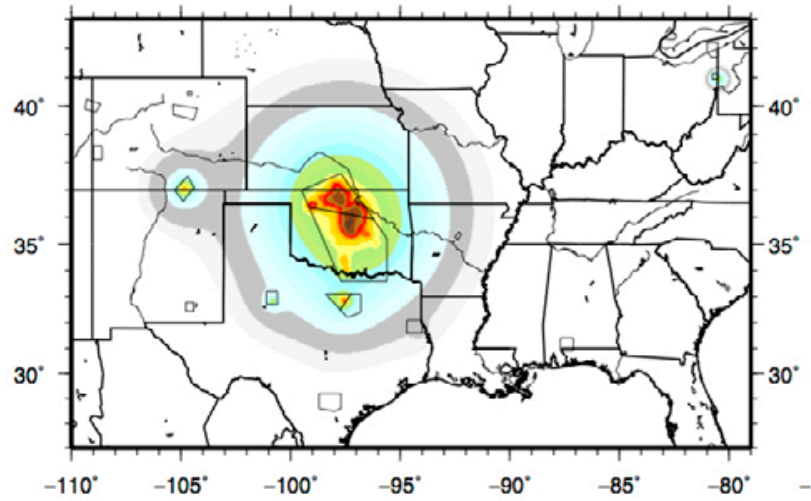

C) $1 \% / y r$ test case, declustered catalog
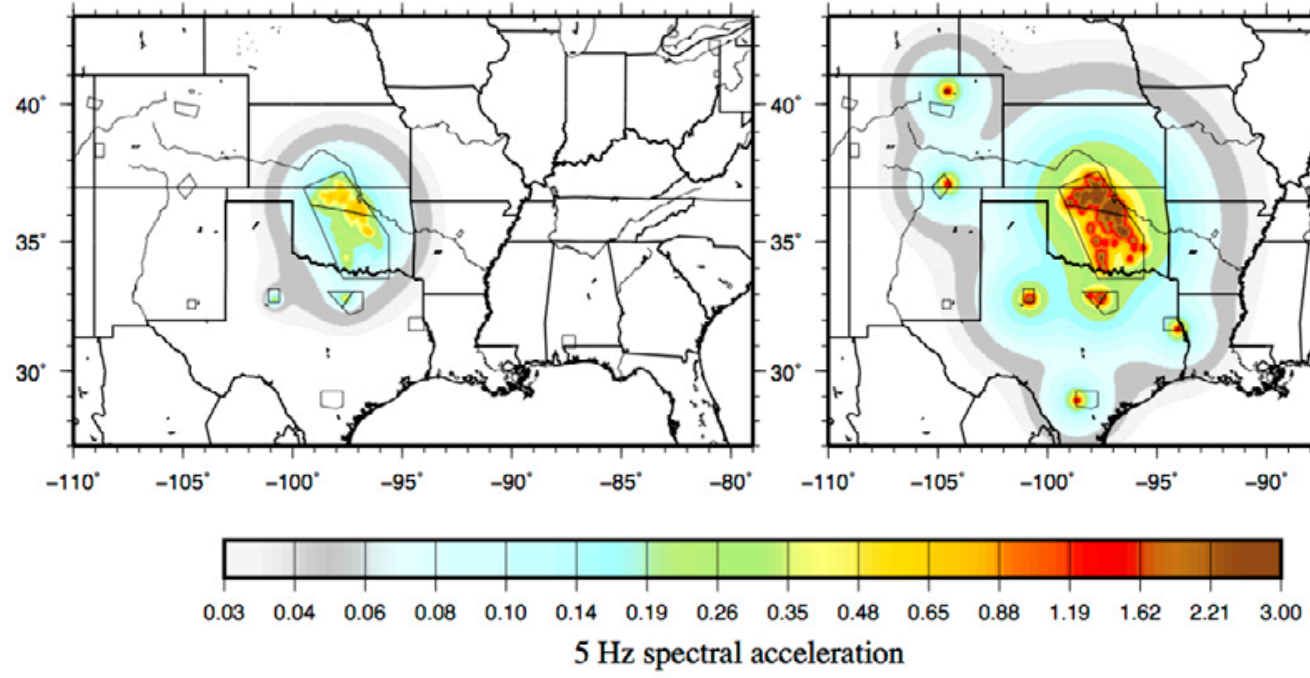

E) Map C - Map A
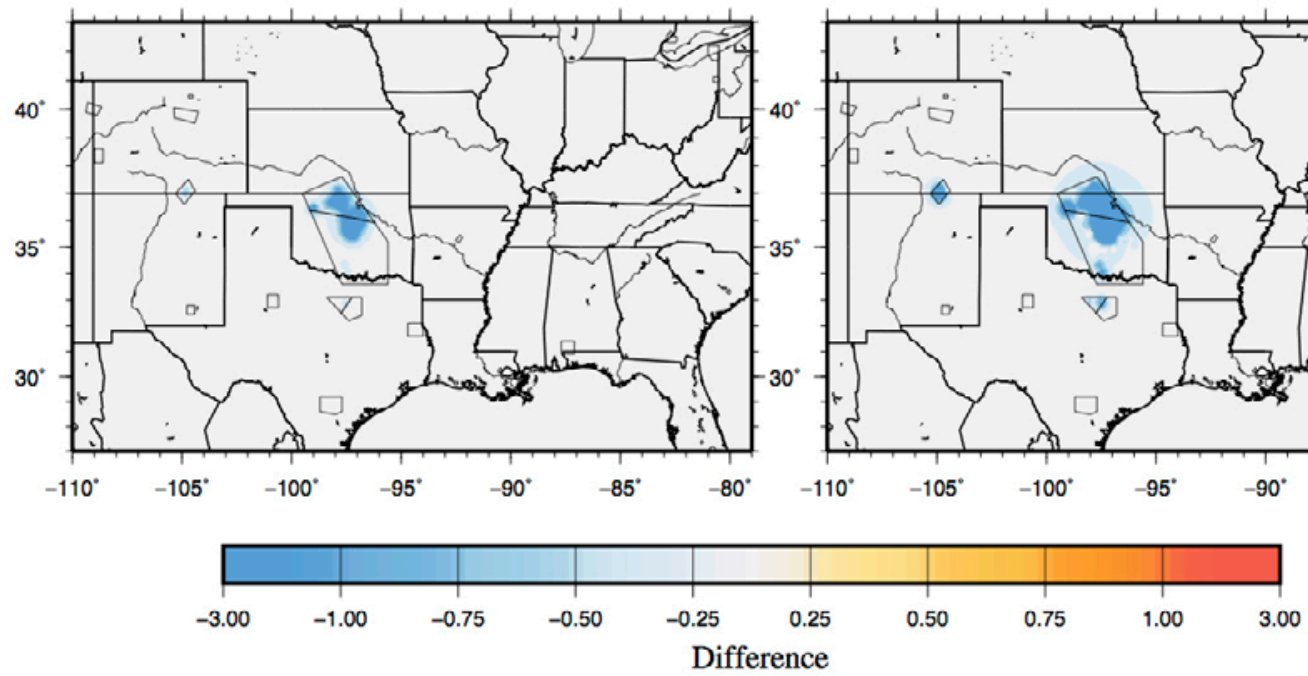

Figure 5. Sensitivity study comparing base model to declustered catalog model. Five-hertz ( 0.2 seconds) spectral accelerations and differences are in units of $g$ (acceleration of gravity).
F) Map D - Map B

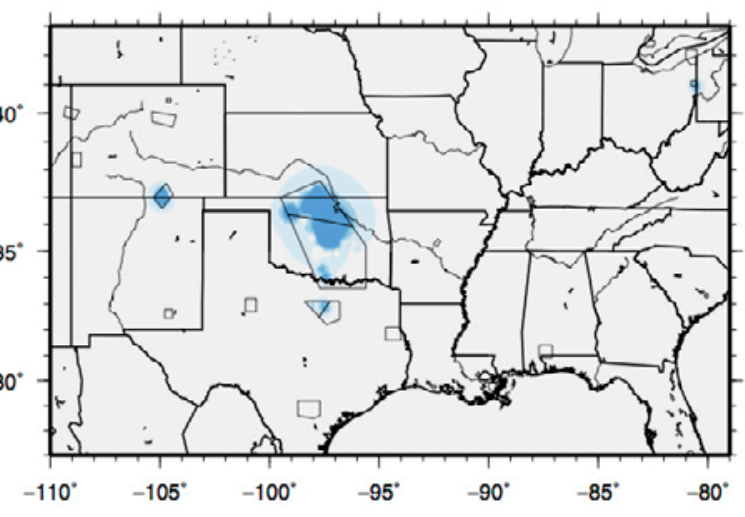

$0^{\circ}$

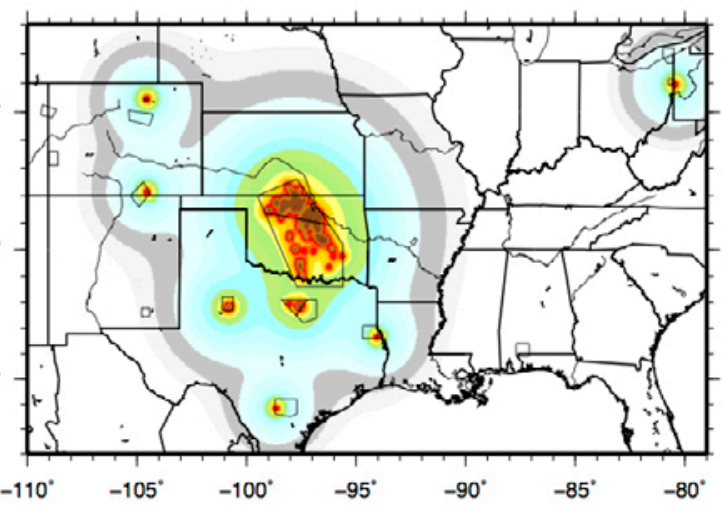

D) $0.04 \% / y r$ test case, declustered catalog 


\section{Relation Between Small and Large Earthquakes—b-Value}

Typically, we use the rate of small earthquakes included in the earthquake catalog to extrapolate the rate of potential large earthquakes. The Gutenberg and Richter (1944) exponential equation is used to quantify this rate. The b-value in this equation represents the slope of the exponential distribution and relates the number or rate of small and large earthquakes. A b-value of 1.0 is determined to be consistent with most declustered global earthquake catalogs. We also determined this b-value of 1.0 to be a reasonable estimate for declustered natural earthquakes in the Central and Eastern United States, and this value was applied in the 2014 NSHM. Our preliminary analysis of earthquakes within induced seismicity zones, using the nondeclustered catalog, indicates that for some regions the b-value may be either about 1.0 or may be larger $(b=1.2-1.5)$, implying that the proportion of small-to-large earthquakes is greater in regions of induced seismicity than the global average (appendix 2). The relation between an elevated $b$-value and fluid injection rates has been studied for enhanced geothermal systems (Bachmann and others, 2011); the b-value can exceed 1.5 during periods of active fluid injection. Figure 6 compares the uniform hazard maps that result from using a b-value of 1.0 and a b-value of 1.5. As expected, the probabilistic ground motions calculated for $b=1.5$ are lower than the ground motions calculated for $b=1$ because the former model forecasts relatively fewer large earthquakes. 
A) $1 \% / y r$ base model, 1 b-value

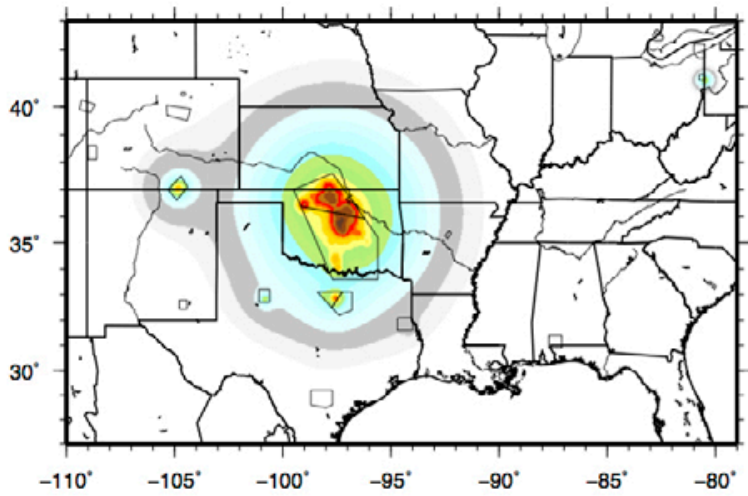

C) $1 \% / y r$ test case, 1.5 b-value

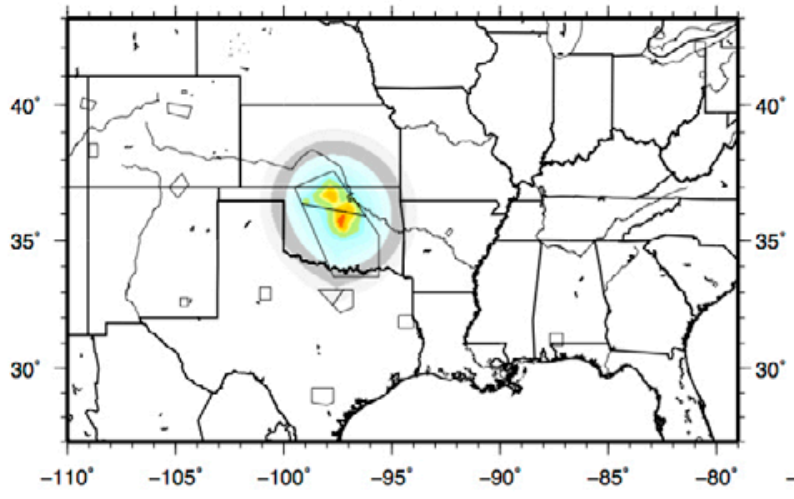

B) $0.04 \% / y r$ base model, $1 \mathrm{~b}$-value

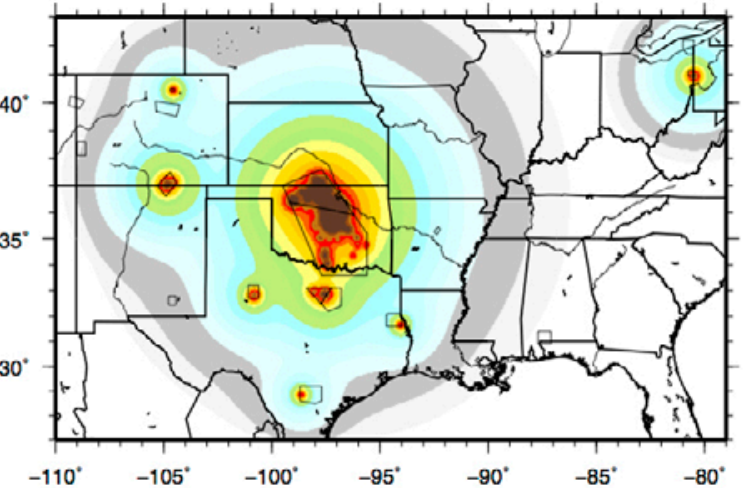

D) $0.04 \% / y r$ test case, $1.5 \mathrm{~b}$-value

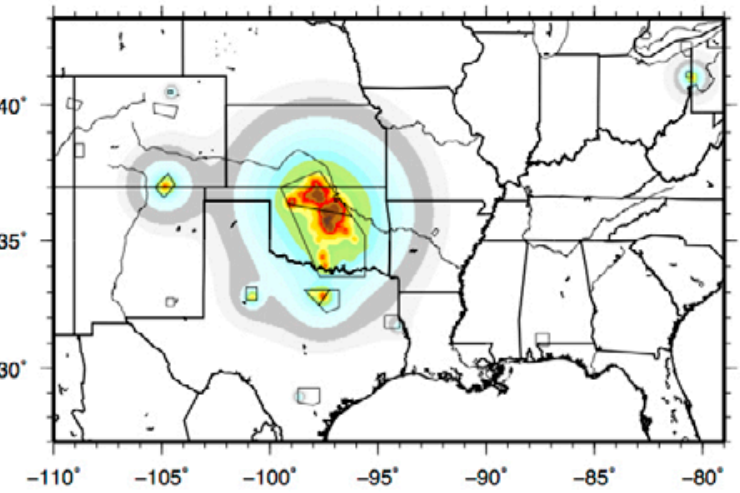

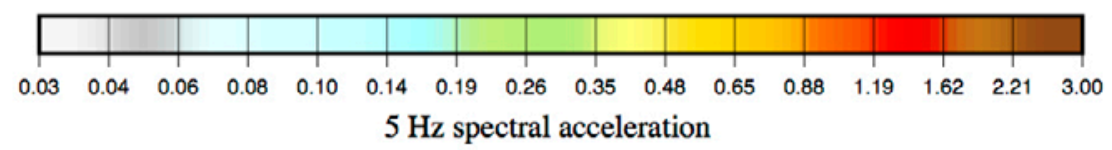

E) Map C - Map A
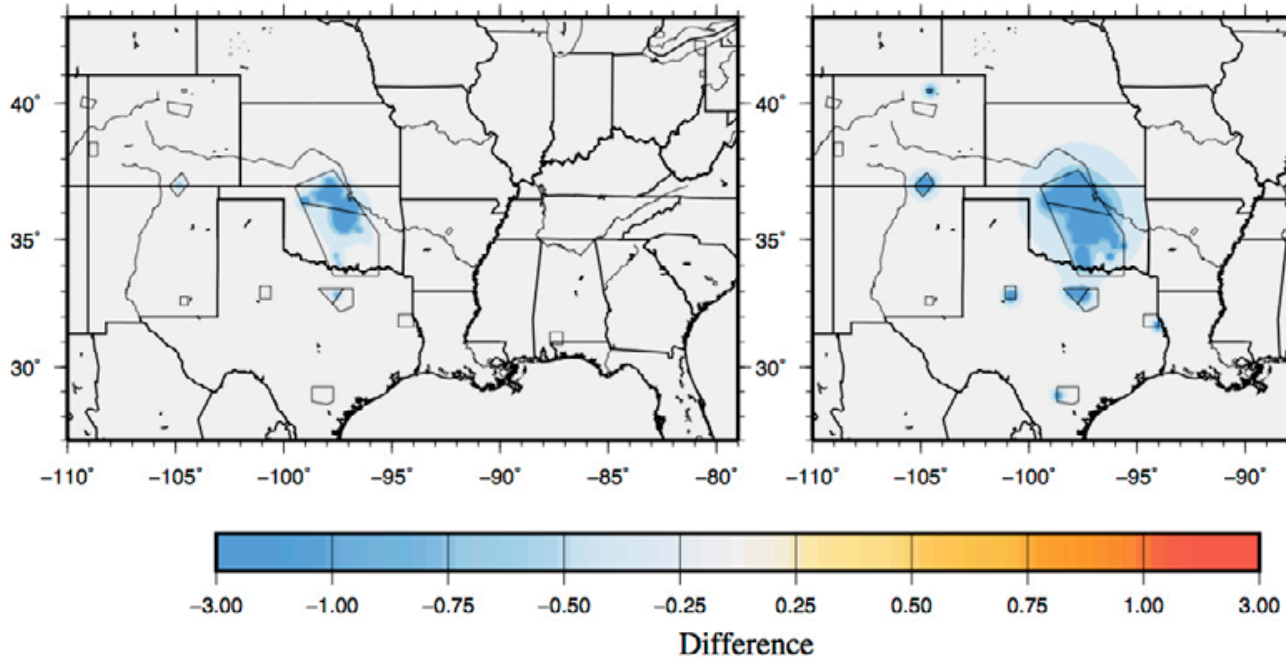

F) Map D - Map B

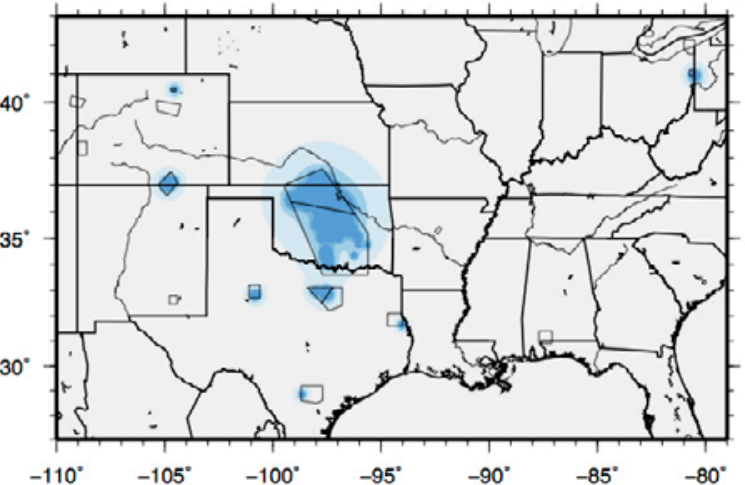

Difference

Figure 6. Sensitivity study comparing a $b$-value (the slope of the curve that relates the numbers of small and large earthquakes) of 1.0 and 1.5. Five-hertz ( 0.2 seconds) spectral accelerations and differences are in units of $g$ (acceleration of gravity). 


\section{Magnitudes Used to Predict Future Earthquakes}

In a well-instrumented region moderate earthquakes will be recorded and cataloged, but small earthquakes below some magnitude completeness threshold can be missed. Completeness levels vary in space and time, and seismicity models, which estimate the rates and locations of large earthquakes by extrapolating from the smaller earthquakes, must account for these variations. Due to the exponential magnitude distribution, there are many more M2.5 earthquakes than M3.0 earthquakes. The lower magnitudes can provide more detailed information on the locations of future earthquakes; therefore, it is advantageous to use the lowest magnitude for which the catalog is complete to assess the hazard. For the 2014 maps (Petersen and others, 2014), we used earthquakes through 2012 with $\mathrm{M}_{\mathrm{W}}$ greater than or equal to 2.7. For this analysis, we compare the uniform hazard maps, which show the ground motions at annual hazard levels of 1 percent and 0.04 percent using catalogs with magnitude thresholds (Mmin) of $\mathrm{M} 2.5,2.7$, and 3.0 to forecast the locations and rates of large earthquakes. Figures 7 and 8 show comparisons of the uniform hazard maps based on these three catalogs. The M2.5 catalog may be deficient in the number of small earthquakes, as it is close to the completeness of the earthquake catalog for many areas; the result of this deficiency will be an under-prediction of the true seismicity rate. 
A) $1 \% / y r$ base model, minimum M2.5

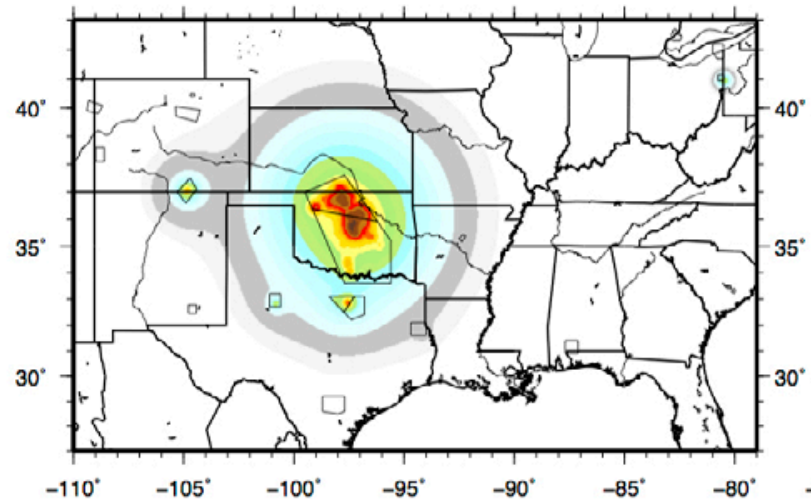

C) $1 \% / y r$ test case, minimum M2.7
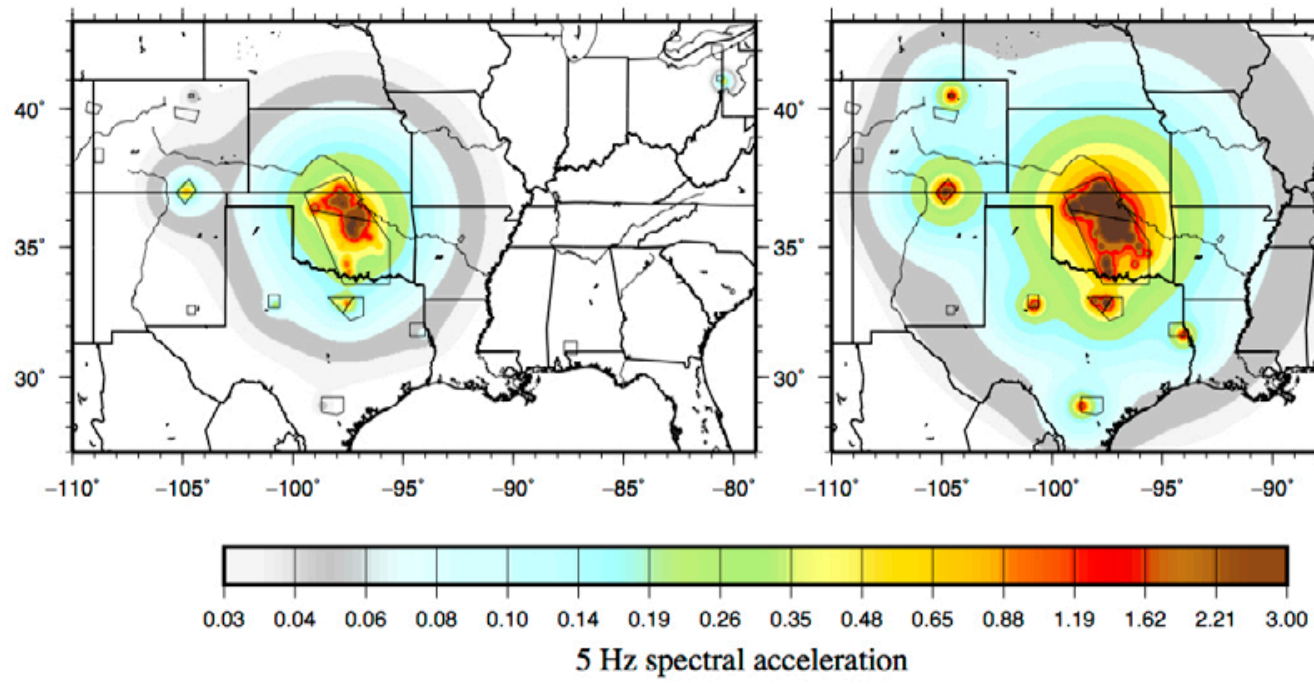

E) Map C - Map A
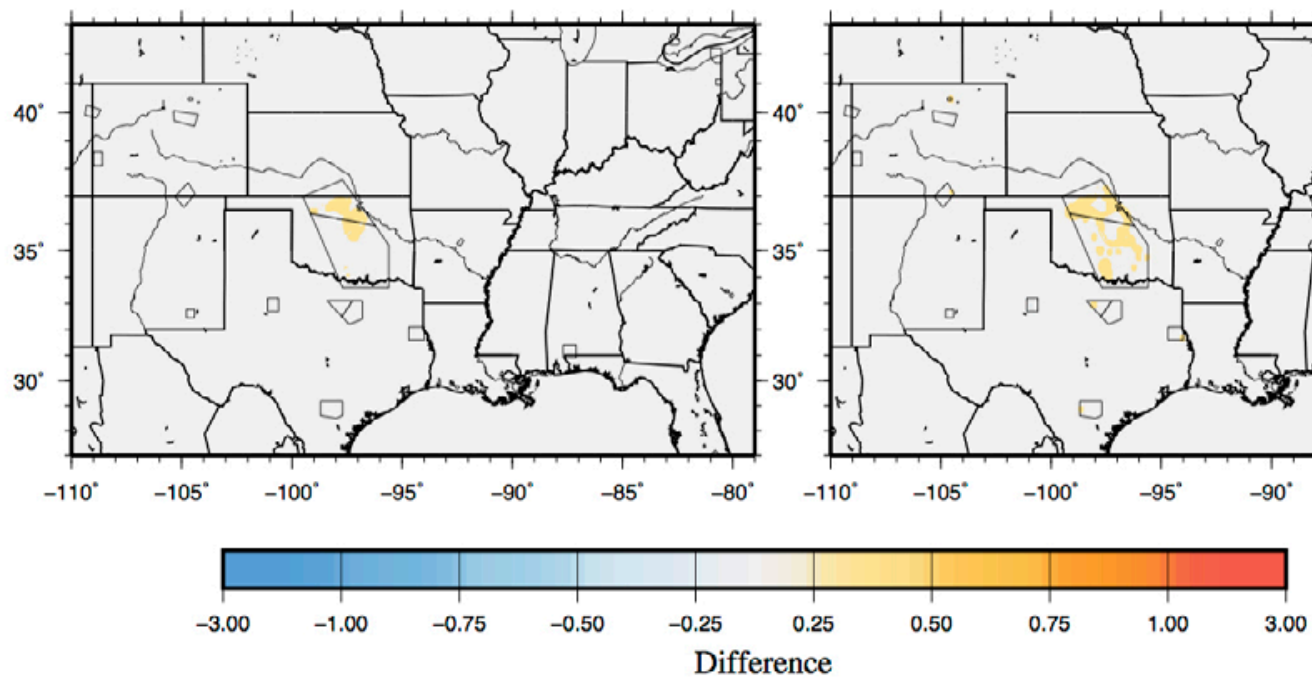

Figure 7. Sensitivity study comparing earthquake catalogs with minimum magnitude set at moment magnitude (M) 2.5 and M2.7. Five-hertz ( 0.2 seconds) spectral accelerations and differences are in units of $g$ (acceleration of gravity).
B) $0.04 \% / y r$ base model, minimum M2.5

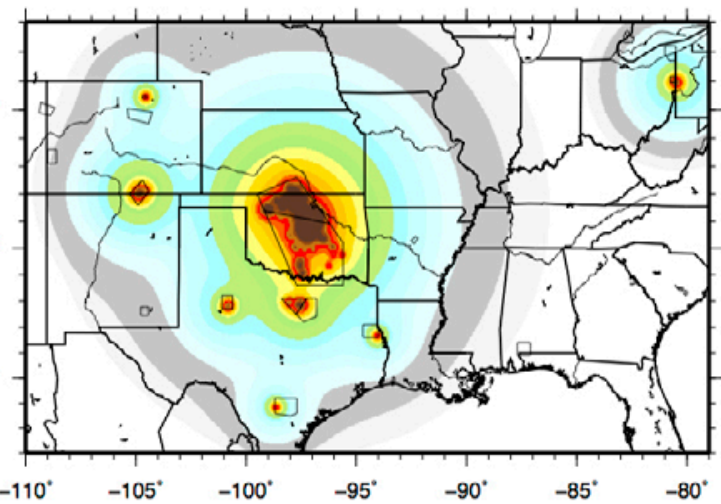

D) $0.04 \% / y r$ test case, minimum M2.7

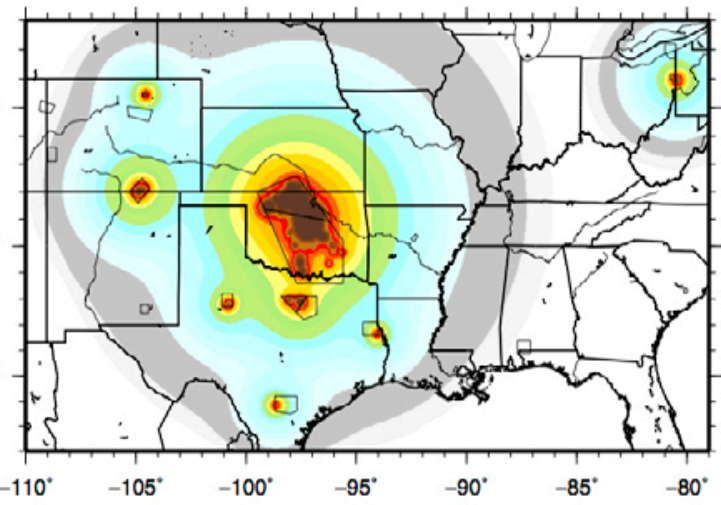

F) Map D - Map B

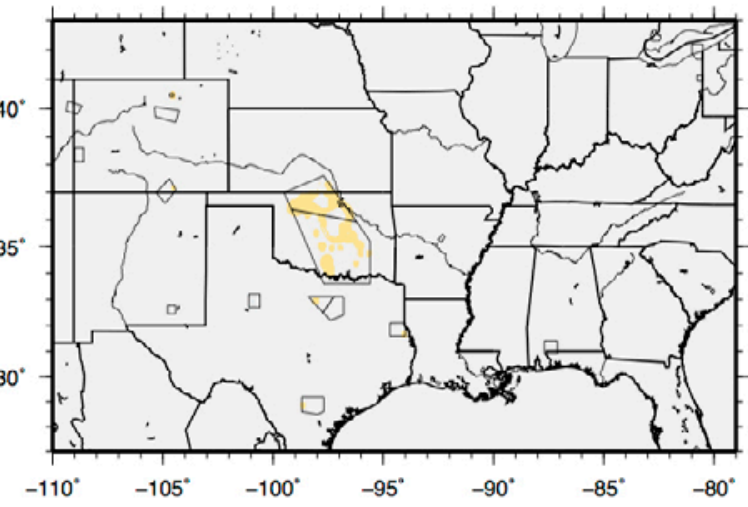

\section{0}


G) $1 \% / y r$ base model, minimum M2.5

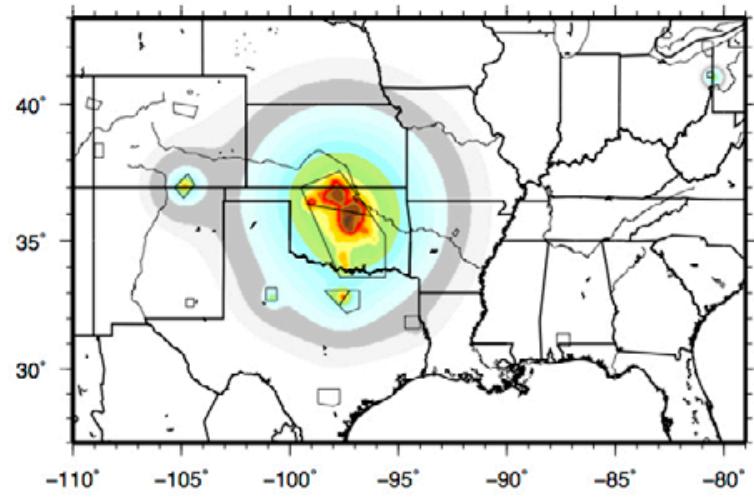

I) $1 \% / \mathrm{yr}$ test case, minimum M3

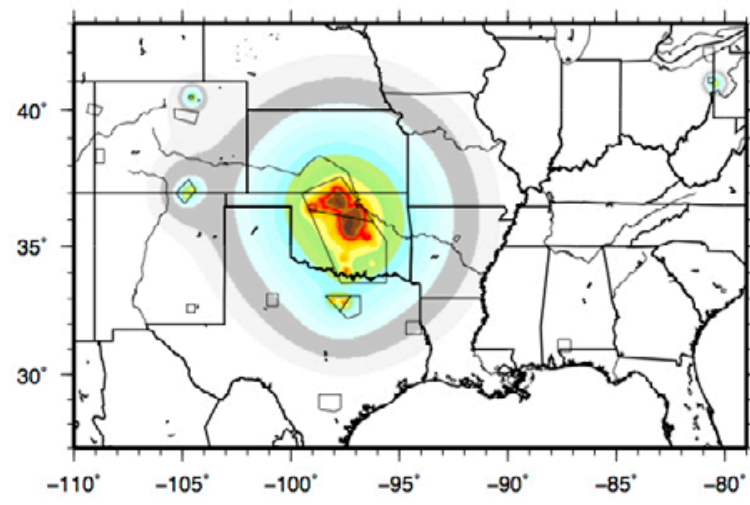

H) $0.04 \% / y r$ base model, minimum M2.5

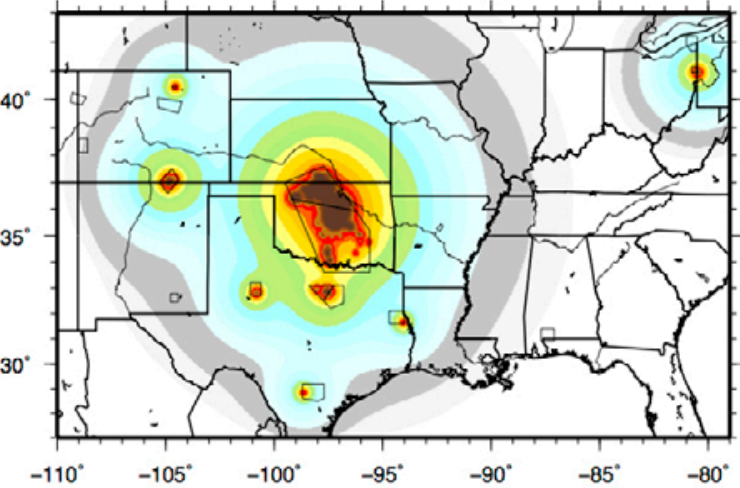

J) $0.04 \% / y r$ test case, minimum M3

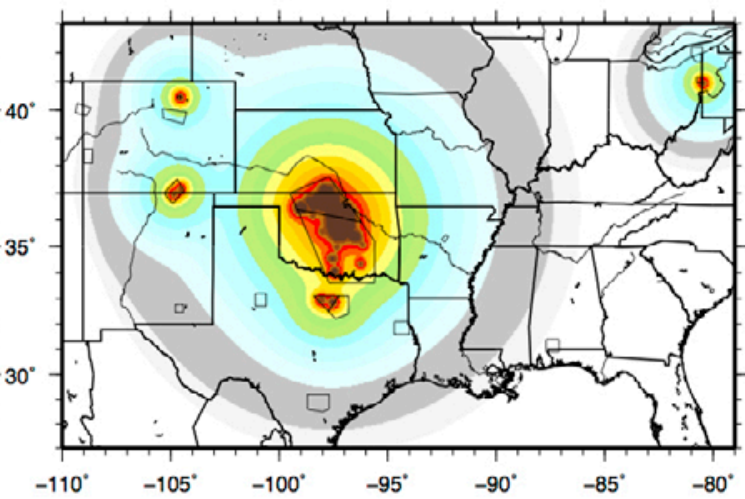

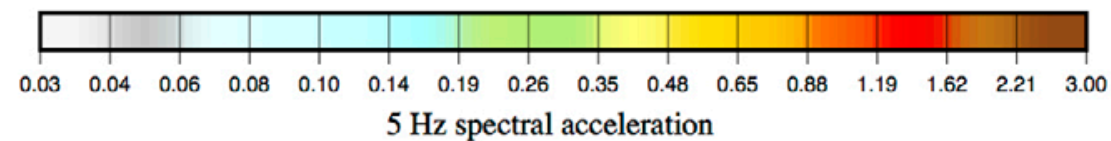

K) Map I - Map G

L) Map J - Map H
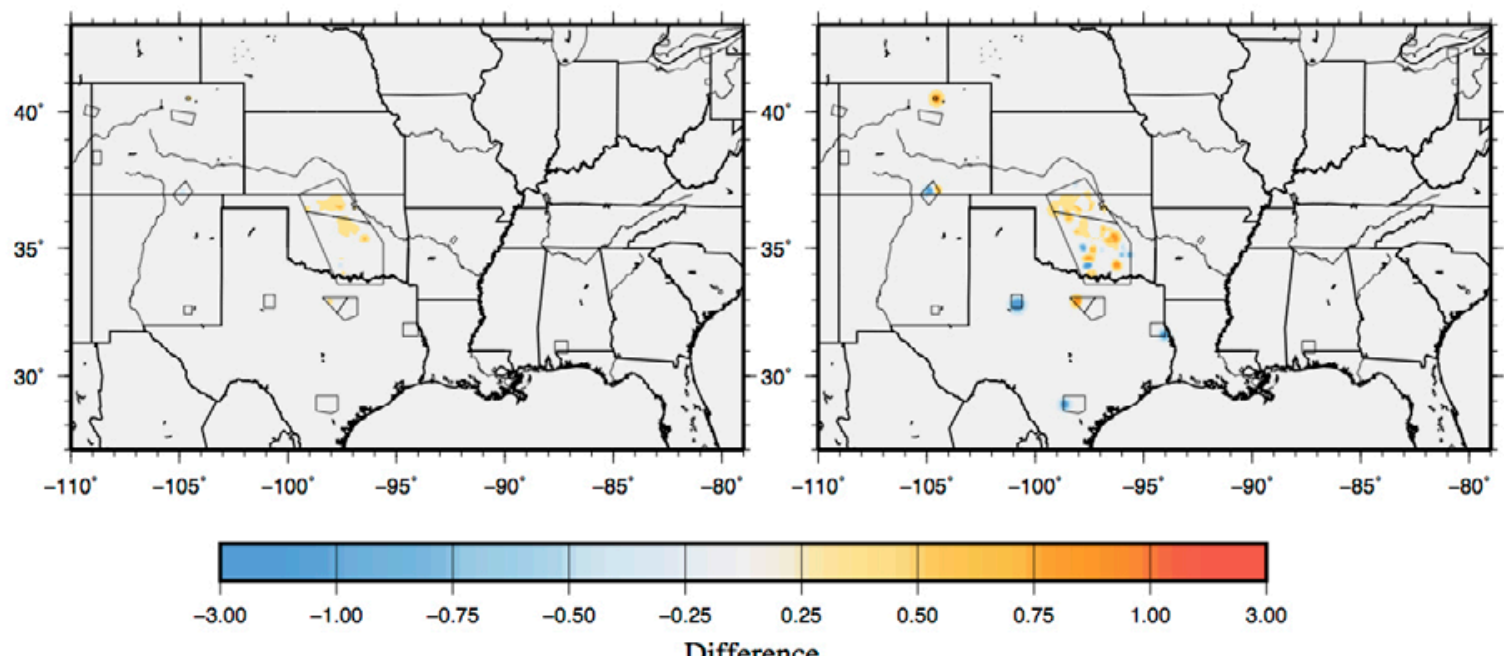

Difference

Figure 8. Sensitivity study comparing earthquake catalogs with minimum magnitude set at moment magnitude (M) 2.5 and M3.0. Five-hertz ( 0.2 seconds) spectral accelerations and differences are in units of $g$ (acceleration of gravity). 


\section{Earthquake Rate Models}

The earthquake rate model is based on the assumption that we can forecast the future rates of induced seismic activity based on information contained in the earthquake catalog. In the workshop, there were many comments suggesting that the current year's seismicity rate is the best predictor of the next year, but it is difficult to project these rates much further in the future than a year or two. For example, prior to 2012, there was virtually no earthquake activity in southern Kansas and northern Oklahoma, but in 2013 and especially in 2014, the number of earthquakes in that region increased dramatically with several hundred earthquakes being recorded (fig. 3). In this region, the 2013 catalog is not a perfect predictor of the 2014 activity - but certainly better than a catalog based on pre-2012 activity.

For this sensitivity study, we have considered two different time intervals: November 1, 2012, to October 31, 2013 (referred to hereinafter as the 2013 catalog), and November 1, 2013, to October 31, 2014 (2014 catalog), to compare changes in seismicity rates and locations. During 2014, no earthquakes greater than M2.5 occurred in 8 zones (Brewton, Dagger Draw, Rangely, Rocky Mountain Arsenal, Greeley, Paradox, Ashtabula, and Guy-Greenbrier; table 1), and only one earthquake occurred in 2 zones (Timpson and Fashing; table 1). Therefore, more than half of the zones experienced little or no seismicity during 2014, and this year's seismicity may or may or may not be a good predictor of next year's activity. If fluid injection has ceased, then this model might be a good predictor. However, if injection is resumed, we could jump back to the previously observed levels or some other level based on the amount and rate of fluid disposal. We may want to account for the possibility that induced activity could resume, especially if we do not have any updated information on the injection rates.

We have computed the hazard for several models that apply alternative rates: (1) 2014 rate, (2) 2013 rate, (3) rate during period of enhanced seismicity, (4) long-term rate - averaged since 1960, and (5) a very low or zero rate after earthquakes have diminished as injection is discontinued. One participant at the workshop suggested that it would be most reasonable to disregard the short-term increase in earthquake rates when injection ceases. One written comment suggested that another logic tree branch should be added to represent a proactive approach to managing hazard. For this branch, a program of monitoring (and perhaps disclosure) would allow regulators to require changes to injection based on the appearance of seismicity on, for example, well-oriented faults of substantial size. With an approach such as this, there would be a rationale for reducing the likelihood of large induced events and would have the merit of giving industry some measure of control over managing the seismic hazard and risk (G. Beroza, written commun., 2014).

A comparison of the uniform hazard maps that result from using the 2013 and 2014 catalogs is shown in figure 9. Probabilistic ground motions based on the 2014 catalog is much higher in central to north-central Oklahoma and south-central Kansas during 2014 compared to the probabilistic ground motions calculated using the 2013 and previous catalogs. The 2014 map shows substantial increases in probabilistic ground motions for the zones associated with Raton Basin, Greeley, Oklahoma, Kansas, Azle, Cogdell, Fashing, Timpson, and Youngstown (locations shown in Fig. 3A). The 2013 map shows substantial increases in probabilistic ground motions for the Raton Basin, Paradox, Oklahoma, Kansas, Dallas - Ft. Worth, Cogdell, and Timpson. Activity in Oklahoma, southern Kansas, Azle, Cogdell, and Youngstown is much higher in the 2014 catalog than in the 2013 catalog; hence the probabilistic ground motion is higher when using the 2014 catalog. The activity was higher in 2013 for Paradox, southern Oklahoma, Dallas - Ft. Worth, and Timpson compared to 2014, and thus the probabilistic ground motion is higher for these areas using the 2013 catalog. In general, the probabilistic ground motion can differ by more than a factor of two when applying the 2013 compared to the 2014 catalog. Testing the predictions of these two models with current activity would help us to understand how to improve the models for future iterations. 
A) $1 \% / y r$ base model, $11 / 1 / 13$ to $10 / 31 / 14$ catalog

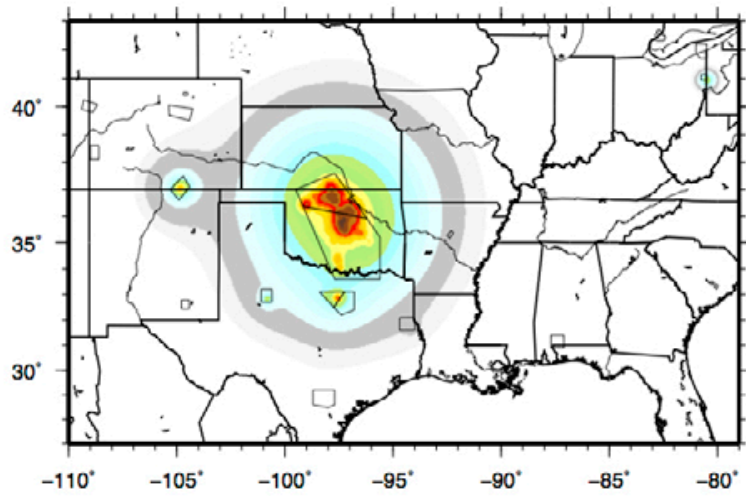

C) $1 \% / y r$ test case, $11 / 1 / 12$ to $10 / 31 / 13$ catalog

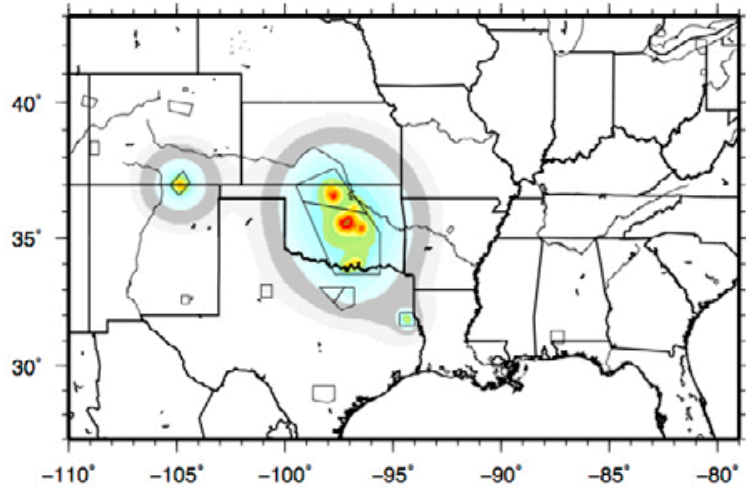

B) $0.04 \% / y r$ base model, $11 / 1 / 13$ to $10 / 31 / 14$ catalog

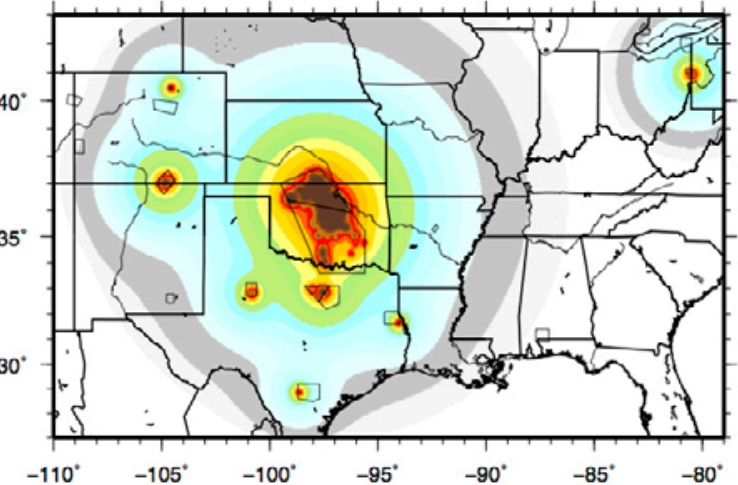

D) $0.04 \% / y r$ test case, $11 / 1 / 12$ to $10 / 31 / 13$ catalog

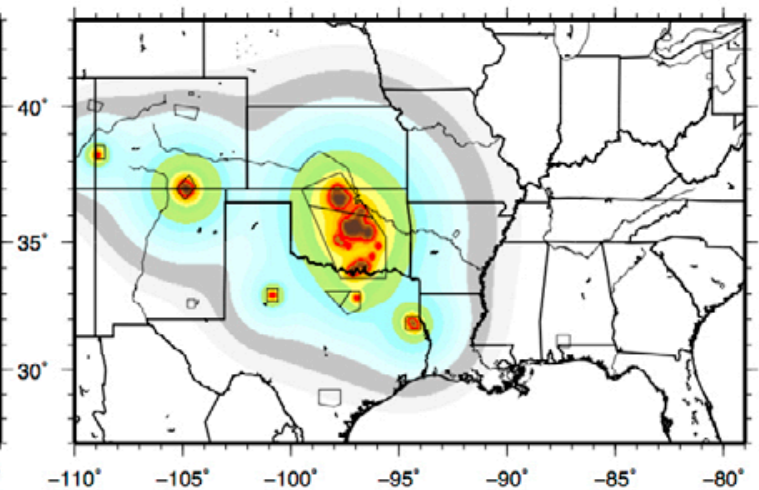

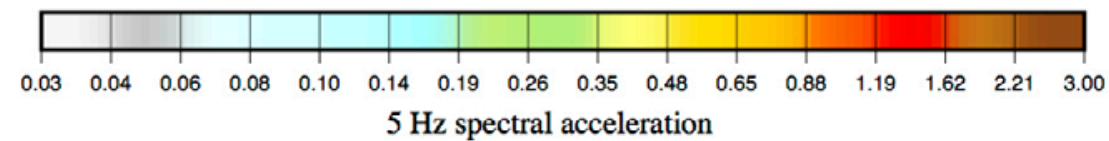

E) Map C - Map A

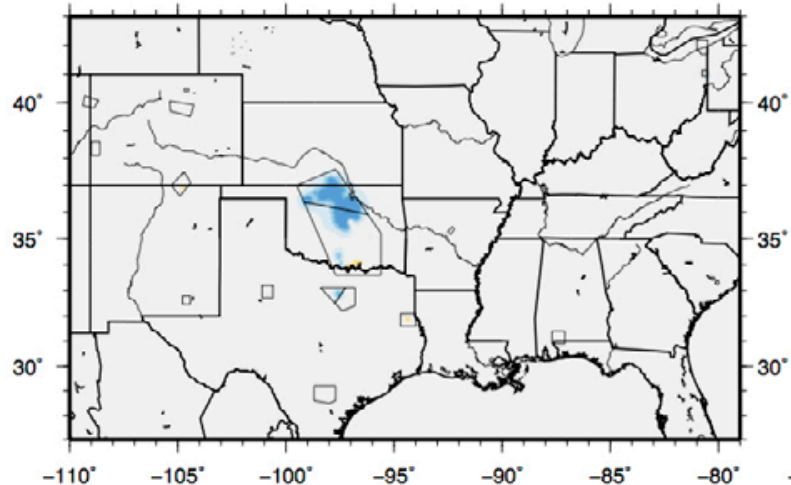

F) Map D - Map B

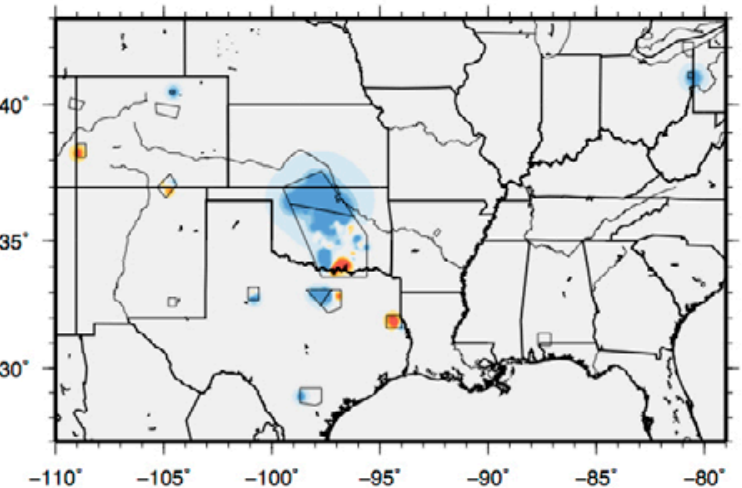

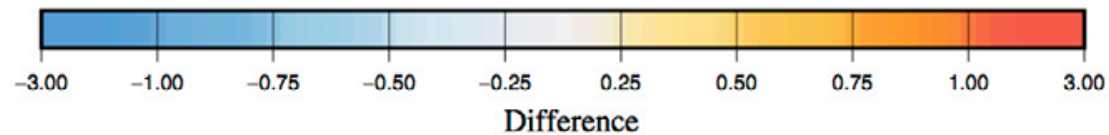

Figure 9. Sensitivity study comparing hazard calculated from 2014 and 2013 catalogs. The 2014 catalog is from November 1, 2013, to October 31, 2014. The 2013 catalog is from November 1, 2012, to October 31, 2013. Fivehertz ( 0.2 seconds) spectral accelerations and differences are in units of $g$ (acceleration of gravity). 


\section{Earthquake Location Models}

The 2014 NSHM used fixed kernel and adaptive smoothing kernel distances to predict the locations of future earthquakes. In previous models, we applied a 50-km correlation length (35-km standard deviation length) distance parameter for the fixed kernel model. At the workshop, it was suggested that a smaller smoothing length might be more appropriate for estimating the locations of seismicity in a 1-year period. This shorter length would reflect better earthquake locations and tighter clusters. For our sensitivity study, we compare the uniform hazard maps generated using a fixed correlation length of $5 \mathrm{~km}$ and $50 \mathrm{~km}$ to assess the effect of the smoothing distance. The comparison of alternative smoothing distances in estimating locations of future earthquakes is shown in figure 10 . Differences in the probabilistic ground motions from using these two smoothing parameters are quite high. The larger smoothing distances result in an increased probabilistic ground motion at larger distances from the induced seismicity zones. This is represented as a halo in the difference map. Appendix 1 shows a preliminary analysis to assess the predictive power of seismicity models in predicting future earthquakes. 
A) $1 \% / \mathrm{yr}$ base model, $5 \mathrm{~km}$ smoothing

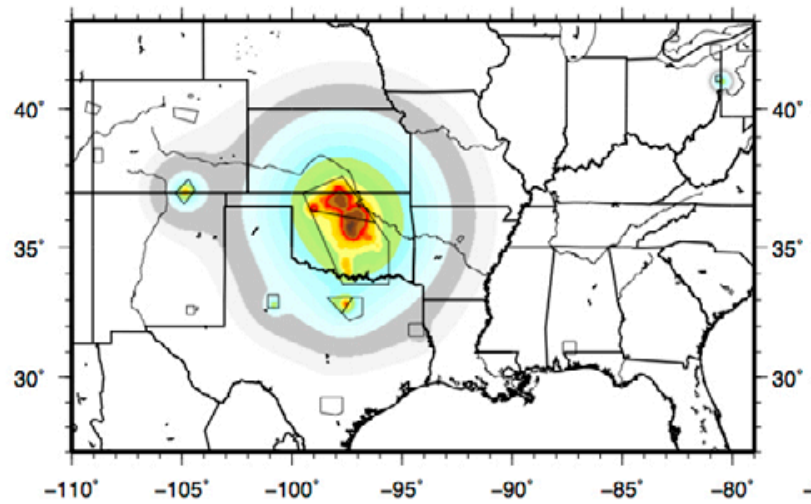

C) $1 \% / \mathrm{yr}$ test case, $50 \mathrm{~km}$ smoothing

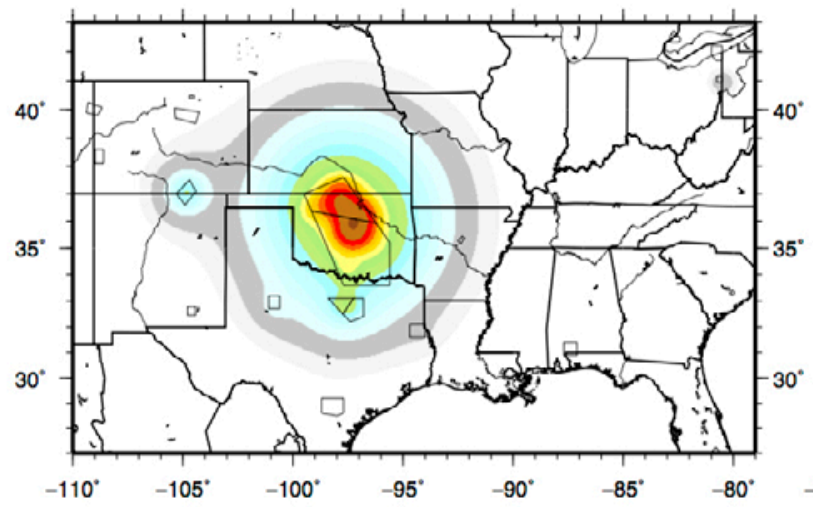

B) $0.04 \% / \mathrm{yr}$ base model, $5 \mathrm{~km}$ smoothing

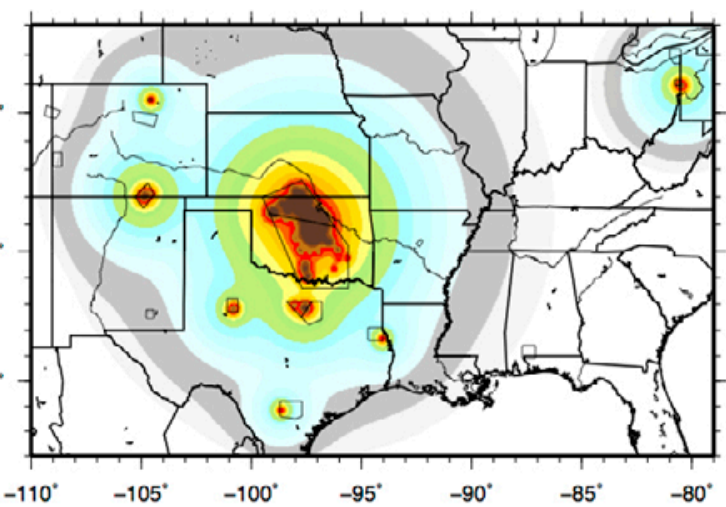

D) $0.04 \% / \mathrm{yr}$ test case, $50 \mathrm{~km}$ smoothing

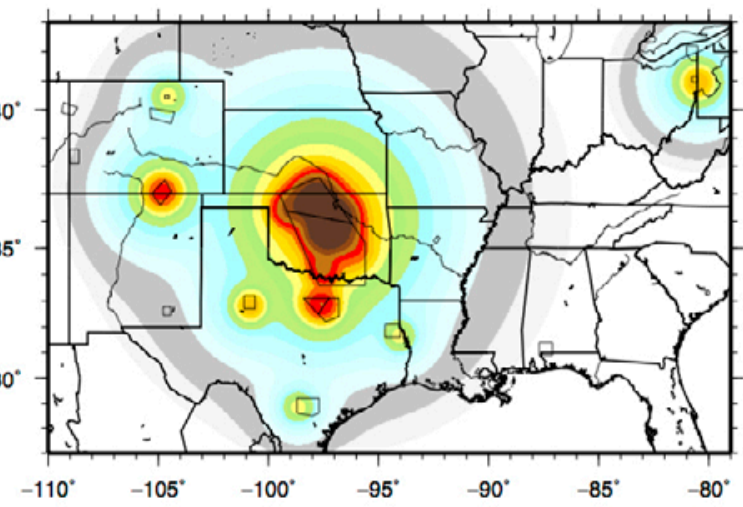

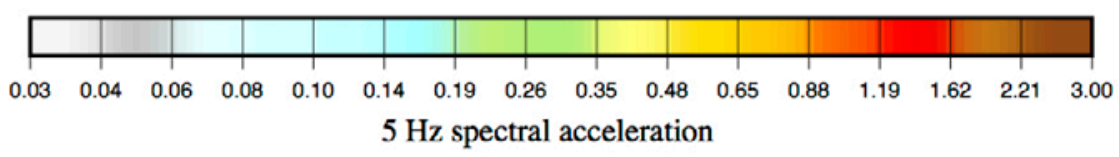

E) Map C - Map A
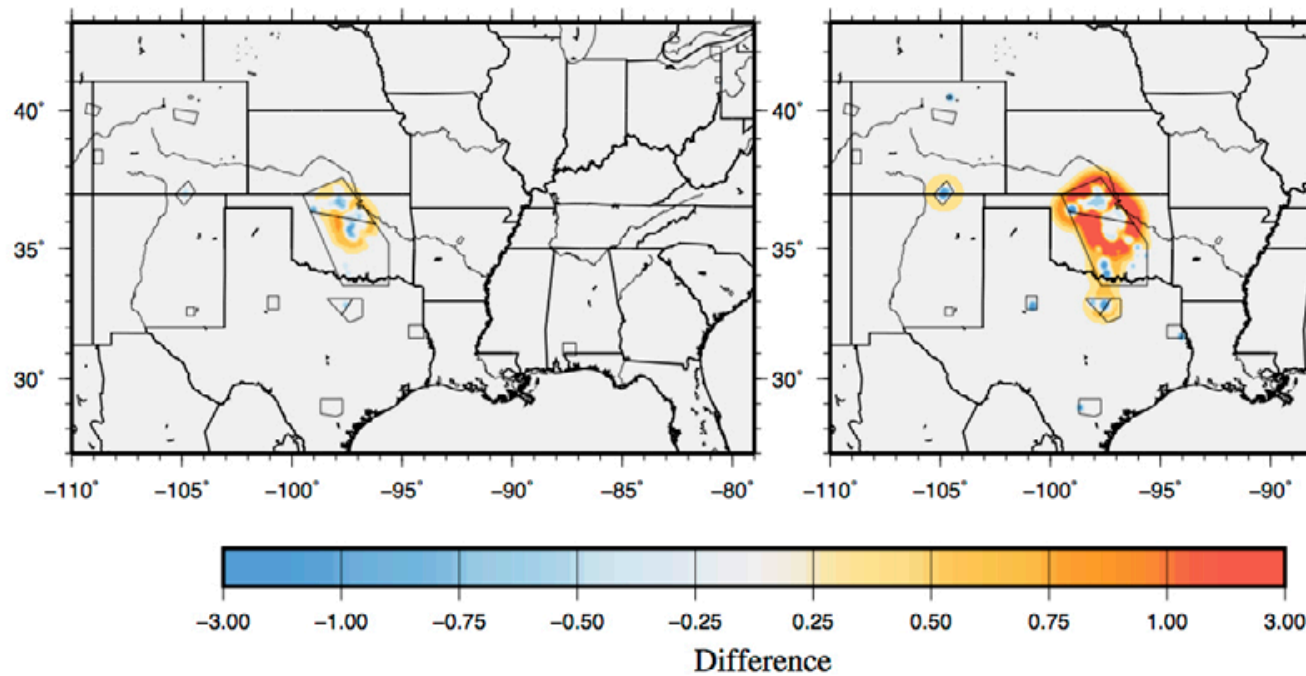

F) Map D - Map B

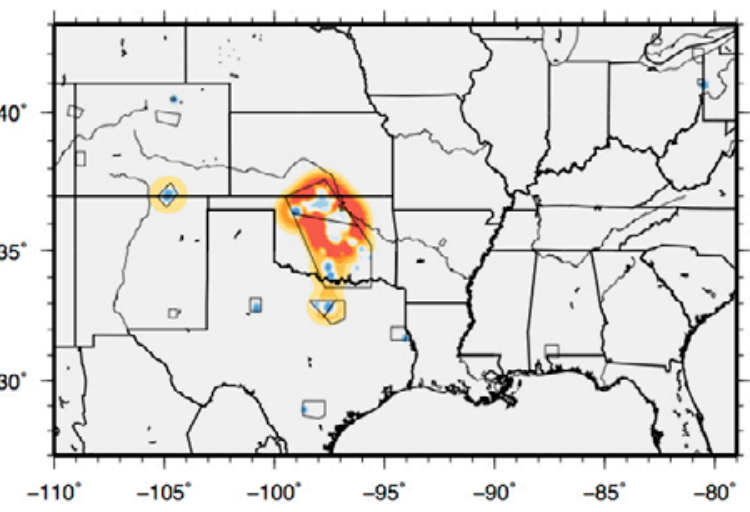

\section{(1)}

Figure 10. Sensitivity study comparing earthquake location models based on smoothing parameters with 5-kilometer $(\mathrm{km})$ and 50-km width. Five-hertz (0.2 seconds) spectral accelerations and differences are in units of $g$ (acceleration of gravity). 


\section{Earthquake Maximum Magnitudes}

The maximum magnitude that can be generated by induced seismicity is not easy to assess because we can only rely on the largest observed earthquake, global analogs, or physical principles. The maximum magnitude should be larger than the magnitude of the largest observed injection induced earthquake because we only have a short observation period. McGarr (2014) argues that the maximum potential magnitude of an injection induced earthquake is limited by the total injected volume, whereby the largest earthquake possible increases in magnitude with increased injection volume. The largest United States induced earthquake to date has been the 2011 M5.6 Prague, Oklahoma earthquake (Keranen and others, 2013); however, earthquakes greater than M6 or M7 also have been generated near impounded dams or near sites of gas withdrawal. For example, Gupta (2002) indicates that the 1967 Koyna M6.3 (India) was the largest and most damaging reservoir-triggered earthquake. Simpson and Leith (1985) suggested that the 1984 M7.0 Gazli (Uzbekistan) earthquake may have been induced by gas withdrawal. There is also some debate about whether the 2008 M7.9 Wenchuan (China) earthquake was induced by reservoir impoundment (Kerr and Stone, 2009; Deng and others, 2010; Gahalaut and Gahalaut, 2010). Alternatively, the induced seismicity may trigger tectonic earthquakes on adjacent fault structures, as suggested by Keranen and others (2014). Participants at the workshop felt that the USGS induced seismicity models should consider the possibility of triggering large regional earthquakes and should consider the same maximum magnitude distribution as was used for the tectonic earthquakes in the NSHM model which has a mean of 7.0 but extends from M6.5 to M7.95 with low weights at the ends of the distribution. For the sensitivity study, we also considered a model with maximum magnitude of M6.0, close to that which we have observed. The uniform hazard maps for these two cases are shown in figure 11. The difference in probabilistic ground motions is significant and varies by about 25 percent, but causes much less of an effect than many of the other factors that are being considered in the logic tree. 
A) $1 \% / y r$ base model, CEUS Mmax

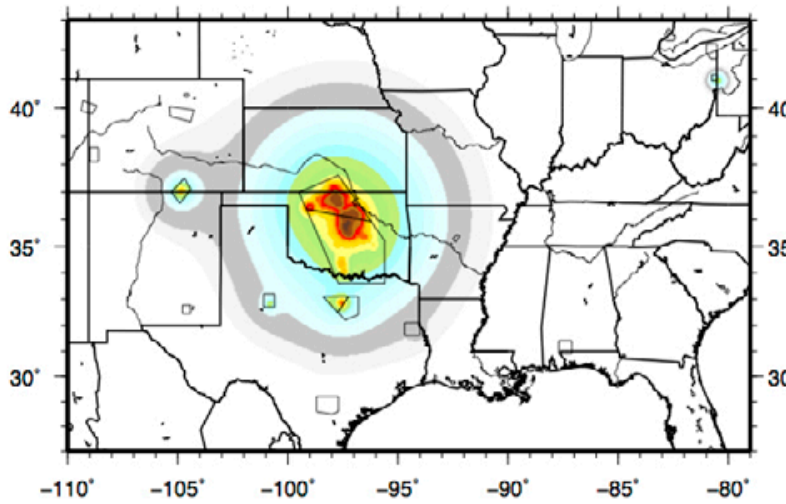

C) $1 \% /$ yr test case, M6 Mmax

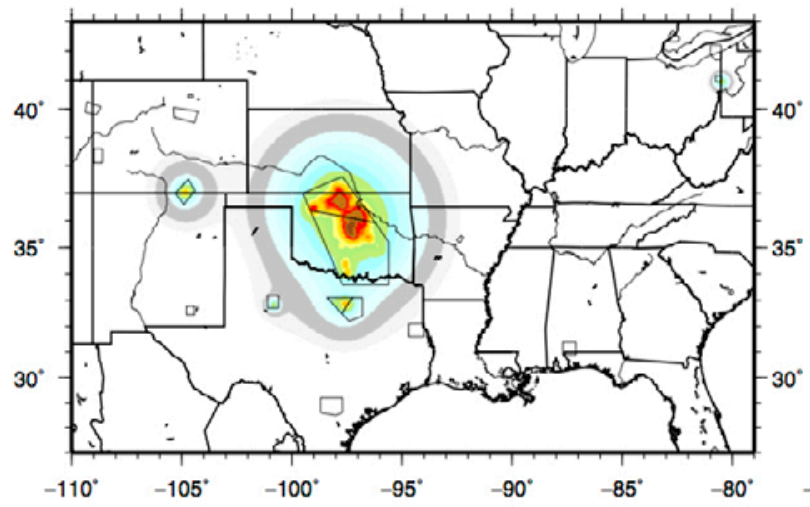

B) $0.04 \% / y r$ base model, CEUS Mmax

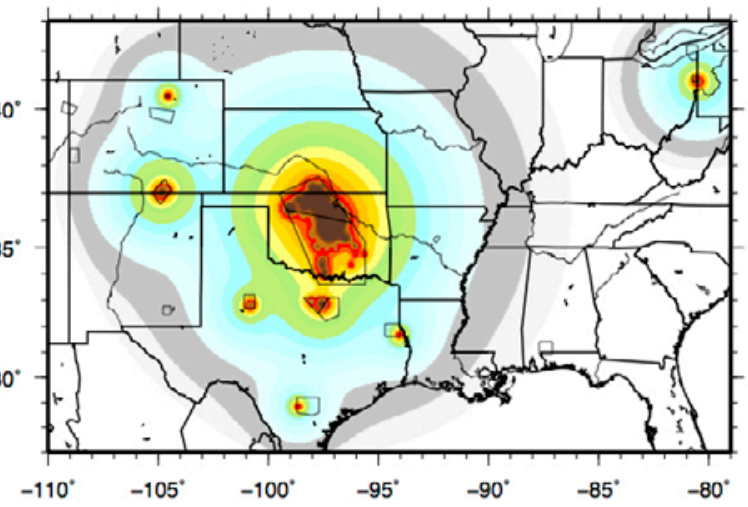

D) $0.04 \% / \mathrm{yr}$ test case, M6 Mmax

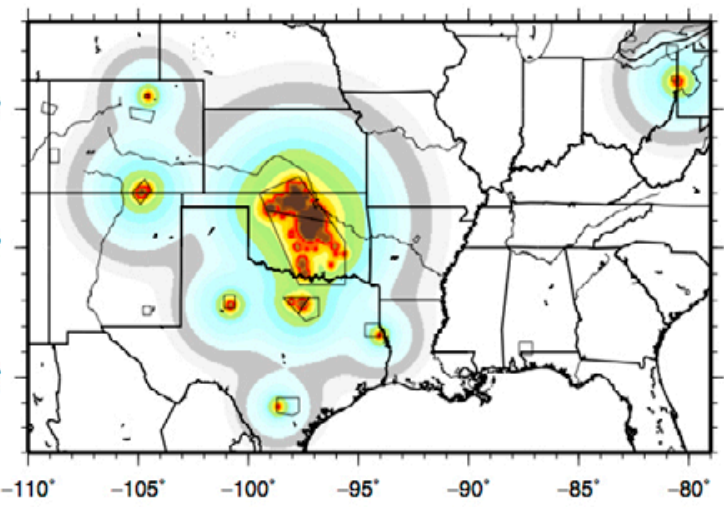

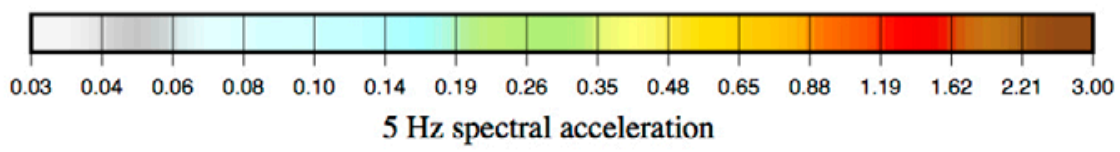

E) Map C - Map A
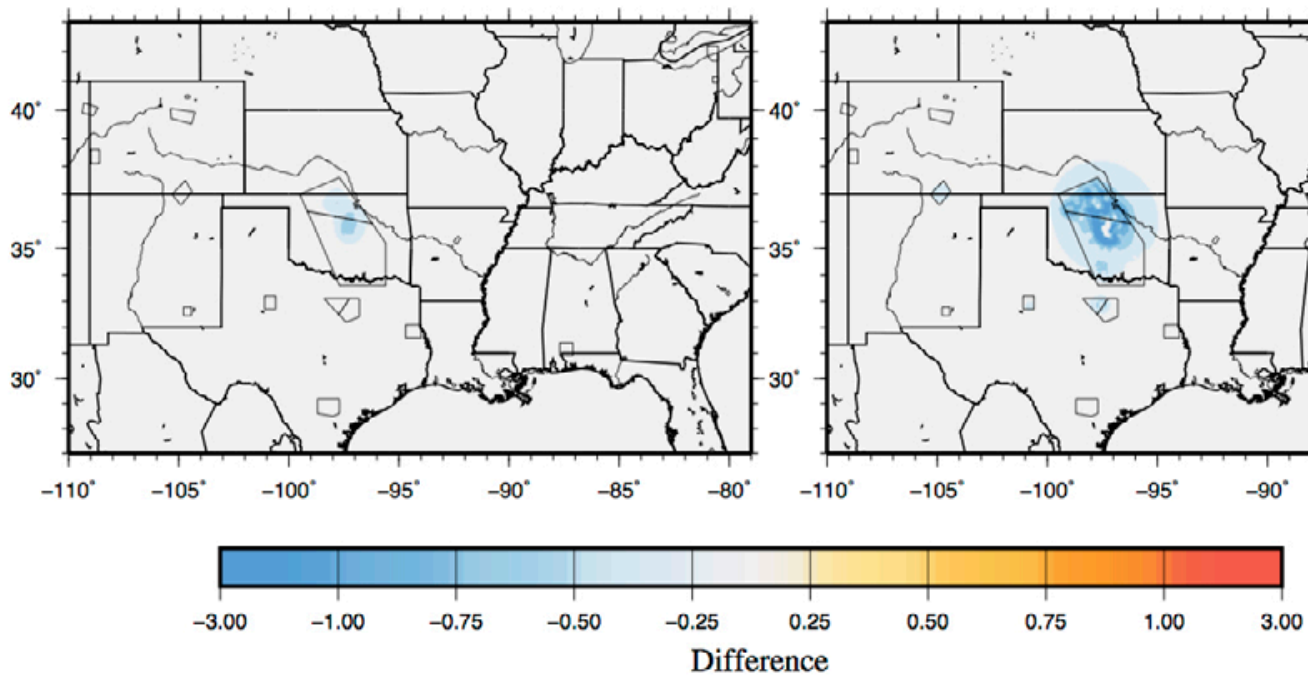

F) Map D - Map B

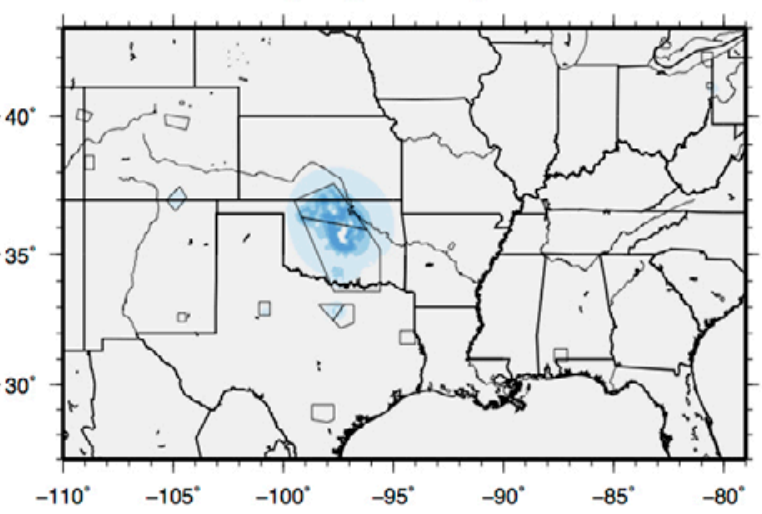

Figure 11. Sensitivity study comparing the NSHM craton maximum magnitude (Mmax) model (mean moment magnitude $[\mathrm{M}] 7$ ), and an M6.0 maximum magnitude. Five-hertz ( 0.2 seconds) spectral accelerations and differences are in units of $g$ (acceleration of gravity). 


\section{Earthquake Ground Motion Models}

Ground motions have been recorded from many suspected induced earthquakes. These ground motions provide information on the earthquake source and ground shaking characteristics. In general, comparisons shown at the workshop indicate that the ground motions are quite similar between induced and natural earthquakes, especially for long period ground shaking. However, other studies indicate that induced earthquake ground motions may differ from natural ground motions (McGarr and Fletcher, 2005; Hough, 2014). The main difference may be the depth, which is typically less than $5 \mathrm{~km}$ in the case of induced seismicity. Regrettably, none of the 8 equations that were applied in the 2014 NSHM have a depth term (table 2). Therefore, it is difficult to account for this difference in the hazard calculations at this time. New ground motion models are being developed as part of the NGA-East project (http://peer.berkeley.edu/ngaeast/), and these equations will allow for consideration of depth in calculating the ground shaking. Once these new equations are published, it will be possible to account for the shallower depths of the induced earthquakes in the hazard models.

At this time, we have made comparisons using the highest and lowest ground motion models to show the span of ground motions that are considered in the current equations. A comparison between one of the highest and lowest equations considered in the analysis is shown in figure 12. This comparison shows that the probabilistic ground motions for the highest ground motion model are nearly a factor of two higher than the lowest ground motion model leading to a large epistemic uncertainty. This large uncertainty is not unique to induced earthquakes. Additional research on the source (for example, stress drops) and the ground shaking characteristics of induced earthquakes could reduce the epistemic uncertainty in the hazard models. 
A) $1 \% / y r$ GMM high case, Tavakoli and Pezeshk

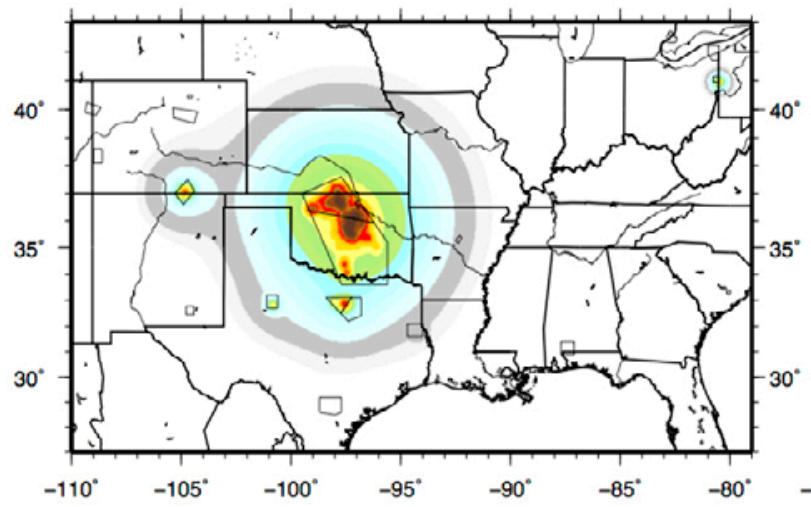

C) $1 \% / y r$ GMM low case, Atkinson, 2008'

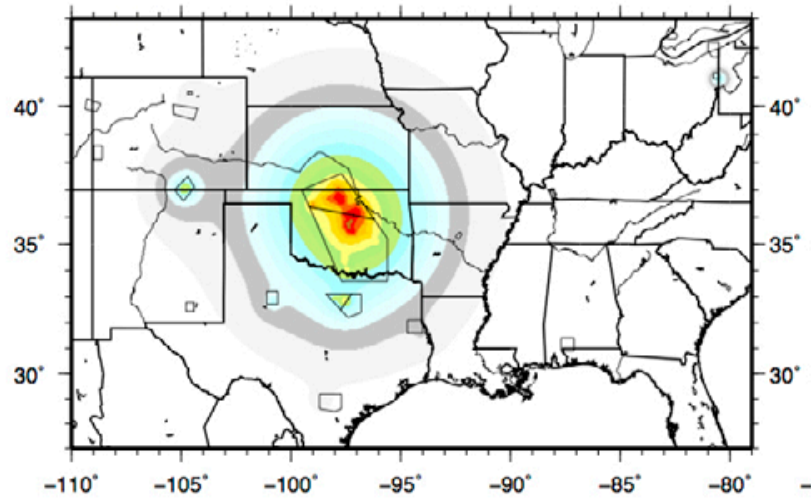

B) $0.04 \% / y r$ GMM high case, Tavakoli and Pezeshk

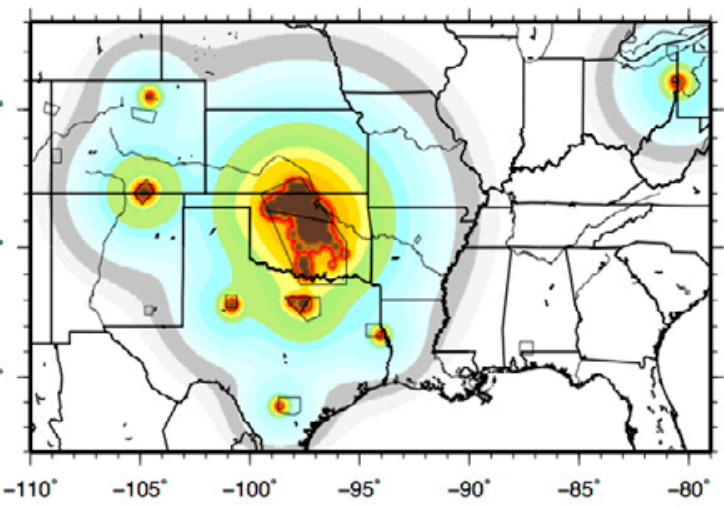

D) $0.04 \% / y r$ GMM low case, Atkinson, 2008'

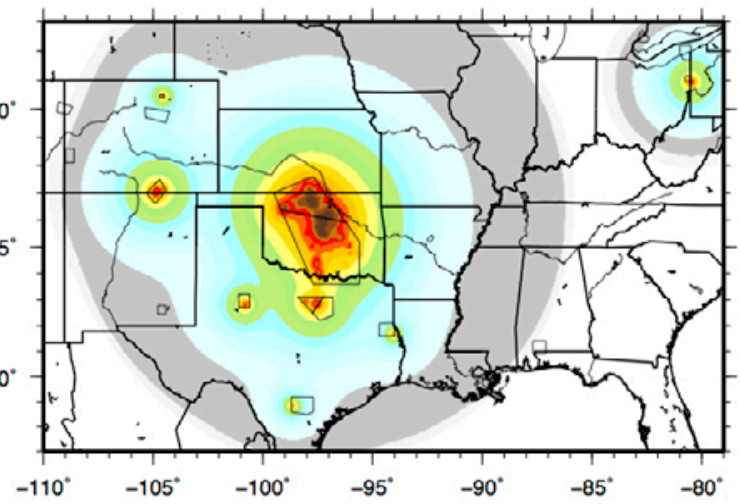

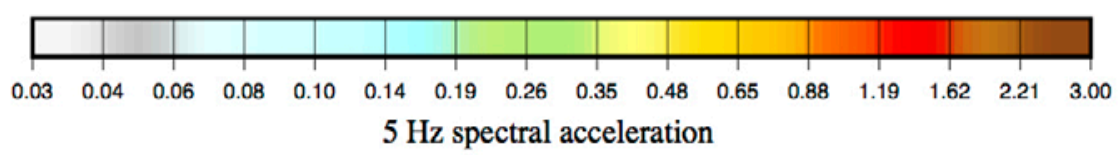

E) Map C - Map A

F) Map D - Map B
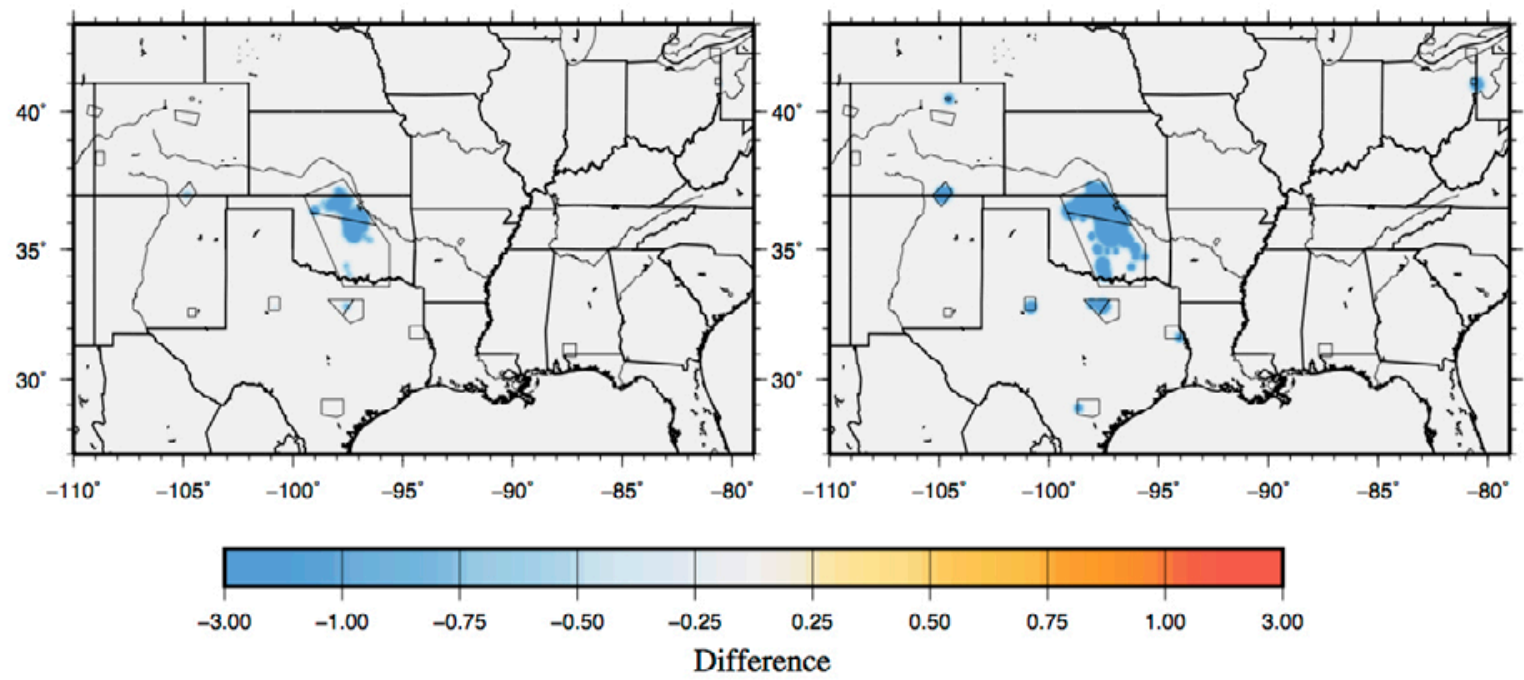

Figure 12. Sensitivity study comparing low and high ground motion model. Five-hertz (0.2 seconds) spectral accelerations and differences are in units of $g$ (acceleration of gravity). 
Table 2. Central and Eastern United States ground motion models and weights in the 2014 hazard models.

\begin{tabular}{lccc}
\hline \multicolumn{1}{c}{ 2014 Ground motion models } & Abbreviation & Type & Weight \\
\hline Frankel and others (1996) & FEA-96 & Single corner & 0.06 \\
Toro and others (1997), Toro (2002) & T0RO-02 & Single corner & 0.13 \\
Silva and others (2002) & SILVA-02 & Single corner & 0.06 \\
Campbell (2003) & CAMP-03 & Hybrid & 0.13 \\
Tavakoli and Pezeshk (2005) & PEZ-05 & Hybrid & 0.13 \\
Atkinson and Boore (2006) & AB06' & Dynamic corner & 0.25 \\
Pezeshk and others (2011) & PEZ11 & Hybrid & 0.16 \\
Atkinson (2008) & A08 & Reference empirical & 0.08 \\
\hline
\end{tabular}

\section{Comparison of the 2014 NSHM Combined with Alternative Input Models}

We have combined the 2014 NSHM with the induced seismicity input models to develop 1-percent and 0.04-percent probability of exceedance in 1-year maps, for 5-Hz spectral acceleration and a uniform firm rock site condition. The 0.04 -percent annual probability of exceedance uniform hazard maps are based on the same rate of exceedance as the final 2014 maps for 2-percent probability of exceedance in 50 years. We compare the new maps with the 2014 maps for which the suspected induced earthquakes were deleted. Results for the base case model are shown in figure 13: nondeclustered catalog with earthquakes down to M2.5, $\mathrm{b}=1.0,5-\mathrm{km}$ smoothing, Mmax from NSHM, and 8 ground motion models. Figure 14 shows the same parameters for the base case but considers the minimum magnitude (Mmin) of M3.0 in the catalog instead of M2.5 to calculate earthquake rates (for both cases, earthquakes from magnitude 4.7 to the maximum magnitudes are used to calculate probabilistic seismic ground shaking hazard). For figures 15 and 16, we also use the same parameters but consider a declustered rather than a nondeclustered catalog and a b-value of 1.5 rather than 1.0 , respectively. Figure 17 shows the base case parameters with two variations: a declustered catalog and 50-km smoothing. All of these models indicate that, for both of these probability levels, the Oklahoma induced seismicity is a major contributor to the seismic ground shaking hazard. Probabilistic ground motions are highest with the following parameter choices: nondeclustered catalog, 2014 rates, NSHM maximum magnitude, and a b-value of 1.0. Probabilistic ground motions are lower when applying the steeper b-value and the declustered catalog. Appendix 3 shows ratios of the sensitivity study models combined with the 2014 NSHM for which induced seismicity was extracted. 
A) $1 \% / y r$ base model and 2014 NSHM

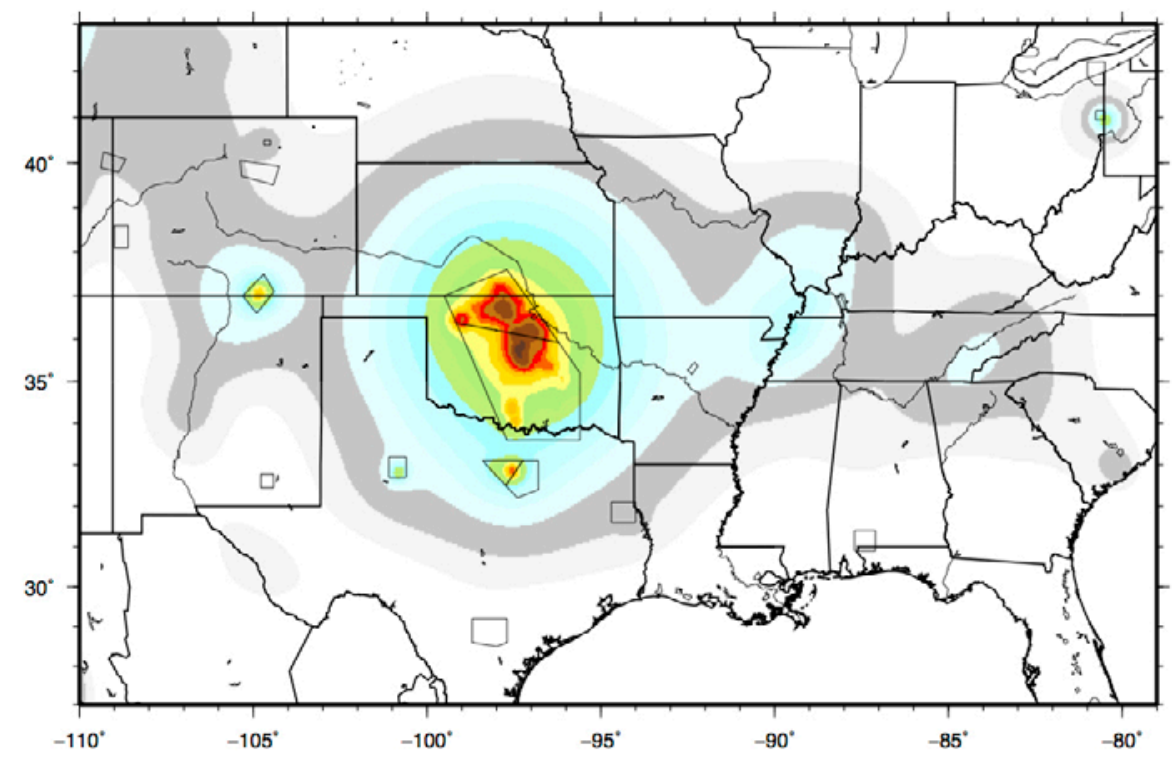

B) $0.04 \% / \mathrm{yr}$ base model and $2014 \mathrm{NSHM}$
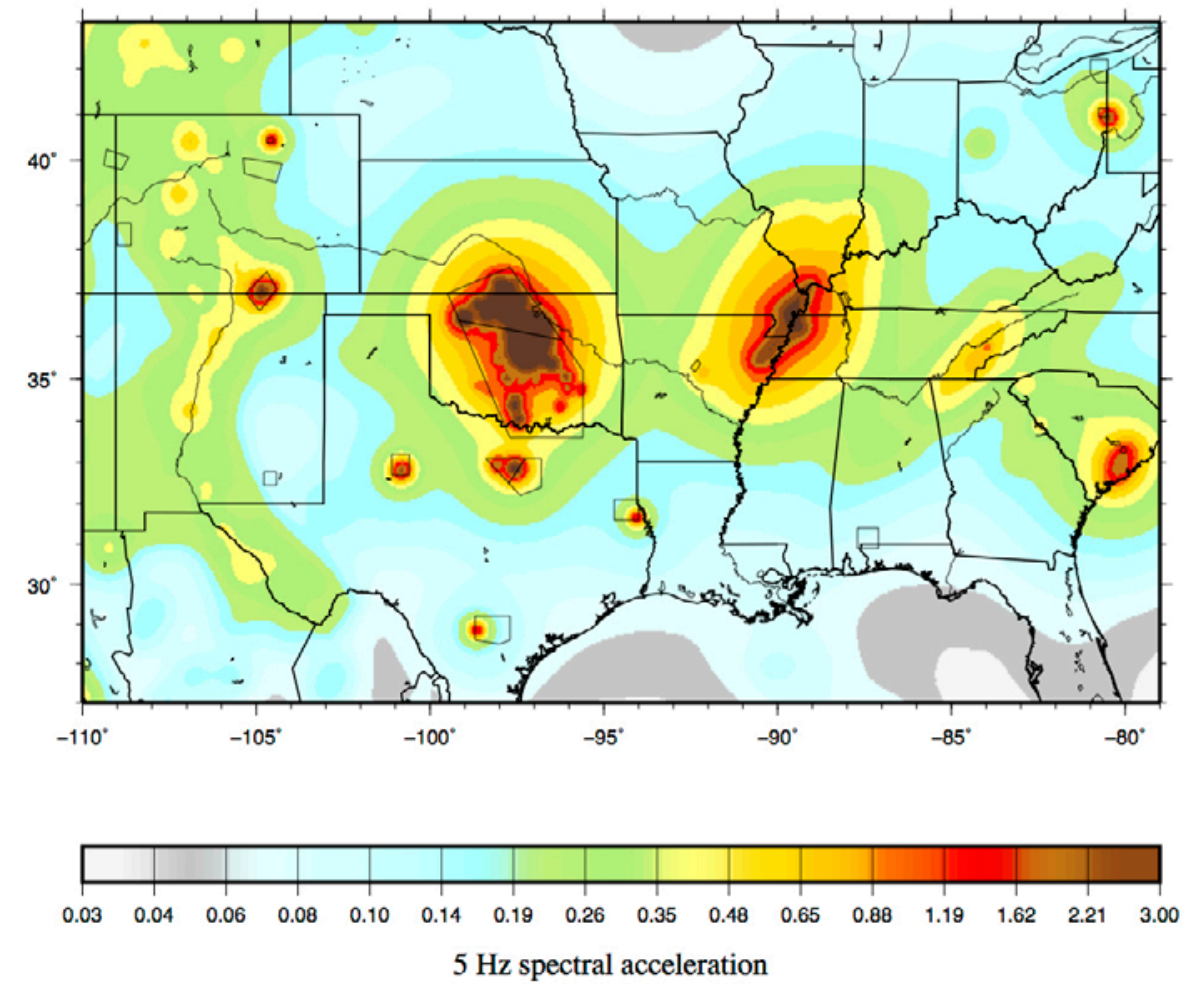

Figure 13. 2014 NSHM combined with induced seismicity hazard. Uniform hazard maps for 1-percent (top) and 0.04-percent (bottom) probability of exceedance in 1 year. This base case model uses a 2014 nondeclustered catalog with magnitudes greater than minimum magnitude (Mmin) 2.5, b-value equal to 1.0, 5 kilometers $(\mathrm{km})$ smoothing, 8 National Seismic Hazard Model (NSHM) ground motion models (GMM), and NSHM craton maximum magnitude (Mmax) model (mean M7). Five-hertz (5-Hz, 0.2 seconds) spectral accelerations are in units of acceleration of gravity $(\mathrm{g})$. 
A) $1 \% / y r$ test case with minimum M3 and 2014 NSHM

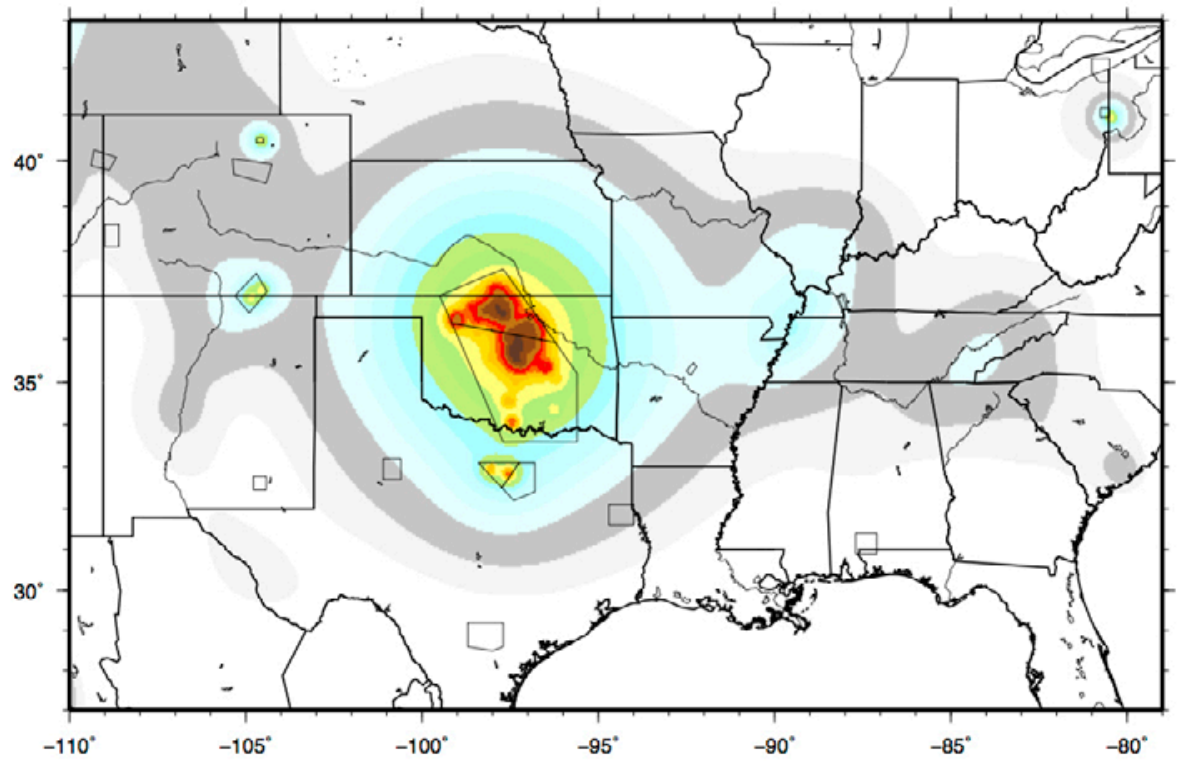

B) $0.04 \% / y r$ test case with minimum M3 and 2014 NSHM
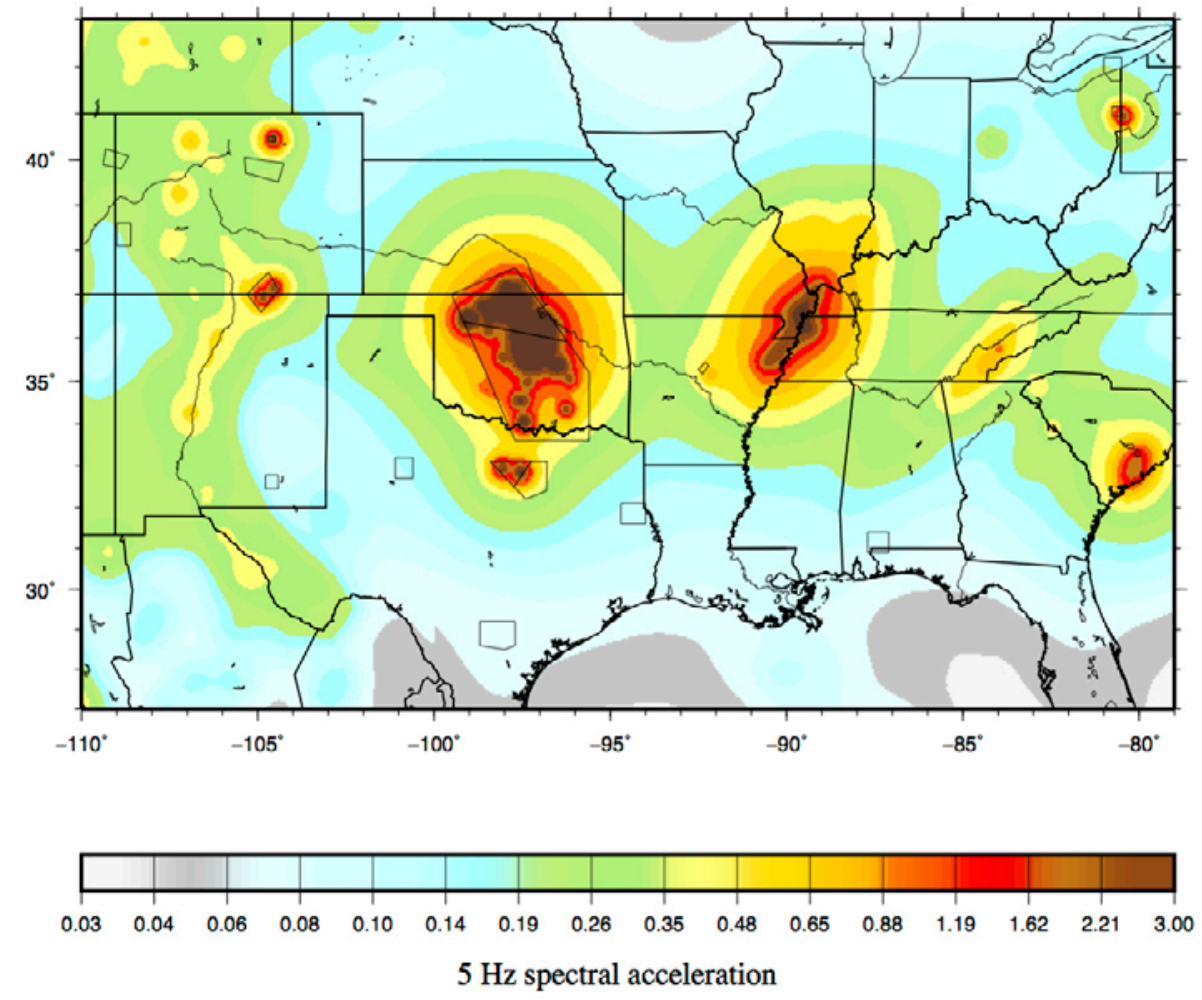

Figure 14. 2014 NSHM combined with induced seismicity hazard. Uniform hazard maps for 1-percent (top) and 0.04-percent (bottom) probability of exceedance in 1 year. This model uses a 2014 nondeclustered catalog with magnitudes greater than minimum magnitude $(\mathrm{Mmin}) 3.0$, b-value equal to 1.0, 5 kilometers $(\mathrm{km})$ smoothing, 8 National Seismic Hazard Model (NSHM) ground motion models (GMM), and NSHM craton maximum magnitude (Mmax) model (mean M7). Five-hertz (5-Hz, 0.2 seconds) spectral accelerations are in units of acceleration of gravity (g). 
A) $1 \% / y r$ test case with a declustered catalog and 2014 NSHM

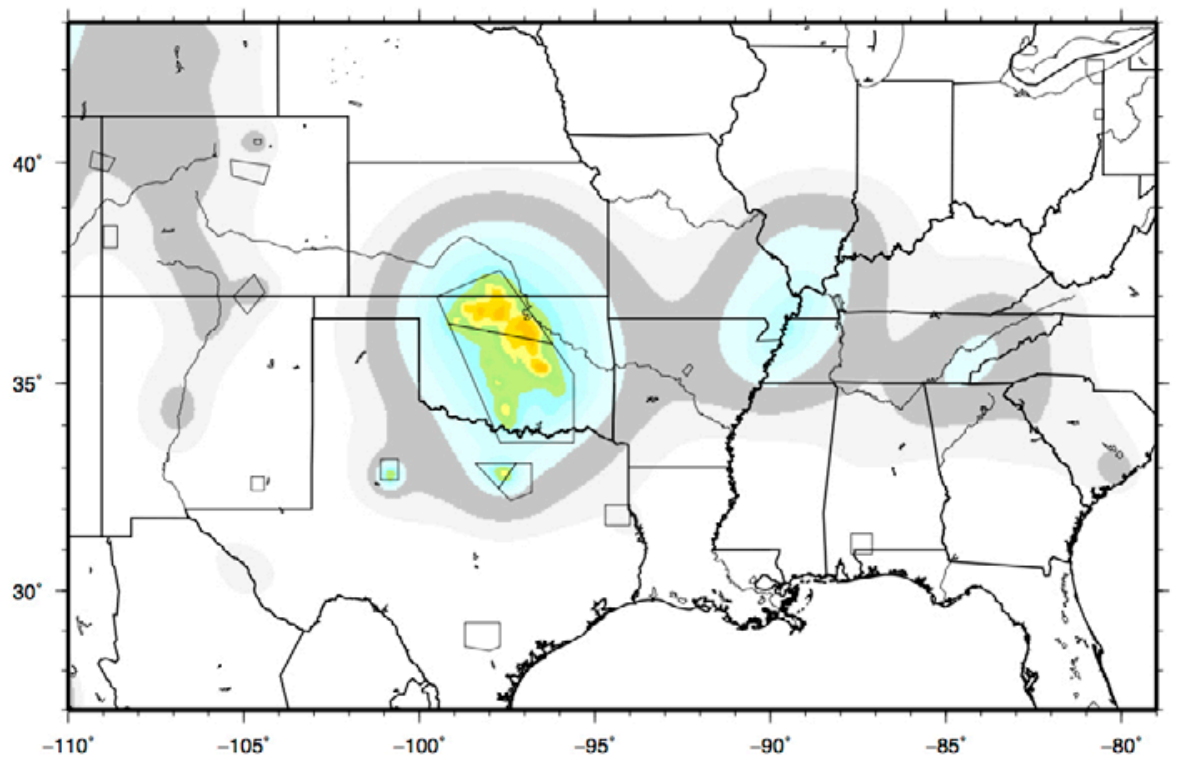

B) $0.04 \% / y r$ test case with a declustered catalog and 2014 NSHM
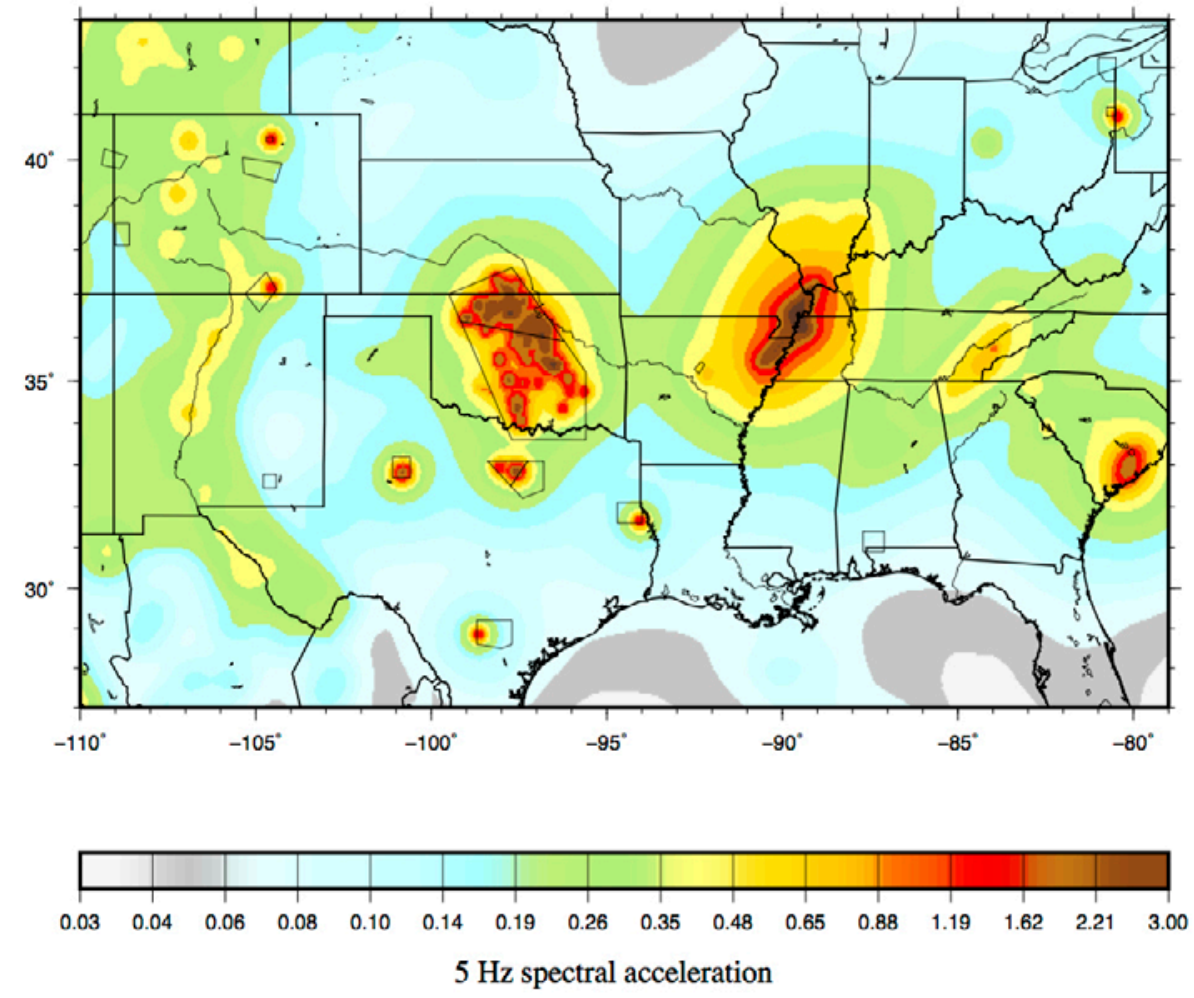

Figure 15. 2014 NSHM combined with induced seismicity hazard. Uniform hazard maps for 1-percent (top) and 0.04-percent (bottom) probability of exceedance in 1 year. This model uses a 2014 declustered catalog with magnitudes greater than minimum magnitude $(\mathrm{Mmin}) 2.5$, b-value equal to 1.0, 5 kilometers $(\mathrm{km})$ smoothing, 8 National Seismic Hazard Model (NSHM) ground motion models (GMM), and NSHM craton maximum magnitude (Mmax) model (mean M7). Five-hertz (5-Hz, 0.2 seconds) spectral accelerations are in units of acceleration of gravity (g). 
A) $1 \% / y r$ test case with a 1.5 b-value and 2014 NSHM

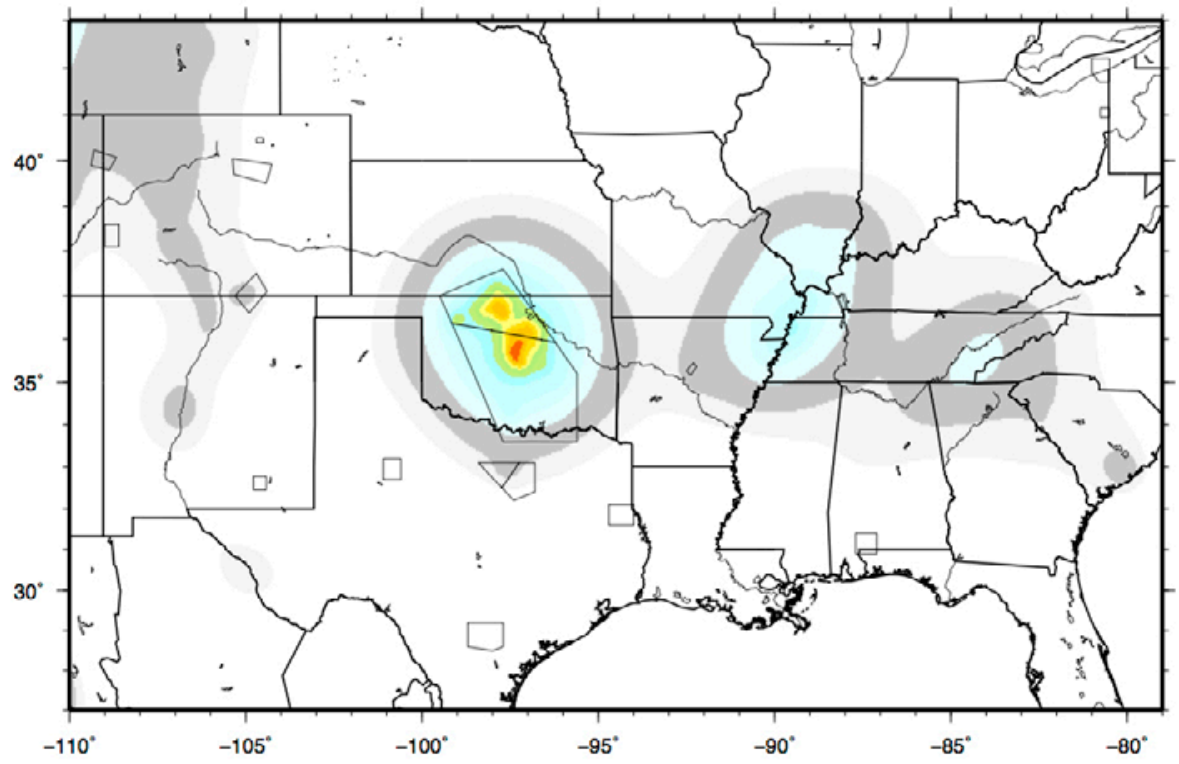

B) $0.04 \% / \mathrm{yr}$ test case with a $1.5 \mathrm{~b}$-value and $2014 \mathrm{NSHM}$
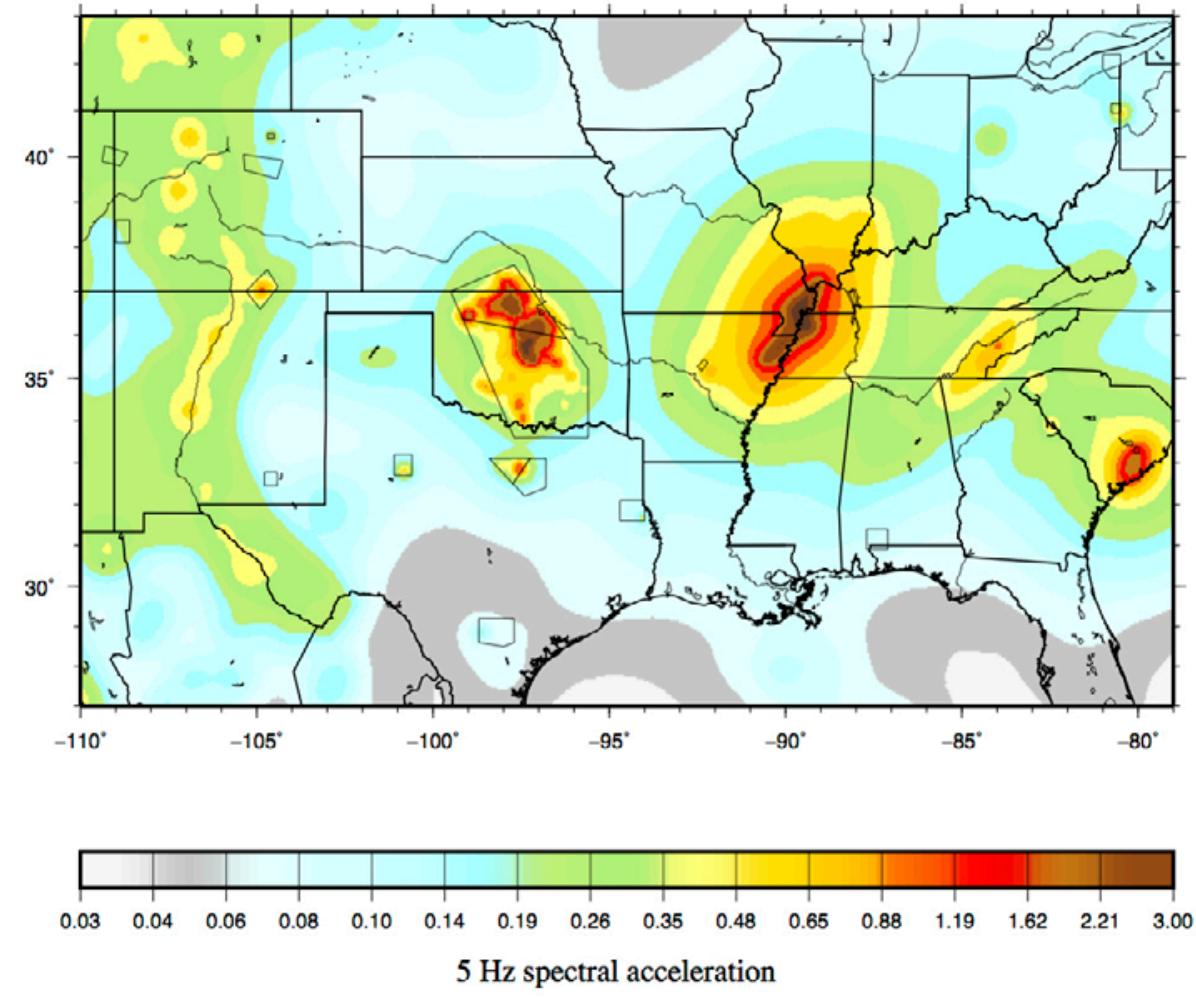

Figure 16. 2014 NSHM combined with induced seismicity hazard. Uniform hazard maps for 1-percent (top) and 0.04-percent (bottom) probability of exceedance in 1 year. This model uses a 2014 nondeclustered catalog with magnitudes greater than minimum magnitude $(\mathrm{Mmin}) 2.5$, b-value equal to $1.5,5$ kilometers $(\mathrm{km})$ smoothing, 8 National Seismic Hazard Model (NSHM) ground motion models (GMM), and NSHM craton maximum magnitude (Mmax) model (mean M7). Five-hertz (5-Hz, 0.2 seconds) spectral accelerations are in units of acceleration of gravity (g). 
A) $1 \% / \mathrm{yr}$ test case with a declustered catalog and $50 \mathrm{~km}$ smoothing; combined with the $2014 \mathrm{NSHM}$

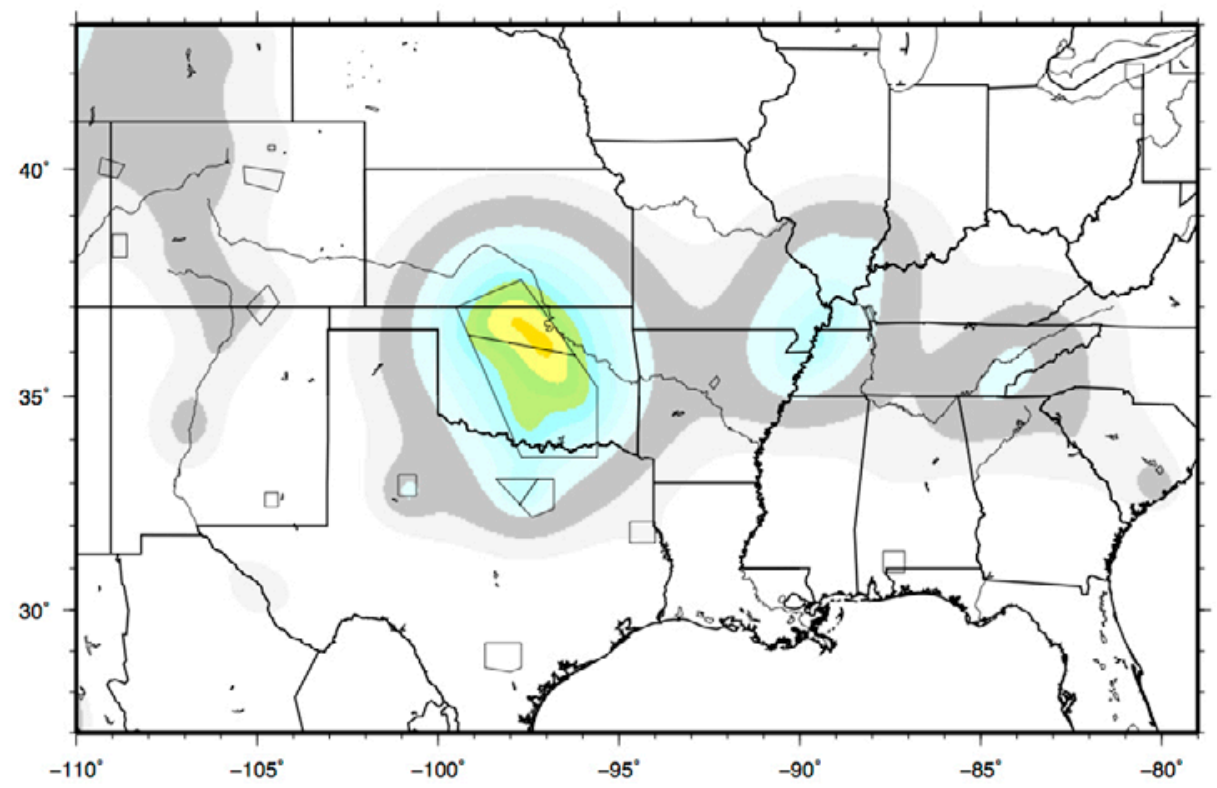

B) $0.04 \% / \mathrm{yr}$ test case with a declustered catalog and $50 \mathrm{~km}$ smoothing; combined with the $2014 \mathrm{NSHM}$
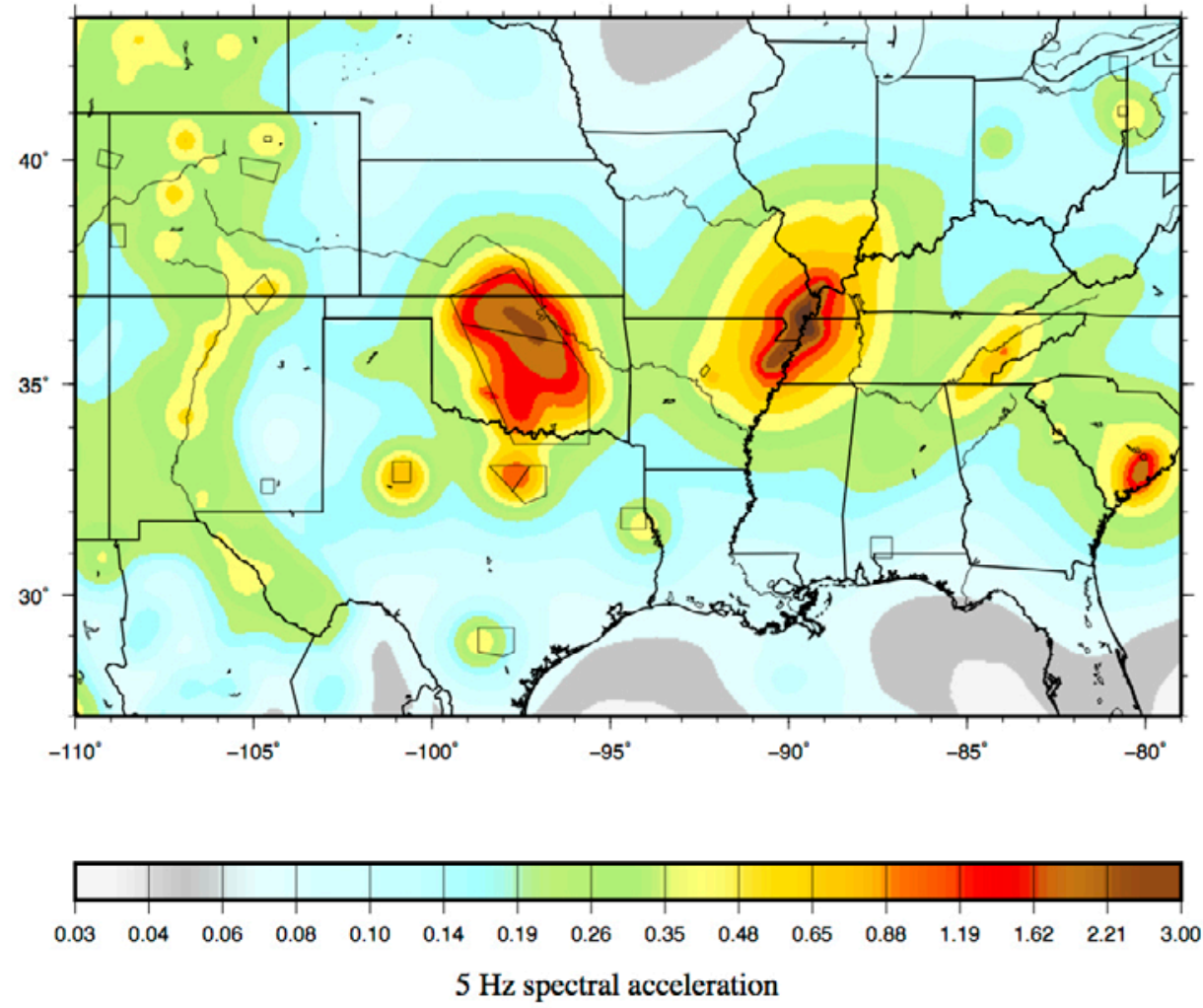

Figure 17. 2014 NSHM combined with induced seismicity hazard. Uniform hazard maps for 1-percent (top) and 0.04-percent (bottom) probability of exceedance in 1 year. This model uses a 2014 declustered catalog with magnitudes greater than minimum magnitude (Mmin) 2.5, b-value equal to 1.0, $50 \mathrm{~km}$ smoothing, 8 National Seismic Hazard Model (NSHM) ground motion models (GMM), and NSHM craton maximum magnitude (Mmax) model (mean M7). Five-hertz (5-Hz, 0.2 seconds) spectral accelerations are in units of acceleration of gravity (g). 
The differences and ratios of the new models compared to the 2014 NSHM are so large that we need to consider several important modeling issues when developing the final model: (1) Is the methodology appropriate for this spatio-temporal clustering behavior of induced seismicity? (2) Should we consider truncation of ground motion model or the aleatory distribution of the ground motion at levels that are very high? (3) What source input parameters are most appropriate for consideration of this very high seismic activity rate?

Hazard curves shown in figure 18 represent the rate of exceedance for different ground motion levels. The curves show very marked differences in the hazard (annual rate of exceedance) close to a factor of 100 for a wide range of ground motion values for Oklahoma City. This increase is consistent with the new earthquake rates that are more than a factor of 100 greater in some active areas than those considered in the 2014 models (Petersen and others, 2014).
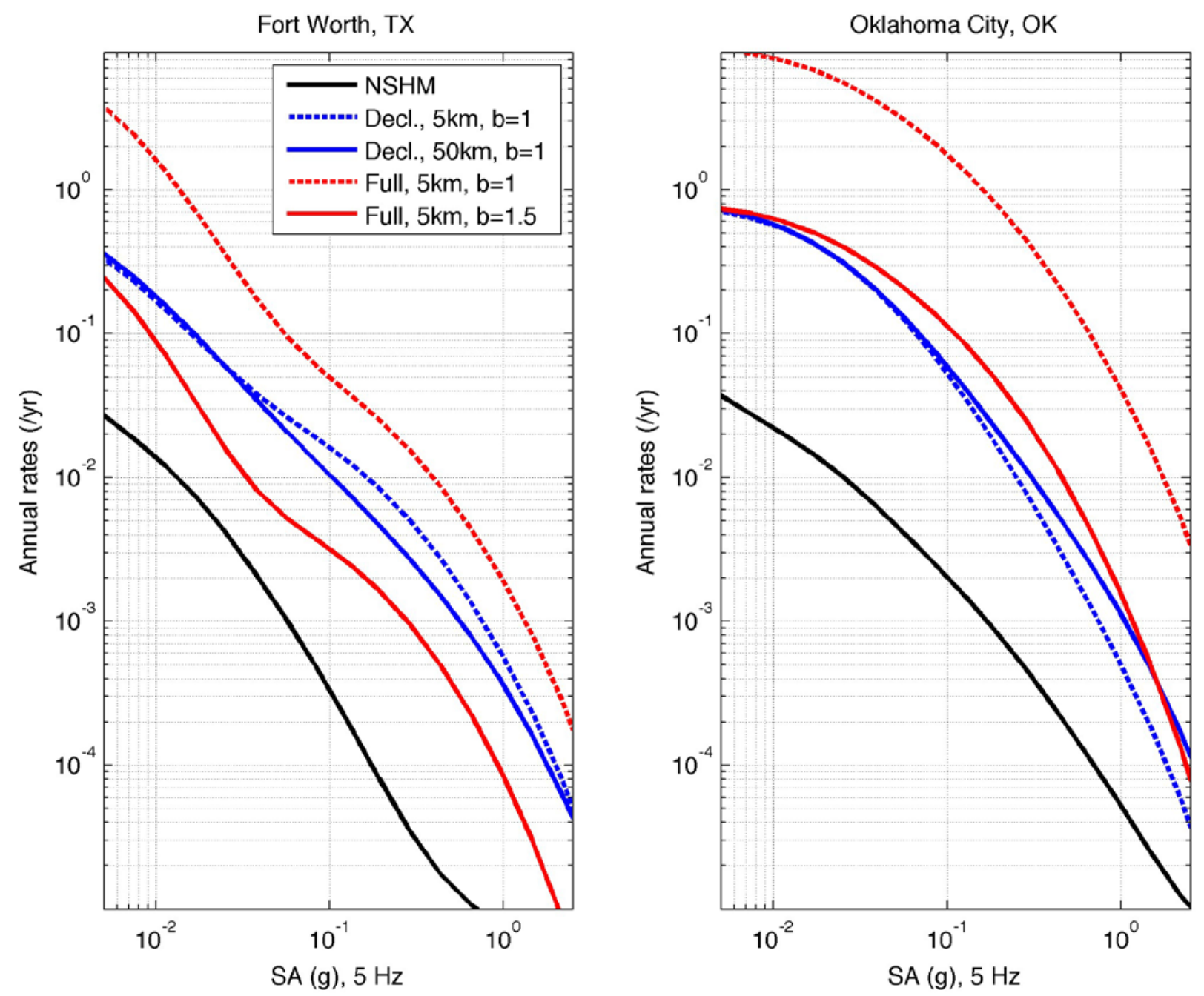

Figure 18. Hazard curves for Fort Worth, Texas and Oklahoma City, Oklahoma, for the 2014 National Seismic Hazard Model (black) and adding the induced seismicity component using the full nondeclustered or declustered catalogs with a b-value (the slope of the curve that relates the numbers of small and large earthquakes) of 1.0 or 1.5 , and for smoothing parameters of 5 kilometers $(\mathrm{km})$ or $50 \mathrm{~km}$. Five-hertz $(5-\mathrm{Hz}, 0.2$ seconds) spectral accelerations (SA) are in units of acceleration of gravity (g). TX is Texas, OK is Oklahoma. 
The probabilistic ground motions calculated in the sensitivity tests are quite high near zones of intense induced seismicity and often are a factor of more than two higher than the 2014 NSHM across broad areas (appendix 3). To put these probabilistic ground motions in context, we compared the deterministic (scenario) ground shaking from the Frankel and others (1996) ground motion model. Results are shown in table 3. Ground motions (median and 84th percentile) for $5-\mathrm{Hz}$ spectral acceleration also exceed $2 \mathrm{~g}$ (acceleration of gravity) at short distances (less than $10 \mathrm{~km}$ ). Near-source, peak ground accelerations recorded from the 2011 Prague M5.6 earthquake ranged between 0.34 and $0.65 \mathrm{~g}$ (acceleration of gravity), which correspond to Modified Mercalli Intensity (MMI) VIII. MMI VIII represents the following: severe shaking; damage slight in specially designed structures; considerable damage in ordinary substantial buildings with partial collapse; damage great in poorly built structures; fall of chimneys, factory stacks, columns, monuments, and walls; and heavy furniture overturned. The probabilistic ground shaking assessments near zones of induced seismicity are typically greater than the median predicted ground shaking. The ground motion models developed from empirical and synthetic data vary by about a factor of 2 at one standard deviation (aleatory variability).

Table 3. Median and 84th percentile ground motions for firm rock site condition (NEHRP BC) from Frankel and others (1996).

[Firm rock site condition is NEHRP BC (National Earthquake Hazards Reduction Program shear wave velocity [time-average] in the upper 30 meters of 760 meters per second), $g$ is acceleration of gravity, $\mathrm{R}$ is hypocentral distance in kilometers (km), PGA is peak ground acceleration, and $\mathrm{Hz}$ is hertz. 84th percentile motions are set equal to median times a factor of 2.0 , assuming sigma $=0.3 \mathrm{common} \log$ units or 0.7 natural $\log$ units]

\begin{tabular}{|c|c|c|c|c|c|}
\hline & \multirow{2}{*}{$\begin{array}{l}\text { Ground } \\
\text { motion }\end{array}$} & \multicolumn{2}{|c|}{ Median $(g)$} & \multicolumn{2}{|c|}{$84^{\text {th }}$ percentile $(g)$} \\
\hline & & $\mathrm{R}=10 \mathrm{~km}$ & $\mathrm{R}=25 \mathrm{~km}$ & $R=10 \mathrm{~km}$ & $\mathrm{R}=25 \mathrm{~km}$ \\
\hline \multirow{3}{*}{ Moment magnitude $=5$} & PGA & 0.36 & 0.10 & 0.72 & 0.20 \\
\hline & $5-\mathrm{Hz}$ & 0.45 & 0.15 & 0.90 & 0.30 \\
\hline & $1-\mathrm{Hz}$ & 0.03 & 0.01 & 0.06 & 0.02 \\
\hline \multirow{3}{*}{ Moment magnitude $=6$} & PGA & 0.85 & 0.27 & 1.70 & 0.54 \\
\hline & $5-\mathrm{Hz}$ & 1.26 & 0.45 & 2.52 & 0.90 \\
\hline & $1-\mathrm{Hz}$ & 0.22 & 0.08 & 0.44 & 0.16 \\
\hline \multirow{3}{*}{ Moment magnitude $=7$} & PGA & 1.78 & 0.60 & 3.56 & 1.20 \\
\hline & $5-\mathrm{Hz}$ & 2.88 & 1.05 & 5.76 & 2.10 \\
\hline & $1-\mathrm{Hz}$ & 0.71 & 0.27 & 1.42 & 0.54 \\
\hline
\end{tabular}

\section{Seismic Hazard Products Suggested at the Workshop}

It is clear that the established, 6-year update schedule for the NSHM is not ideal to address induced seismicity. Annual or even more frequent updates of the hazard model and other products could account for rapid changes in induced seismicity. Workshop participants agreed that creating a short-term (for example, 1 year) hazard model that incorporates induced seismicity would be beneficial. Although this report offers a general idea of how induced seismicity might affect the NSHM, several questions must be answered before a preferred model is put forward. This section contains suggested hazard products and possible research directions discussed at the workshop. 
Although it was not unanimous, the general consensus at the workshop was that the current method of declustering is too severe, and should not be used if the seismic hazard model takes into account a 1-year catalog or less. Workshop participants suggested that a workshop on declustering methods to discuss the appropriate declustering methods (such as the optimal distance and time windows) be held. Also, participants wanted to understand what b-value, catalog, magnitude (minimum magnitude for the catalog [Mmin]), and smooth-seismicity distance (correlation length) should be used to predict future seismicity. Statistical tests should be used to maximize the predictive power of the short-term hazard models. It was also suggested that change-point analysis could be used to assess short-term (annual) seismicity rate fluctuations.

Ground motion models are a key contributor to seismic hazard assessments and participants at the workshop had several comments regarding these important models. They wondered what ground motion models are most appropriate for induced earthquakes. Currently, none of the 2014 NSHM ground motion equations takes depth into account (Petersen and others, 2014). Induced seismicity depths are generally shallower and tend to have lower stress drop than natural earthquakes. It is necessary to incorporate a ground motion model that can properly characterize the shallow depth typical of induced seismicity. Truncation could be appropriate for induced seismicity hazard models. Two options that were discussed are truncating the ground motion models at the 84th percentile level (similar to truncations applied to faults), or at the median value.

Workshop participants had several specific comments about the input hazard parameters. More seismic stations and $\mathrm{V}_{\mathrm{S} 30}$ measurements would be helpful to better locate and quantify induced seismicity. Also, workshop attendees would like an earthquake catalog that differentiates natural earthquakes from induced earthquakes caused by fluid injection, hydraulic fracturing, and other manmade causes. It would be interesting to distinguish the induced earthquakes that are directly caused by hydraulic fracturing (as opposed to the other forms of induced seismicity). This would likely require shared information from the oil and gas industry. Also, attendees wondered how to quantify the optimum minimum magnitude of the probabilistic hazard calculation and maximum magnitude (Mmax) applied in the seismic hazard analysis. Currently M4.7 is the minimum magnitude for the 2014 NSHM hazard calculation. It was suggested at the workshop that a smaller value could be appropriate for the hazard calculation's minimum magnitude to account for nuisance shaking. Also, workshop attendees would like to know if magnitude-area scaling differs between natural and induced earthquakes. We will need to determine the optimum weights to use for the alternative models in the logic tree. How should seismic source characterization models reflect local differences in induced seismicity? The uncertainties associated with seismic source characterization for induced earthquakes should be properly quantified or reduced. Researching the Enola, Arkansas earthquake swarm, or the swarm near Reno, Nevada, could help us understand how tectonic swarms differ from induced seismicity.

Building officials need products that can inform their decisions. Participants also wanted to know how building, bridges, roads, and so on should be designed to withstand induced earthquakes. Also, after a particular size of earthquake occurs, what distance measure should be used to inspect buildings and infrastructure? At the workshop, it was suggested that a parallel could be drawn to surface mining and the setback distance that is used to control ground shaking during operation. Ideally, if induced seismicity could be kept below an established nuisance level, it would be tolerable. However, relatively small earthquakes can cause damage and earthquakes as small as M1.8 can be felt. It was reported at the workshop that an M3.4 earthquake in Oklahoma caused damage to residences (cracked bricks, door frames off center, shattered window, and chimney collapse). Damage from earthquakes, as low as mid-M3, could also affect the well systems, such as casing and pipes. Communities experiencing 
elevated levels of induced seismicity (which includes the citizens, local governments, and industries) are looking to the USGS to understand the associated ground shaking hazard and earthquake risk to society.

To help the engineering community determine if the building standards should be modified, or if a reevaluation of industrial practices would be preferable, a probability gain map could be used to show how the annual seismic hazard has increased because of induced seismicity. One comment from the workshop's regulatory panel was that engineers could determine a reasonable range of ground motions to consider in design by comparing the building code hazard curves with hazard curves that include induced seismicity. To help the community as a whole (citizens and professionals) understand the potential effect of the larger predicted ground motions because of induced seismicity, it would be helpful to compare the new seismic loads to the wind loads, which is a significant building design factor in Oklahoma. A risk matrix could be used to show the probability of a specific MMI and the consequence for the population and structures, ideally taking into account the existing building stock. This matrix might be similar to the type applied in safety of dams.

Communities would also benefit from summary statistics (for example, the probability of exceeding building codes) for the specific cities and towns experiencing such activity, and a map showing the predicted number of felt earthquakes. A cumulative shake map could be produced for areas that have reported significant levels of induced seismicity, such as Oklahoma. This map would display the maximum intensity observed at any location over a given past time-interval based on Did You Feel It? (DYFI?, http://earthquake.usgs.gov/earthquakes/dyfi/) public responses. Also, felt earthquakes from DYFI? could be used to create an empirical hazard curve to compare with the calculated hazard curve.

Deterministic earthquake scenarios could be produced for the areas reporting induced seismicity. Compared to probabilistic seismic hazard, scenarios are straightforward and easier for the general public to appreciate. It was suggested at the workshop that creating scenarios for M6 earthquakes could illustrate the effect of a strong earthquake. The ground shaking could be represented in several ways: peak horizontal ground acceleration (PGA), 1-Hz spectral acceleration, 5-Hz spectral acceleration, and Modified Mercalli Intensity (MMI). MMI describes the level of shaking and damage experienced by an observer. We have already developed a table of scenario ground motions for M6 earthquakes (table 3 ).

Prompt Assessment of Global Earthquakes for Response (PAGER) is a USGS feature that uses shaking estimates from real-time earthquakes (ShakeMap) and then incorporates information on populations and structures to provide a ballpark range of potential human impacts and economic losses. For our purposes, PAGER could be used to estimate the potential risk associated with a particular deterministic earthquake scenario. A PAGER scenario could be produced for several areas reporting induced seismicity. The messaging associated with a PAGER scenario is important. It must be clearly stated that this is a theoretical earthquake (not a prediction), and that the associated losses could vary greatly from the estimates if an earthquake occurred with a drastically a different hypocenter, magnitude, or rupture characteristics.

Operational Earthquake Forecasts provide estimates of aftershock rates or changes in rates and can be automated and updated frequently, on a daily or hourly basis. At the workshop, regulators said that they would like the ability to identify new areas of induced seismicity and to determine when seismicity rates and patterns have changed. Operational Earthquake Forecasts can provide this type of information at a much faster pace than the NSHM.

Participants at the workshop requested advice regarding reasonable guidelines for when to shut down and when to restart injection. This is a difficult problem because it is unknown why induced seismicity occurs near some fluid injection wells and not at others; in some cases seismicity tracks injection, and in other cases seismicity lags. A helpful first step would be to compile a common format (and publicly accessible) database for wastewater injection operations that can be used to compare 
observed seismicity with exploration activities. This would also encourage the information exchange between industry and scientists.

\section{USGS Research Agenda for Induced Seismicity Hazard Studies}

The Documentation for the 2014 Update of the United States National Seismic Hazard Maps states: "We will consider alternative models for including potentially induced seismicity in future versions of the map. Users of the current hazard information should consider that hazard might be higher in these zones of potentially induced seismicity than are presently shown on the map." (Petersen and others, 2014, page 22-23). The USGS and Oklahoma Geological Survey workshop held in Oklahoma and this Open File Report address the need to delineate areas with increased rates of seismicity near sites of hydrocarbon production or wastewater disposal. Our first priority is to develop a short-term (annual based) seismic hazard model that could be updated annually to incorporate the seismic hazard from natural and induced earthquakes. Other priorities are to develop a process-based understanding of induced earthquakes and the seismic hazard they pose, and to work with government, industry, and academia to acquire data and to develop products that will provide information on how to better assess and deal with such seismicity.

\section{Short-Term Hazard Agenda for Induced Earthquakes (2015-16)}

Our first priority is to develop a seismic hazard model for induced seismicity that can be used to show where future earthquakes might occur, how often, and how strong the ground could shake from those earthquakes. The 2014 model did not directly consider the ground shaking hazard from induced seismicity but included seismic zones to indicate where such activity had been identified. To account for this increased seismicity in the new models, scientists need to develop consensus-based models on the following: (1) seismic catalogs, (2) models for assessing short-term rates, (3) models for assessing how to account for future earthquake locations, (4) models for the size of future induced earthquakes, and (5) models for how strong the ground will shake from induced earthquakes. Each of these models requires analysis from a broad group of scientists who are experts in physics of earthquakes, modeling of earthquake recurrence, and modeling of ground shaking.

The seismic catalogs include natural and induced seismicity. They also include dependent (foreshocks and aftershocks) and independent earthquakes. To develop a hazard model, we may need to distinguish between natural and induced seismicity where these different types of earthquakes have different hazard metrics. To accomplish this we will need to understand how the statistical properties of the catalogs (Gutenberg-Richter b-values and magnitude completeness) vary between the 17 regions of induced seismicity and natural earthquake swarms. In addition, hazard methodologies conventionally require assessing rates of earthquakes from a catalog containing independent earthquakes. We need to establish new ways to assess which earthquakes are dependent and independent. The current declustering model uses a simple formula to separate these events based on magnitude and distance windows. However, the 2011 Prague earthquake declustering process resulted in earthquakes being removed from the hazard analysis that were smaller than M5.6 for about three-quarters of a year and within about $50 \mathrm{~km}$ of the earthquake. This catalog reduction may not be appropriate for swarm activity or when earthquake rates are increasing. Alternative seismic declustering models, such as the UCERF3 cluster model (Field, 2014), which was applied in California, allows for more complexity than in the model considered in the 2014 NSHM for the Central and Eastern United States, and may be more appropriate for assessing the seismic hazard in these areas. We may need to test alternative models for declustering or develop a new model based on these induced earthquakes. 
Several statistical models for assessing short-term (annual) rates and future earthquake locations have been considered in this report. It is difficult to assess future earthquake rates since the earthquakes vary rapidly in space and time, and may also depend on economic decisions and regulatory actions. Appendix 1 shows a preliminary example of a likelihood test that can be used to assess the optimal parameters for assessing earthquake rates and locations. Additional testing is needed to determine the optimal earthquake catalog (for example, the duration and minimum magnitude), and the length scale of the smoothing kernels.

At the workshop, we proposed using maximum magnitudes of M6 and M7 (with a distribution obtained from the 2014 NSHM). Alternative maximum magnitude models were not proposed; therefore, it does not seem that there is short-term research that needs to be completed on this input parameter during the next year.

The ground motion models are key inputs for the hazard assessment. New models will allow for a depth parameter that will be helpful in assessing seismic hazard from induced seismicity, as it is typically shallower than the full depth range of many natural earthquakes. To improve these ground motion models, and our assessment of seismic hazard, we need to assess the ground shaking parameters from the hundreds of seismograms that have been collected over the past several years. It is very important to examine the statistical measures of these shaking records, and then to use these records to make an empirical hazard model. This empirical model can be compared with the hazard model obtained using NGA-East models and standard probabilistic hazard methodologies. In addition, estimates of ground properties are needed to forecast ground shaking. These activities will help users gain confidence in the forecasted shaking levels.

\section{Long-Term Research Directions for Understanding Hazard from Induced Earthquakes (2015-20)}

The short-term research agenda addresses the most pressing issues identified through the sensitivity tests of the logic tree (figs. 4-18). The USGS will work with other state and federal government agencies, academia and industry to collect new data that will improve the accuracy and timeliness of the hazard model. A multiyear effort would enable us to develop and validate new findings, and integrate them into future versions of the hazard model. Long-term research activities targeting reduction of epistemic uncertainty in the logic tree (fig. 4) are described in greater detail here.

\section{Catalog}

A more comprehensive catalog of induced earthquakes requires lowering the magnitude detection threshold on a national scale and on the scale of the areas where oil and gas production is taking place, especially from unconventional reservoirs. Because the industrial activities that induce earthquakes change with time, depending on various circumstances, it is necessary to be able to detect at an early stage, the development of a previously unrecognized site of induced seismicity. To do this requires reducing the detection threshold of the national network from its current threshold of about M3 to at least M2, or, ideally, even lower. This improvement of the national network would be invaluable for guiding the deployment of local networks where they are needed to monitor in a timely way detailed behavior of the induced earthquakes.

Local networks must be capable of recording ground motion with wide dynamic range and broad bandwidth with sufficient station coverage for precise hypocentral locations. Magnitude detection thresholds in the range of 0 to 1 are probably achievable, at least in reasonably quiet locations. With location precision of $100 \mathrm{~m}$, or less, the low magnitude thresholds will enable images of previously unmapped structures to be resolved from the well-located hypocenters, although considerable work will 
also need to be done on reducing absolute location uncertainty. Similarly, earthquake focal mechanisms, or better yet, moment tensors, can lead to a better understanding of how the earthquakes are related to the geologic structures and fluid injection activities. Seismic stress drop and radiated seismic energy estimates can yield additional insights regarding the induced earthquakes and their ground motion.

Although most fluid-induced earthquakes that are large enough to be felt are the result of wastewater disposal by deep injection, there are an increasing number of reports of felt earthquakes caused by hydraulic fracturing (Holland, 2011). A low-magnitude threshold will increase the likelihood of detecting these events and gaining insights as to the factors that give rise to them. Gathering data on the timing and location of hydraulic fracturing treatments will also be very valuable to the development of induced seismic hazard models, since the seismic hazard associated with hydraulic-fracture-induced earthquakes terminates with the completion of the hydraulic fracture treatment, and these events may be removed from the earthquake catalog. By identifying earthquakes induced by hydraulic fracturing, we may remove potential bias in the hazard calculation.

Sun and Hartzell (2014) recently demonstrated that local and regional seismic data can be used successfully to develop finite fault models of induced earthquakes. (Extending this capability to lower magnitudes by taking advantage of improved network data could provide some very useful insights concerning the behavior and causes of fluid-induced earthquakes.

\section{Rate Model}

Topics that require additional research include determining the appropriate b-value to use in regions of induced seismicity and fine-tuning declustering methods for induced earthquakes, including regional variability. Evidence suggests that reoccurrence and clustering behavior of induced earthquakes may differ from natural earthquakes (Llenos and Michael, 2013; McNamara and others, 2015). Therefore, identifying alternative ways of quantifying earthquake occurrence rates that are more appropriate for induced seismicity could be used to differentiate induced earthquakes from natural ones.

Another issue is how to determine an appropriate time window over which to estimate seismicity rates. At the Midwest City workshop, it was suggested that the current year's seismicity is a sufficient predictor for the next year's seismicity; however, in Oklahoma, the seismicity rate changed dramatically over the course of one year between 2013 and 2014. Furthermore, how to model seismicity rates in an area if injection suddenly starts and after injection has stopped also needs to be addressed. This requires further research into how external processes such as fluid injection drive earthquake rates, and how earthquake rate models may be able to incorporate available fluid injection data to improve rate estimates.

Future research could also consider the development of seismic hazard assessment methods that do not require the use of stationary Poisson earthquake rates and would vary in time. As the case in Oklahoma shows, earthquake rates can vary significantly in space and time. Developing short-term time-dependent probabilistic seismic hazard assessments can help eliminate the need for declustering, as well as determining what time windows over which to estimate rates.

\section{Location Model (Smoothing)}

Research to explore how to select an optimal spatial smooth kernel would be beneficial. The strong effect that the width of the smoothing kernels has on probabilistic ground motion is demonstrated by figure 10. A large smoothing kernel, such as $50 \mathrm{~km}$, can reduce the probabilistic ground motion in the area of the seismicity and increase the effect of the ground shaking hazard farther from the initial area of the seismicity. Given that induced seismicity is likely going to be limited to areas affected by 
fluid injection, we might expect that a narrower smoothing kernel would be valuable for estimating the seismic hazard. How to select this kernel is complex, though, as sometimes we see earthquake triggering limited to an area very close to an injection well (Kim, 2013) and in others cases we see earthquake triggering extending to tens of kilometers beyond injection wells (Keranen and others, 2014). Analysis of a number of areas of induced earthquakes with quality locations and wastewater injection wells could be analyzed and modeled to better understand the range of distances that are characteristic of induced earthquakes.

Research into the interaction of induced seismicity with known faults is important for understanding future induced earthquake locations. As presented at the workshop, M. Zoback suggested that we forecast the likelihood of whether an area will have induced earthquakes based upon the orientation of faults and stress fields. The development of fault and stress databases could help forecast seismic hazard in areas of seismicity associated with oil and gas production.

\section{Maximum Magnitude}

Research has been completed to discuss whether the maximum magnitude of an induced earthquake correlates with the total volume of fluids injected (Hallo and others, 2014; McGarr, 2014; Zoller and Holschneider, 2014). Additional research in these areas would be helpful as well as research to determine if the maximum induced earthquake size is the same as the maximum natural earthquake size for the region. Numerical modeling and observational studies of Mmax are needed to better understand whether Mmax varies with time. For example as injection increases, does Mmax increase as well? Whether observed faults and faults inferred from seismicity can be used to estimate Mmax is another research question. In many areas, we see lineations of seismicity that are 10 or more kilometers long, but none of these areas have to date reported an earthquake that ruptures a large fraction of the lineation.

\section{Ground Motion Models}

Several studies have indicated that ground motions from induced earthquakes may differ from their counterparts for natural earthquakes (McGarr and Fletcher, 2005; Hough, 2014). The differences could be related to the shallow depths of induced earthquakes, usually located in the shallow crystalline basement, or to stress drops that appear to be lower than those for natural events, or some combination of these two factors. In any case, induced earthquake ground motion prediction equations could be developed in the course of determining useful hazard models. There are already numerous datasets available for developing ground motion prediction equations for induced earthquakes, including recorded ground motion and intensities. More comprehensive network coverage will give rise to considerably more data to constrain these equations. Ground motion data recorded by local networks and regional stations out to epicentral distances of $100 \mathrm{~km}$ are ideally suited to developing the required ground motion models. In addition to magnitude and hypocentral distance, the ground motion models probably need to account for hypocentral depth, site response and, perhaps, stress drop and basin effects. Where adequate velocity models have been developed, synthetic seismograms may prove useful for interpreting the observed ground motion.

\section{Beyond the Logic Tree}

Seismic hazard models that incorporate a process-based understanding of injection-induced seismicity would be useful to assess probabilistic seismic hazard. By combining information on the state 
of stress, hydrologic properties of injection formations and the basement, and the locations and orientations of faults with injection data, we have the possibility of building predictive models that anticipate the seismic potential of an area based on its past history. As shown at the workshop, the initiation of seismicity in the Mississippi Lime Play of north-central Oklahoma and south-central Kansas followed the development of the field with a lag of months to a year. Investigations of this type are needed elsewhere to understand where and when this could be a useful tool to forecast if the seismic hazard will change based on the expansion of activities in a particular field.

Developing methodologies would enable rapid updates of the hazard model as the underlying parameters of the seismic hazard change. The seismic hazard may go up or down, depending on specifics of the situation, and our hazard products need to be current at all times. Operational Earthquake Forecasting (OEF) is a developing capability that uses rigorously tested statistical models of earthquake sequences to continuously update the seismic hazard estimates (Jordan and others, 2014). Operational earthquake forecasting for induced earthquakes could also be informed by physical models that incorporate hydrogeology, fluid pressure diffusion and forecasts produced by physics-based earthquake simulators. All of these extensions to the hazard model should improve significantly the reliability and performance of industry "traffic light" systems for managing the seismic hazard posed by injection-induced earthquakes.

\section{Conclusions}

Modeling induced seismicity in probabilistic seismic hazard analysis is very difficult, since we do not understand some of the fundamental differences between natural and induced earthquakes, and because the seismic activity can change based on changes in human activity. Predicting when and where induced seismicity will occur in the future is challenging. For example, induced seismicity does not occur near every disposal well, so it is important that we continue to study and learn more about how these earthquakes are generated, so we can better assess future patterns and trends. In Oklahoma, activity rates have varied exponentially, and earthquakes have migrated several tens of kilometers over a year or two. These changes may be related to oil and gas exploration activity but they also may depend on physical processes, which are poorly understood. Many decisions are critical for the analysis, including modeling decisions about earthquake catalogs, rates, locations, maximum magnitudes, and ground motions. Many questions remain, and additional research would enable us to better characterize data, models, and methods. Likelihood testing can be used to evaluate which models and parameters are optimal in forecasting future earthquakes. Our preliminary analysis (appendix 1) supports the use of the recent part of the earthquake catalog, though we may want to consider the use of shorter time periods than one year for developing the smoothed seismicity models. Such analyses will guide our implementation of the logic tree in developing final models.

The sensitivity studies we present here indicate very high probabilistic ground motions that differ considerably from previous hazard products that excluded induced earthquakes. The high and variable probabilistic ground motions contained in this report may be difficult for users to implement; working together with regulators and industry will enable us to determine how to better portray the seismic hazard in regions where induced seismicity is active. Possible future directions include seismic hazard models that are updated annually, as operational earthquake forecasts that provide daily or hourly updates, or as shake maps that show how the ground shakes or how it could shake. Workshop participants felt that these kinds of products may be useful for public agencies or industry groups that need to make decisions on economics and public safety. 


\section{References Cited}

Ake, Jon, Mahrer, Kenneth, O’Connell, Daniel, and Block, Lisa, 2005, Deep-injection and closely monitored induced seismicity at Paradox Valley, Colorado: Bulletin of the Seismological Society of America, v. 95, no. 2, p. 664-683.

Algermissen, S.T., and Perkins, D.M., 1976, A probabilistic estimate of the maximum acceleration in rock in the contiguous United States: U.S. Geological Survey Open-File Report 76-416, 45 p., 2 plates, scale 1:7,500,000.

Atkinson, G.M., 2008, Ground-motion prediction equations for eastern North America from a referenced empirical approach-Implications for epistemic uncertainty: Bulletin of the Seismological Society of America, v. 98, no. 3, p. 1304-1318. [Also available at http://dx.doi.org/10.1785/0120070199.]

Atkinson, G.M., and Boore, D.M., 2006, Earthquake ground-motion prediction equations for eastern North America: Bulletin of the Seismological Society of America, v. 96, no. 6, p. 2181-2205. [Also available at http://dx.doi.org/10.1785/0120050245.]

Bachmann, C.E., Wiemer, S., Woessner, J., and Hainzl, S., 2011, Statistical analysis of the induced Basel 2006 earthquake sequence-Introducing a probability-based monitoring approach for Enhanced Geothermal Systems: Geophysical Journal International, v. 186, no. 2, p. 793-807.

Block, L.V., Wood, C.K., Yeck, W.L., and King, V.M., 2014, The 24 January 2013 ML 4.4 earthquake near Paradox, Colorado, and its relation to deep well injection: Seismological Research Letters, v. 85, no. 3, p. 609-624. [Also available at http://dx.doi.org/10.1785/0220130188.]

Brown, W.A., and Frohlich, Cliff, 2013, Investigating the cause of the 17 May 2012 M4.8 earthquake near Timpson, east Texas [abs.]: Seismological Research Letters, v. 84, 374 p.

Buchanan, R.C., Newell, K.D., Evans, C.S., and Miller, R.D., 2014, Induced seismicity-The potential for triggered earthquakes in Kansas: Kansas Geological Survey, Public Information Circular 36.

Building Seismic Safety Council, 2009, NEHRP recommended seismic provisions for new buildings and other structures, 2009 edition: FEMA report P-750. (Also available at http://www.fema.gov/media-library/assets/documents/18152?id=4103.)

Campbell, K.W., 2003, Prediction of strong ground motion using the hybrid empirical method and its use in the development of ground motion (attenuation) relations in eastern North America: Bulletin of the Seismological Society of America, v. 93, no. 3, p. 1012-1033.

Cornell, C.A., 1968, Engineering seismic risk analysis: Bulletin of the Seismological Society of America, v. 58, n. 5, p. 1583-1606.

Davis, S.D., and Pennington, W.D., 1989, Induced seismic deformation in the Cogdell oil field of west Texas: Bulletin of the Seismological Society of America, v. 79, no. 5, p. 1477-1494.

Deng, Kai, Zhou, Shiyong, Wang, Rui, Robinson, Russell, Zhao, Cuiping, and Cheng, Wanzheng, 2010, Evidence that the $2008 \mathrm{M}_{\mathrm{w}} 7.9$ Wenchuan earthquake could not have been induced by the Zipingpu reservoir: Bulletin of the Seismological Society of America, November 2010, v. 100, no. 5B, p. 2805-2814.

DeShon, H.R., Hornbach, M.J., Ellsworth, W.L., Oldham, H.R., Hayward, C., Stump, B.W., Frohlich, C., Olson, J.E., and Luetgert, J.H., 2014, Understanding north Texas seismicity-A joint analysis of seismic data and 3D pore pressure modeling [abs.]: American Geophysical Union 2014 Fall Meeting. [Also available at https://agu.confex.com/agu/fm14/meetingapp.cgi\#Paper/10515.]

Ellsworth, W.L., 2013, Injection-induced earthquakes: Science, v. 341, no. 6142. [Also available at http://dx.doi.org/10.1126/science.1225942.] 
Evans, D.M., 1966, The Denver area earthquakes and the Rocky Mountain Arsenal Disposal Well: The Mountain Geologist, v. 3, p. 23-36.

Field, E.H., Arrowsmith, R.J., Biasi, G.P., Bird, Peter, Dawson, T.E., Felzer, K.R., Jackson, D.D., Johnson, K.M., Jordan, T.H., Madden, Christopher, Michael, A.J., Milner, K.R., Page, M.T., Parsons, Tom, Powers, P.M., Shaw, B.E., Thatcher, W.R., Weldon, R.J. II, Zeng, Yuehua, 2014, Uniform California Earthquake Rupture Forecast, Version 3 (UCERF3)-The Time- Independent Model: Bulletin of the Seismological Society of America, v. 104, no. 3, pp. 1122-1180.

Frankel, Arthur, Mueller, Charles, Barnhard, Theodore, Perkins, David, Leyendecker, E.V., Dickman, Nancy, Hanson, Stanley, and Hopper, Margaret, 1996, National seismic hazard mapsDocumentation June 1996: U.S. Geological Survey Open-File Report 96-532, 110 p.

Frankel, A.D., Petersen, M.D., Mueller, C.S., Haller, K.M., Wheeler, R.L., Leyendecker, E.V., Wesson, R.L., Harmsen, S.C., Cramer, C.H., Perkins, D.M., and Rukstales, K.S., 2002, Documentation for the 2002 update of the national seismic hazard maps: U.S. Geological Survey Open-File Report 2002420, 39 p.

Frohlich, Cliff, Hayward, Chris, Stump, Brian, and Potter Eric, 2011, The Dallas-Fort Worth earthquake sequence-October 2008 through May 2009: Bulletin of the Seismological Society of America, v. 101, no. 1, p. 327-340. [Also available at http://dx.doi.org/10.1785/0120100131.]

Gahalaut, Kalpna, and Gahalaut, V.K., 2010, Effect of the Zipingpu reservoir impoundment on the occurrence of the 2008 Wenchuan earthquake and local seismicity: Geophysical Journal International, v. 181, no. 1, p. 277-285.

Gardner, J.K., and Knopoff, Leon, 1974, Is the sequence of earthquakes in southern California, with aftershocks removed, Poissonian?: Bulletin of the Seismological Society of America, v. 64, no. 5, p. $1363-1367$.

Gomberg, Joan, and Wolf, Lorraine, 1999, Possible cause for an improbable earthquake-The $1997 \mathrm{M}_{\mathrm{W}}$ 4.9 southern Alabama earthquake and hydrocarbon recovery: Geology, v. 27, no. 4, p. 367-370.

Gupta, H.K., 2002, A review of recent studies of triggered earthquakes by artificial water reservoirs with special emphasis on earthquakes in Koyna, India: Earth Science Reviews, v. 58, nos. 3-4, p. 279-310.

Gutenberg, Beno, and Richter, C.F., 1944, Frequency of earthquakes in California: Bulletin of the Seismological Society of America, v. 34, no. 4, p. 185-188.

Hallo, Mirosalv, Oprsal, Ivo, Eisner, Leo, and Ali, M.Y., 2014, Prediction of magnitude of the largest potentially induced seismic event: Journal of Seismology, v. 18, no. 3, p. 421-431.

Healy, J.H., Rubey, W.W., Griggs, D.T., and Raleigh, C.B., 1968, The Denver earthquakes: Science, v. 161 , no. 3848, p. 1301-1310.

Holland, Austin, 2011, Examination of Possibly Induced Seismicity from Hydraulic Fracturing in the Enola Field, Garvin County, Oklahoma: Oklahoma Geological Survey Open-File Report OF1-2011, $28 \mathrm{p}$.

Horton, Steve, 2012, Disposal of hydrofracking waste fluid by injection into subsurface aquifers triggers earthquake swarm in central Arkansas with potential for damaging earthquake: Seismological Research Letters, v. 83, no. 2, p. 250-260. [Also available at http://dx.doi.org/10.1785/gssrl.83.2.250.] Horton, Stephen, Ogwari, Paul, Ausbrooks, Scott, 2013, Naturally occurring and induced earthquakes in central Arkansas [abs.]: Eastern Section Seismological Society of America, 2013 Annual Meeting. Hough, W.E., 2014, Shaking from injection-induced earthquakes in the central and eastern United States: Bulletin of the Seismological Society of America, v. 104, no. 5, p. 2619-2626. 
Jordan, T.H., Marzocchi, W., Michael, A.J., Gerstenberger, M.C., 2014, Operational earthquake forecasting can enhance earthquake preparedness: Seismological Research Letters, v. 85, no. 5, p. 955-959.

Keranen, K.M., Savage, H.M., Abers, G.A., and Cochran E.S., 2013, Potentially induced earthquakes in Oklahoma, USA - Links between wastewater injection and the $2011 \mathrm{M}_{\mathrm{w}} 5.7$ earthquake sequence: Geology, v. 41, no. 6, p. 699-702. [Also available at http://dx.doi.org/10.1130/G34045.1.]

Keranen, K.W., Weingarten, M., Abers, G.A., Bekins, B.A., and Ge, S., 2014, Sharp increase in central Oklahoma seismicity since 2008 induced by massive wastewater injection: Science, v. 345, no. 6195, p. 448-451.

Kerr, R.A., and Stone, R., 2009, A human trigger for the great quake of Sichuan?: Science, v. 323, no. 5912, 322 p. [Also available at http://dx.doi.org/10.1126/science.323.5912.322.]

Kim, W.Y., 2013, Induced seismicity associated with fluid injection into a deep well in Younstown, Ohio: Journal of Geophysical Research, v. 118, no. 7, p. 3506-3518. [Also available at http://dx.doi.org/10.1002/jgrb.50247.]

Llenos, A.L., and Michael, A.J., 2013, Modeling earthquake rate changes in Oklahoma and ArkansasPossible signatures of induced seismicity: Bulletin of the Seismological Society of America, v. 103, no. 5, p. 2850-2861. [Also available at http://dx.doi.org/10.1785/0120130017.]

McGarr, Arthur, 2014, Maximum magnitude earthquakes induced by fluid injection: Journal of Geophysical Research, v. 119, no. 2, p. 1008-1019. [Also available at http://dx.doi.org/10.1002/2013JB010597.]

McGarr, Arthur, and Fletcher, J.B., 2005, Development of ground-motion prediction equations relevant to shallow mining-induced seismicity in the Trail Mountain Area, Emery County, Utah: Bulletin of the Seismological Society of America, v. 95, no. 1, p. 31-47.

McNamara, D.E., Benz, H.M., Herrmann, R.B., Bergman, E.A., Earle, P., Holland, A., Baldwin, R., and Gassner, A., 2015, Earthquake hypocenters and focal mechanisms in central Oklahoma reveal a complex system of reactivated subsurface strike-slip faulting: Geophysical Research Letters. [Also available at http://dx.doi.org/10.1002/2014GL062730.]

Meremonte, M.E., Lahr, J.C., Frankel, A.D., Dewey, J.W., Crone, A.J., Overturf, D.E., Carver, D.L., and Bice, T.W., 2001, Investigation of an earthquake swarm near Trinidad, CO: U.S. Geological Survey Open-File Report 02-0073.

Pennington, W.D., Davis, S.D., Carlson, S.M., DuPree, J., and Ewing, T.E., 1986, The evolution of seismic barriers and asperities caused by the depressuring of fault planes in oil and gas fields of south Texas: Bulletin of the Seismological Society of America, v. 76, no. 4, p. 939-948.

Petersen, M.D., Frankel, A.D., Harmsen, S.C., Mueller, C.S., Boyd, O.S., Luco, Nicolas, Wheeler, R.L., Rukstales, K.S., and Haller, K.M., 2012, The 2008 U.S. Geological Survey national seismic hazard models and maps for the central and eastern United States, in Cox, R.T., Tuttle, M.P., Boyd, O.S., and Locat, Jacques, eds., Recent advances in North American paleoseismology and neotectonics east of the Rockies: Geological Society of America Special Paper 493, p. 243-257. [Also available at http://dx.doi.org/10.1130/2012.2493(12).]

Petersen, M.D., Frankel, A.D., Harmsen, S.C., Mueller, C.S., Haller, K.M., Wheeler, R.L., Wesson, R.L., Zeng, Yuehua, Boyd, O.S., Perkins, D.M., Luco, Nicolas, Field, E.H., Wills, C.J., and Rukstales, K.S., 2008, Documentation for the 2008 update of the United States national seismic hazard maps: U.S. Geological Survey Open-File Report 2008-1128, 128 p. 
Petersen, M.D., Moschetti, M.P., Powers, P.M., Mueller, C.S., Haller, K.M., Frankel, A.D., Zeng, Yuehua, Rezaeian, Sanaz, Harmsen, S.C., Boyd, O.S., Field, Ned, Chen, Rui, Rukstales, K.S., Luco, Nico, Wheeler, R.L., Williams, R.A., and Olsen, A.H., 2014, Documentation for the 2014 update of the United States national seismic hazard maps: U.S. Geological Survey Open-File Report 20141091, $210 \mathrm{p}$.

Pezeshk, Shahram, Zandieh, Arash, and Tavakoli, Behrooz, 2011, Hybrid empirical ground-motion prediction equations for eastern North America using NGA models and updated seismological parameters: Bulletin of the Seismological Society of America, v. 101, no. 4, p. 1859-1870. [Also available at http://dx.doi.org/10.1785/0120100144.]

Pursley, Jana, Bilek, S.L., and Ruhl, C.J., 2013, Earthquake catalogs for New Mexico and bordering areas-2005-2009: New Mexico Geology, v. 35, no. 1, p. 3-12.

Raleigh, C.B., J.H. Healy, and J.D. Bredehoeft, 1976, An experiment in earthquake control at Rangely, Colorado: Science, v. 191, no. 4233, p. 1230-1237. [Also available at http://dx.doi.org/10.1126/science.191.4233.1230.]

Rubinstein, J.L., Ellsworth, W.L, McGarr, Arthur, and Benz, H.M., 2014a, The 2001-present induced earthquake sequence in the Raton Basin of northern New Mexico and southern Colorado: Bulletin of the Seismological Society of America, v. 104, no. 5, p. 2162-2181. [Also available at http://dx.doi.org/10.1785/0120140009.]

Rubinstein, J.L., Ellsworth, W.L., Llenos, A., and Walter, S., 2014b, Is the recent increase in seismicity in southern Kansas natural? [abs.]: American Geophysical Union, 2014 Fall Meeting.

Sanford, A.R., Mayeau, T.M., Schlue, J.W., Aster, R.C., and Jaksha, L.H., 2006, Earthquake catalogs for New Mexico and bordering areas-1999-2004: New Mexico Geology, v. 28, no. 4, p. 99-109.

Seeber, Leonardo, Armbruster, J.G., and Kim, W.Y., 2004, A fluid-injection triggered earthquake sequence in Ashtabula, Ohio-Implications for seismogenesis in stable continental regions: Bulletin of the Seismological Society of America, v. 94, no. 1, p. 76-87.

Silva, W.J., Gregor, Nick, and Darragh, Robert, 2002, Development of regional hard rock attenuation relations for central and eastern North America: Pacific Engineering and Analysis Technical Report, 57 p. [Also available at http://www.pacificengineering.org/CEUS/Development\%20of\%20Regional\%20Hard_ABC.pdf.]

Simpson, D.W., and Leith, W., 1985, The 1976 and 1984 Gazli, USSR, earthquakes - Were they induced?: Bulletin of the Seismological Society of America, v. 75, n. 5, p. 1465-1468.

Sun, Xiaodan, and Hartzell, Stephen, 2014, Finite-fault slip model of the $2011 \mathrm{M}_{\mathrm{w}} 5.6$ Prague, Oklahoma earthquake from regional waveforms: Geophysical Research Letters, v. 41, no. 12, p. 4207-4213.

Sumy, Danielle, Cochran, Elizabeth, Keranen, K.M., Wei, Maya, and Abers, G.A., 2014, Observations of static Coulomb stress triggering of the November 2011 M5.7 Oklahoma earthquake sequence: Journal of Geophysical Research, v. 119, no. 3, p. 1904-1923. [Also available at http://dx.doi.org/10.1002/2013JB010612.]

Tavakoli, Behrooz, and Pezeshk, Shahram, 2005, Empirical-stochastic ground-motion prediction for eastern North America: Bulletin of the Seismological Society of America, v. 95, no. 6, p. 2283-2296.

Toro, G.R., 2002, Modification of the Toro and others (1997) attenuation equations for large magnitudes and short distances: Risk Engineering Technical Report, 10 p. [Also available at http://www.ce.memphis.edu/7137/PDFs/attenuations/Toro_2001_(modification_1997).pdf.]

Toro, G.R., Abrahamson, N.A., and Schneider, J.F., 1997, Model of strong ground motions from earthquake in central and eastern North America-Best estimates and uncertainties: Seismological Research Letters, v. 68, no. 1, p. 41-57. 
Yeck, W., Sheehan, A., Weingarten, M., and Nakai, J., 2014, The 2014 Weld County, Colorado, earthquakes-A developing case of induced seismicity? [abs.]: American Geophysical Union, 2014 Fall Meeting. [Also available at https://agu.confex.agu/agu/gm14/meetingapp.cgii\#Paper/29513.] Zoller, Gert, and Holschneider, Matthias, 2014, Induced seismicity — What is the size of the largest expected earthquake?: Bulletin of the Seismological Society of America, v. 104, no. 6, p. 3153-3158. 


\section{Appendix 1: Initial Likelihood Tests of Potential Seismicity-Rate Models for Induced Seismicity in Oklahoma, Southern Kansas and North-Central Texas}

By Morgan P. Moschetti and Susan M. Hoover

We investigate the effects of smoothing parameters, catalog type and catalog duration on likelihood parameters to guide future research and the selection of seismicity rate models for seismic hazard calculations. Based on input received at the workshop and observed variations in the seismicity in Oklahoma, southern Kansas and north-central Texas (OK-KS-TX), we develop various smoothedseismicity models and test the ability of these models to predict the spatial distributions of earthquakes that occurred May 2014 through October 2014 (2014.2, fig. 1-1). We test the smoothed-seismicity models using the data-consistency in likelihood space method (Schorlemmer and others, 2007), which we describe below.

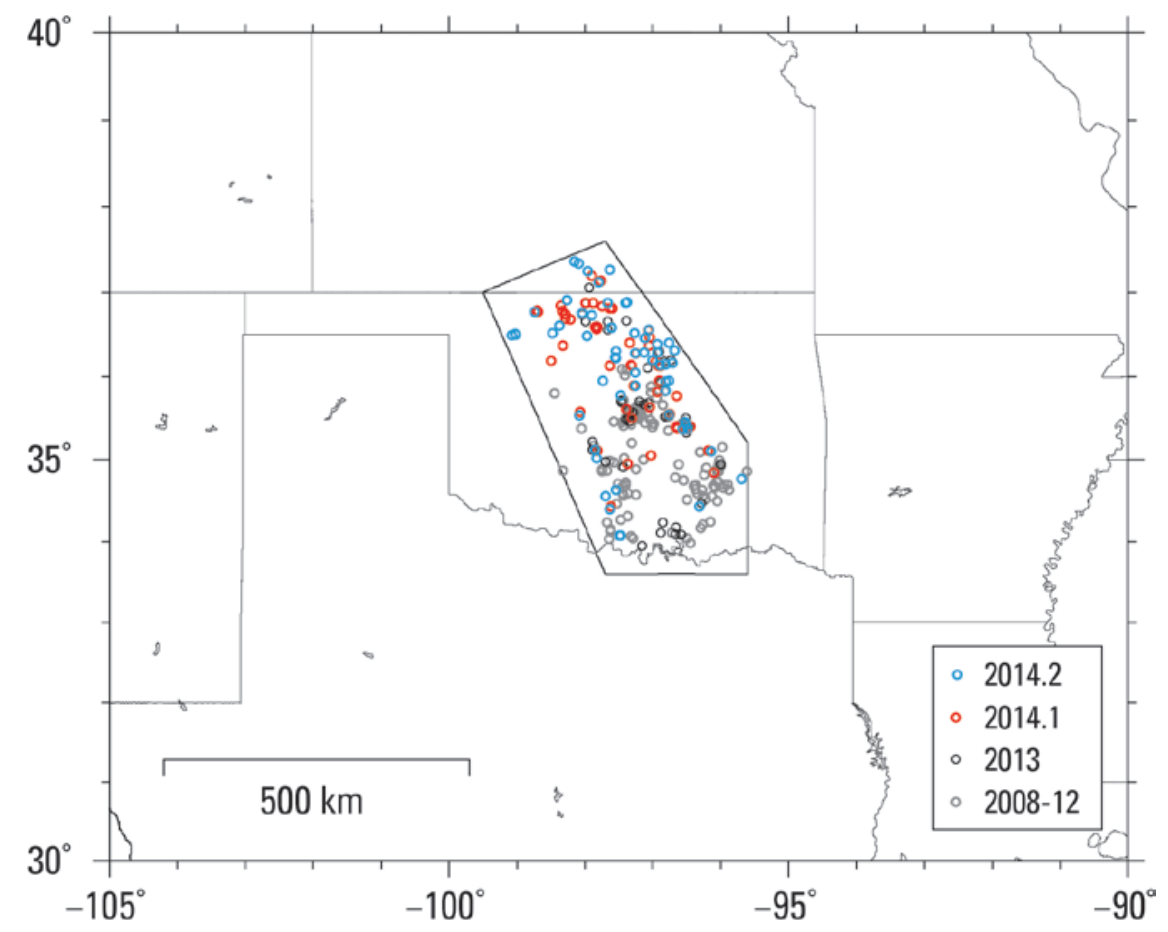

Figure 1-1. Earthquake catalog of potentially induced seismicity in Oklahoma, southern Kansas and north-central Texas. The polygon and earthquake catalogs are the ones described in the main text of this open-file report. The legend indicates the occurrence time of the earthquakes used in this study. Years and fractional years (for example, 2014.2) are defined in table 1-1.

This appendix describes the construction of smoothed-seismicity models, the likelihood testing method, and our preliminary likelihood results. We examine the ability of 20 smoothed-seismicity models to predict the spatial distributions of earthquakes from the most recent part of the earthquake catalog by varying 3 parameters in the construction of the models: (1) the time period for selecting 
earthquakes from the catalog; (2) whether we use the full (nondeclustered) or declustered earthquake catalog; and (3) the smoothing distance.

\section{Time Periods for Smoothed-Seismicity Models}

We calculate smoothed-seismicity models using earthquakes from five different time periods from an updated version of the Central and Eastern United States earthquake catalog, originally developed for the 2014 NSHM (Petersen and others, 2014). Because variations in seismicity rates from induced seismicity are inherently time-dependent, but the smoothed-seismicity models are treated in a time-independent manner, we test the effect of smoothed-seismicity models developed from earthquake catalogs as short as 6 months. However, the earthquake catalogs that we use in this study range from 6 months to 5 years in duration. The starting and ending dates of the time periods used in this study are summarized in table 1-1; note that earthquakes from the time periods named 2013 and 2014 (for example, 2013.1) do not always fall within their respective calendar years. We refer to the time periods as (1) 2008-12 (5 years); (2) 2013.1 (6 months); (3) 2013.2 (6 months); (4) 2013 (1 year); (5) 2014.1 (6 months); and (6) 2014.2 (6 months). Time periods 1-5 are used to develop smoothed-seismicity models, and time period 6 (2014.2) is used in testing the smoothed-seismicity models, as described below.

Table 1-1. Time periods and abbreviations used in development of smoothed seismicity models for likelihood testing. Starting and ending dates are given in MM/DD/YY format.

\begin{tabular}{cccc}
\hline $\begin{array}{c}\text { Time period } \\
\text { number }\end{array}$ & $\begin{array}{c}\text { Time period } \\
\text { abbreviation }\end{array}$ & Start & End \\
\hline$(1)$ & $2008-12$ & $01 / 01 / 08$ & $12 / 31 / 12$ \\
$(2)$ & 2013.1 & $11 / 01 / 12$ & $04 / 30 / 13$ \\
$(3)$ & 2013.2 & $05 / 01 / 13$ & $10 / 31 / 13$ \\
$(4)$ & 2013 & $11 / 01 / 12$ & $10 / 31 / 13$ \\
$(5)$ & 2014.1 & $11 / 01 / 13$ & $04 / 30 / 14$ \\
$(6)$ & 2014.2 & $05 / 01 / 14$ & $10 / 31 / 14$ \\
\hline
\end{tabular}

The number of earthquakes greater than or equal to $(\geq)$ moment magnitude (M) 2.5 in the earthquake catalogs of time periods 1-5 suggests significant variations in the seismicity rate in the OKKS-TX region. We compute annual earthquake rates from the earthquake catalogs with durations ranging from 6 months to 5 years to make direct comparisons between the apparent rates of the five time periods (table 1-2). A significant increase in seismicity rate since 2008 is shown in table 1-2. Although the numbers of earthquakes in the declustered catalogs from time periods 5 (2014.1) and 6 (2014.2) are similar, there are substantial differences in the numbers from the full (nondeclustered) catalogs from these time periods. 
Table 1-2. Comparison of earthquake (greater than or equal to moment magnitude $[M] 2.5$ ) numbers and calculated annual earthquake rates from the full (nondeclustered) and decl (declustered) catalogs used in developing (forecast catalog) and likelihood testing (test catalog) the smoothed-seismicity models.

$[\mathrm{M} \geq 2.5$ is moment magnitude greater than or equal to 2.5 , \# eqs is number of earthquakes, /yr is per year, decl is declustered. Column headings are defined in table 1-1]

\begin{tabular}{lccccccc}
\hline & \multicolumn{3}{c}{ Forecast catalog $(\mathrm{M} \geq \mathbf{2 . 5})$} & & Test catalog \\
\cline { 2 - 6 } \cline { 3 - 6 } & $\mathbf{2 0 0 8 - 1 2}$ & $\mathbf{2 0 1 3 . 1}$ & $\mathbf{2 0 1 3 . 2}$ & $\mathbf{2 0 1 3}$ & $\mathbf{2 0 1 4 . 1}$ & & $\mathbf{2 0 1 4 . 2}$ \\
\hline \# eqs, full & 393 & 61 & 103 & 163 & 581 & 984 \\
\# eqs/yr, full & 78.6 & 122 & 206 & 163 & 1162 & 1968 \\
\# eqs, decl & 120 & 19 & 32 & 51 & 56 & 112 & 61 \\
\# eqs/yr, decl & 24 & 38 & 64 & 51 & & 122 \\
\hline
\end{tabular}

\section{Smoothed-Seismicity Models}

All smoothed-seismicity models for this analysis assume the Gutenberg-Richter (GR) magnitude-frequency relation (Ishimoto and Iida, 1939; Gutenberg and Richter, 1944):

$$
\log _{10} N(m)=a-b m
$$

where $N(m)$ is the number of earthquakes with $\mathrm{M} \geq m$, and $a$ and $b$ are the GR parameters controlling the seismicity rate and the relative proportion of earthquakes with different magnitudes. We use two bvalues in the calculation of smoothed-seismicity models for potential induced seismicity, following the results on earthquake recurrence presented in appendix 2. For the smoothed-seismicity models computed from the full (nondeclustered) earthquake catalog for time periods $2-5$ (2013.1, 2013.2, 2013, and 2014.1), we use $b=1.6$, because preliminary calculations show that a higher $b$-value might be more appropriate for induced seismicity in OK-KS-TX (appendix 2). For the smoothed-seismicity models computed from the declustered earthquake catalog, and for the smoothed-seismicity model computed from the full (nondeclustered) catalog and time period 1 (2008-12), we use $b=1.0$ in consistent practice with the 2014 NSHM which addresses declustered seismicity for 2012 and previous years (Petersen and others, 2014). For all models, we assume a minimum magnitude of completeness (Mc) of M2.5 in calculating the a-values; however, recent results, including those presented in appendix 2 suggest that this Mc may be too low for this region, and consequently, our computed seismicity rates may underestimate the true seismicity rate.

All smoothed-seismicity models are developed with the use of isotropic, Gaussian functions for the smoothing kernels:

$$
K_{\sigma_{j}}\left(\left|r_{j}-r_{i}\right|, \sigma_{j}\right)=C\left(\sigma_{j}\right) \exp \left(\frac{-\left|r_{j}-r_{i}\right|}{2 \sigma_{j}^{2}}\right)
$$

where $C\left(\sigma_{j}\right)$ is a normalization coefficient and $\sigma_{j}$ is the smoothing distance. For this study, we investigate the effect of two smoothing distances: $3.54 \mathrm{~km}(5-\mathrm{km}$ correlation length) and $35.4 \mathrm{~km}$ (50-km correlation length). 


\section{Likelihood Testing}

We test all smoothed-seismicity models using the data-consistency in likelihood space (L-test) (Schorlemmer and others, 2007), which is one of the likelihood parameters employed by the RELM and CSEP projects (Schorlemmer and Gerstenberger, 2007; Zechar and others, 2010). The likelihood parameter for the L-test assumes that the probability of earthquake occurrence is given by the Poisson probability:

$$
p\left(\mu_{i}, n_{i}\right)=\frac{\left(\mu_{i}^{*}\right)^{n_{i}} e^{-\mu_{i}^{*}}}{n_{i} !}
$$

where $\mu_{i}$ and $n_{i}$ are the predicted and observed number of earthquakes in the ith cell, respectively. Predicted earthquake numbers are calculated from the smoothed-seismicity models by specifying a time window of interest. We adopt the seismicity-rate-normalization scheme described by others (for example, Werner and others, 2011), which has the effect of equalizing the number of modeled and observed earthquakes for the likelihood testing:

$$
\mu_{i}^{*}=\frac{\mu_{i} N_{\text {test }}}{\Sigma_{i} \mu_{i}}
$$

where $N_{\text {test }}$ is the number of earthquakes in the testing catalog. By normalizing the observed and predicted earthquake counts, the effect of the aggregated seismicity rate is ignored and the L-test examines only the spatial distribution of earthquake occurrence.

Likelihood calculations use the logarithm of equation 3 to give the log-likelihood associated with a smoothed-seismicity model, $m$ :

$$
\begin{gathered}
L L_{m}=\sum_{i} \log \left(p\left(\mu_{i}, n_{i}\right)\right) \\
L L_{m}=\sum_{i} n_{i} \log \mu_{i}^{*}-\sum_{i} n_{i} \log n_{i}-\sum_{i} \mu_{i}^{*}
\end{gathered}
$$

To make comparisons between the smoothed-seismicity models developed in this study, we used the information gain parameter, $G_{m}$, which describes the probability gain per earthquake from using the smoothed-seismicity model, $m$, relative to the use of a seismicity rate model with a reference uniform rate in all cells, $L L_{\text {ref. }}$.

$$
G_{m}=\exp \left(\frac{L L_{m}-L L_{r e f}}{N_{\text {test }}}\right)
$$

\section{Initial Likelihood Results}

To compute the likelihood from the L-test, we compute smoothed-seismicity from the full (nondeclustered) and declustered earthquake catalogs in the time periods 1-5 (2008-12, 2013.1, 2013.2, 2013, 2014.1) and test the models against the earthquakes that occurred in time period 6 (2014.2). Smoothed-seismicity models are developed using correlation lengths of $5 \mathrm{~km}$ and $50 \mathrm{~km}$. All combinations of earthquake catalogs and smoothing parameters are used for a total of 20 smoothedseismicity models -2 options for the full (nondeclustered) and declustered catalogs, 5 catalog time periods, and 2 correlation lengths. 
Information gain values (equation 7) from all 20 models are tested with $\mathrm{M} \geq 2.5$ and $\mathrm{M} \geq 3.5$ earthquake catalogs from time period 6 (2014.2). The gain values from the $\mathrm{M} \geq 2.5$ catalog are plotted in figure 1-2; gain values from the $\mathrm{M} \geq 3.5$ testing catalog are not presented but show similar trends. Higher information gains result from the use of the more recent earthquake catalogs $(2013,2013.2,2014.1)$. Information gains from the smoothed-seismicity model derived from the declustered catalog are slightly better than the gains from the full (nondeclustered) catalog. However, the differences between the information gains resulting from the different correlation lengths $(5 \mathrm{~km}$ and $50 \mathrm{~km})$ are far more pronounced. The smoothed-seismicity models generated with $50-\mathrm{km}$ correlation lengths show far better predictive power for characterizing the spatial distribution of earthquakes from time period 6 (2014.2) than do the models developed with 5-km correlation lengths.

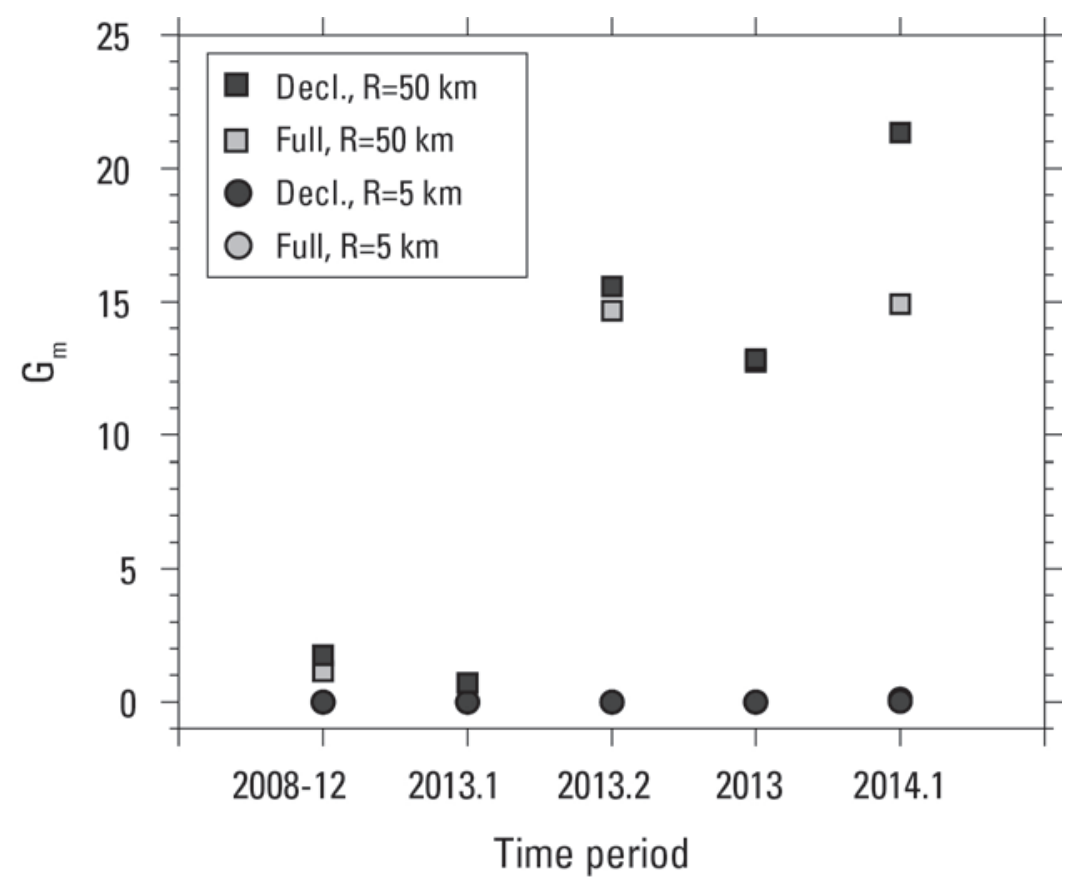

Figure 1-2. Information gain $\left(G_{m}\right)$ from the 20 smoothed-seismicity rate models computed using a testing catalog of moment magnitude $(\mathrm{M})$ greater than or equal to 2.5 earthquakes from time period 6 (2014.2). Time periods for the forecast catalogs are defined in table 1-1. Shape and color of the plotting symbols differentiate between the full (nondeclustered) and decl. (declustered) catalogs and the correlation lengths used in the smoothed seismicity models, as described by the legend. Note that because they yield similar information gains, the symbol for the full (nondeclustered) catalog using an R (correlation length) equal to 5 kilometers $(\mathrm{km})$ is eclipsed by the symbol for the declustered catalog. Similarly, the symbols for the full (nondeclustered) catalog using R equal to $50 \mathrm{~km}$ during the catalog periods 2013.1 and 2013 are blocked because they plot at the same point as the declustered catalog.

Plots of the smoothed-seismicity rates and earthquake epicenter locations from time period 6 (2014.2) testing catalog are highly informative for understanding the information gain results. Figure 1-3 depicts the smoothed-seismicity models constructed from the declustered catalogs for earthquakes in time period 5 (2014.1) using correlation lengths of $5 \mathrm{~km}$ (fig. 1-3A) and $50 \mathrm{~km}$ (fig. 1-3B), overlain by the epicentral locations of $\mathrm{M} \geq 2.5$ earthquakes in the testing catalog. Of the 61 earthquakes in the testing catalog, 25 earthquakes occur in cells where the rates of the $5-\mathrm{km}$ smoothed-seismicity model are higher than the rates the 50-km smoothed-seismicity model; in comparison, 32 earthquakes occur in cells where the $50-\mathrm{km}$ smoothed-seismicity model has higher rates. However, 36 earthquakes occur where 
the rates of the 5-km smoothed-seismicity model are lower than the rates of the reference, uniform model, whereas only 7 earthquakes occur where the rates of the 50-km smoothed-seismicity model are lower than the reference, uniform rate.
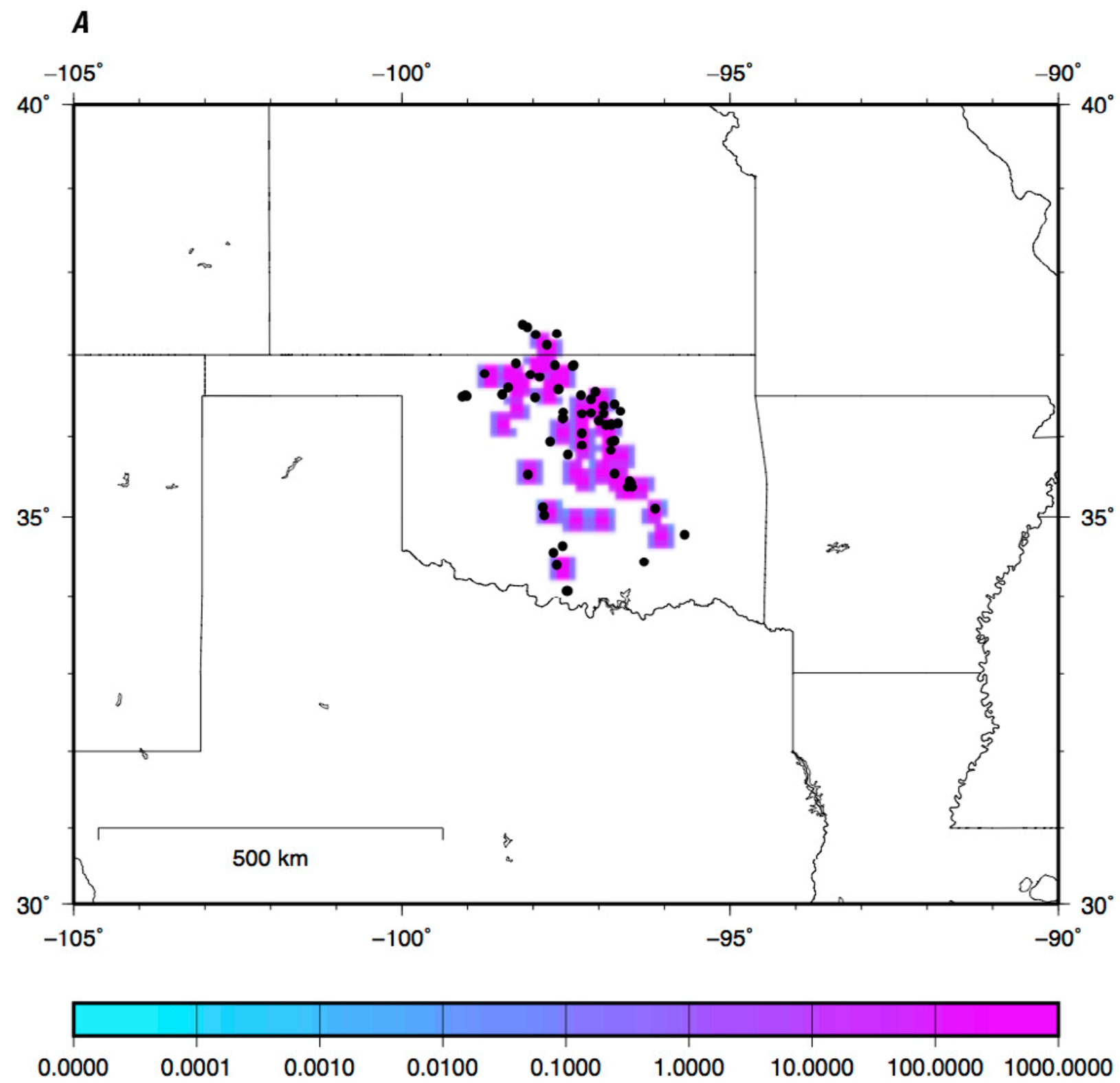

Figure 1-3. Comparison of smoothed-seismicity models using correlation lengths of: $A, 5 \mathrm{~km}$ and $B, 50 \mathrm{~km}$. Both smoothed-seismicity models use earthquakes from the declustered catalog, for time period 5 (2014.1); the color bar indicates number of earthquakes for time period 5 (2014.1) with a moment magnitude greater than or equal to $(\geq)$ 0 , using 0.1 by 0.1 degree grid cells. Epicenters from $M \geq 2.5$ earthquakes from the testing catalog (time period 6 , 2014.2) are plotted as black circles. 

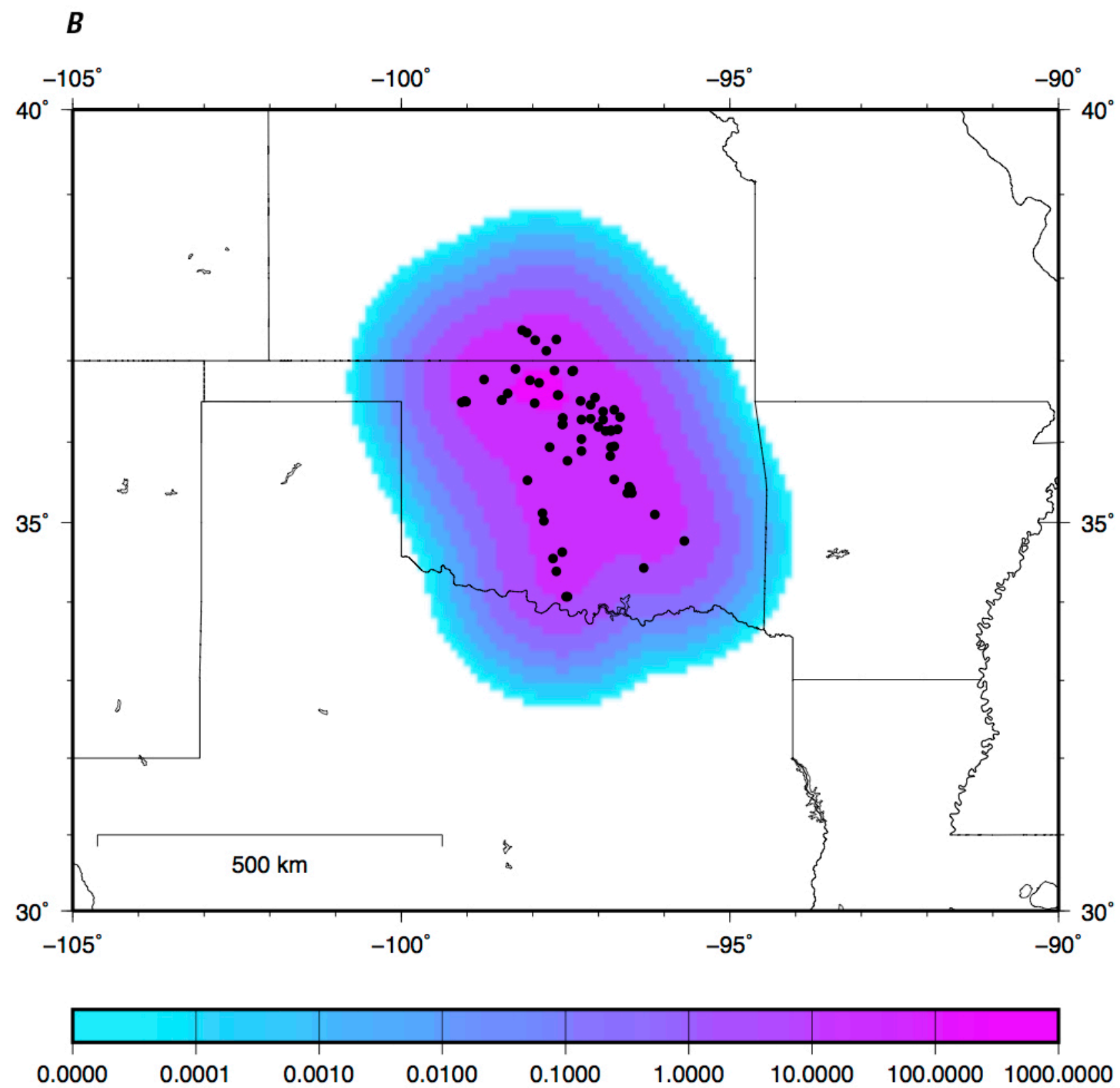

Figure 1-3. Comparison of smoothed-seismicity models using correlation lengths of: $A, 5 \mathrm{~km}$ and $B, 50 \mathrm{~km}$. Both smoothed-seismicity models use earthquakes from the declustered catalog, for time period 5 (2014.1); the color bar indicates number of earthquakes for time period 5 (2014.1) with a moment magnitude greater than or equal to $(\geq)$ 0 , using 0.1 by 0.1 degree grid cells. Epicenters from $M \geq 2.5$ earthquakes from the testing catalog (time period 6 , 2014.2) are plotted as black circles. - Continued

Figure 4 presents summary comparisons of the first term of the log-likelihood expression (equation 6) for all cells containing earthquakes. Comparison of these per-cell log-likelihoods (fig. 1-4A) shows the large number of earthquakes occurring in cells with low rates for the 5-km smoothedseismicity model. Binned log-rate terms (fig. 1-4B) for the $5-\mathrm{km}$ smoothed-seismicity model show a bimodal distribution; many earthquakes occur where the 5-km smoothed-seismicity rates are high, but 
many earthquakes also occur where the $5-\mathrm{km}$ smoothed-seismicity rates are low. By comparison, most earthquakes occur where the $50-\mathrm{km}$ smoothed-seismicity rates are relatively high. Use of intermediate correlation lengths (between $5 \mathrm{~km}$ and $50 \mathrm{~km}$ ) may give higher likelihood values than we have calculated here.
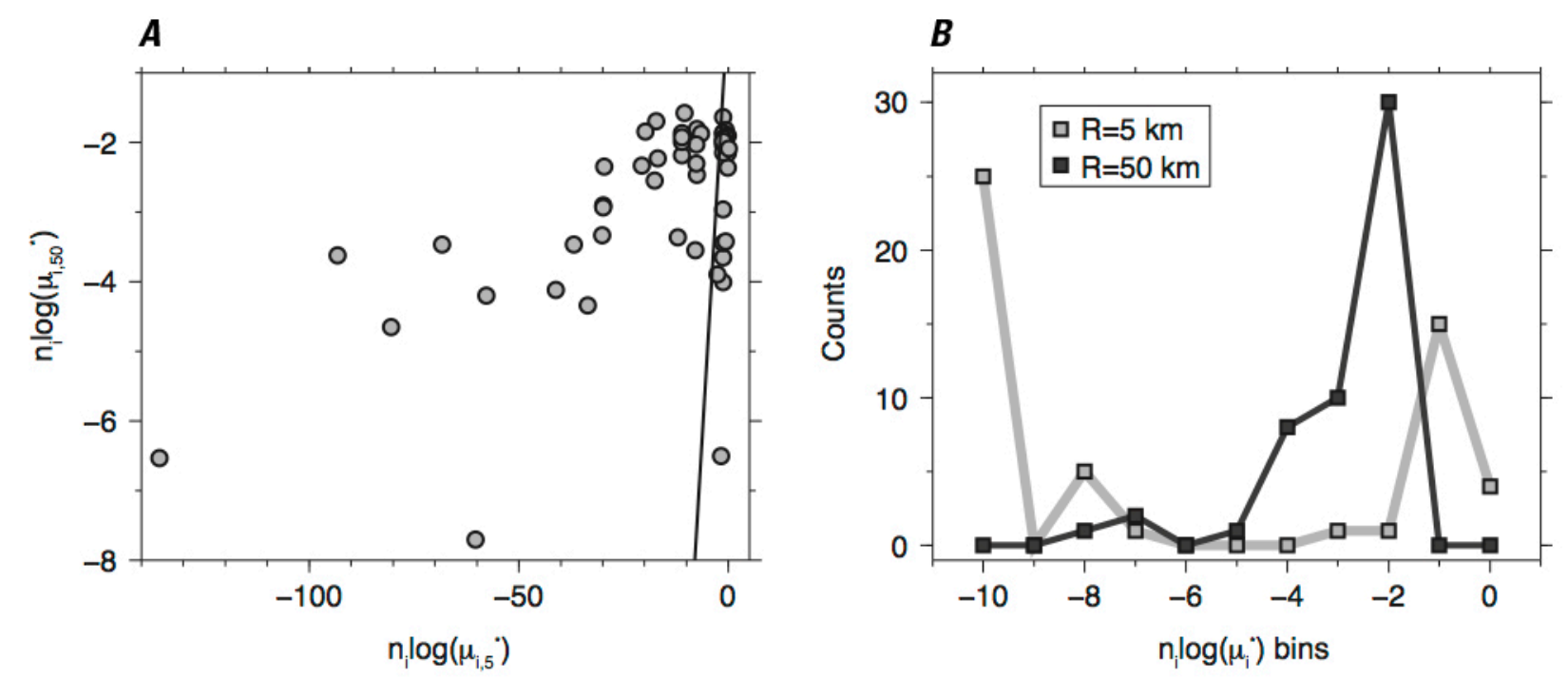

Figure 1-4. Summary plots of log-likelihood contributions from smoothed-seismicity models with 5-kilometer ( $\mathrm{km})$ and 50-km correlation lengths. Smoothed-seismicity models were developed from time period $5(2014.1)$ and the declustered catalog. $A$, Comparison of the first term of the log-likelihood (Equation 6$), n_{i} \log \mu_{i}^{*}$, from models developed from $5 \mathrm{~km}\left(n_{i} \log \mu_{i, 5}^{*}\right)$ and $50 \mathrm{~km}\left(n_{i} \log \mu_{i, 50}^{*}\right)$ correlation lengths. The solid line has unit slope and zero intercept for reference; symbols above the line are indicate a better prediction of the spatial pattern of time period 6 (2014.2) seismicity by the 50-km-smoothed model, and values below the line indicate better prediction by the $5-\mathrm{km}$-smoothed model. $B$, Binned earthquake counts of the first term of the log-likelihood (equation 6), $n_{i} \log \mu_{i}^{*}$, indicating the large fraction of cells containing earthquakes from the $50-\mathrm{km}$-smoothed model that predicted very low log-seismicity rates $\left(\log \left(\mu_{i}^{*}\right)<-9\right)$.

\section{References Cited}

Gutenberg, B., and Richter, C.F., 1944, Frequency of earthquakes in California: Bulletin of the Seismological Society of America, v. 34, no. 4, p.185-188.

Ishimoto, M., and Iida, K., 1939, Observations of earthquakes registered with the microseismograph constructed recently: Bulletin of the Earthquake Research Institute, v. 17, p. 443-478.

Petersen, M.D., Moschetti, M.P., Powers, P.M., Mueller, C.S., Haller, K.M., Frankel, A.D., Zeng, Yuehua, Rezaeian, Sanaz, Harmsen, S.C., Boyd, O.S., Field, Ned, Chen, Rui, Rukstales, K.S., Luco, Nico, Wheeler, R.L., Williams, R.A., and Olsen, A.H., 2014, Documentation for the 2014 update of the United States national seismic hazard maps: U.S. Geological Survey Open-File Report 2014$1091,210 \mathrm{p}$.

Schorlemmer, Danijel, and Gerstenberger, M.C., 2007, RELM testing center: Seismological Research Letters, v. 78, no. 1, p. 30-36.

Schorlemmer, Danijel, Gerstenberger, M.C., Wiemer, S., Jackson, D.D., and Rhoades, D.A., 2007, Earthquake likelihood model testing: Seismological Research Letters, v. 78, no. 1, p. 17-29. 
Werner, M.J., Helmstetter, A., Jackson, D.D., and Kagan, Y.Y., 2011, High-resolution long-term and short-term earthquake forecasts for California: Bulletin of the Seismological Society of America, v. 101 , no. 4 , p. 1630-1648.

Zechar, J.D., Schorlemmer, Danijel, Liukis, Maria, Yu, John, Euchner, Fabian, Maechling, P.J., and Jordan, T.H., 2010, The collaboratory for the study of earthquake predictability perspective on computational earthquake science: Concurrency and Computation-Practice and Experience, v. 22, no. 12 , p. 1836-1847. 


\section{Appendix 2: Recurrence Analysis in Recent (2001-14) Oklahoma Earthquakes}

There are sufficient numbers of earthquakes in the full (nondeclustered) subcatalogs from the Oklahoma-south and Oklahoma-north zones to analyze completeness levels and magnitude-frequency distributions. To estimate b-values (the slope of the curve that relates the numbers of small and large earthquakes), we apply Weichert's (1980) method that accounts for variable completeness. Consistent with the 2014 national maps (Petersen and others, 2014), we show results for moment magnitude (M) greater than or equal to M2.7.

The Oklahoma-south catalog is mapped in figure 2-1A, and earthquake counts in 0.5-magnitude unit and 2-year bins are listed in table 2-1. For the analysis, we assume completeness levels of M2.7 since 2013 and M4.7 since 2011. Binned, incremental, annual earthquake rates, and the b-value estimate of $1.26 \pm 0.05$ are plotted in figure $2-1 B$.

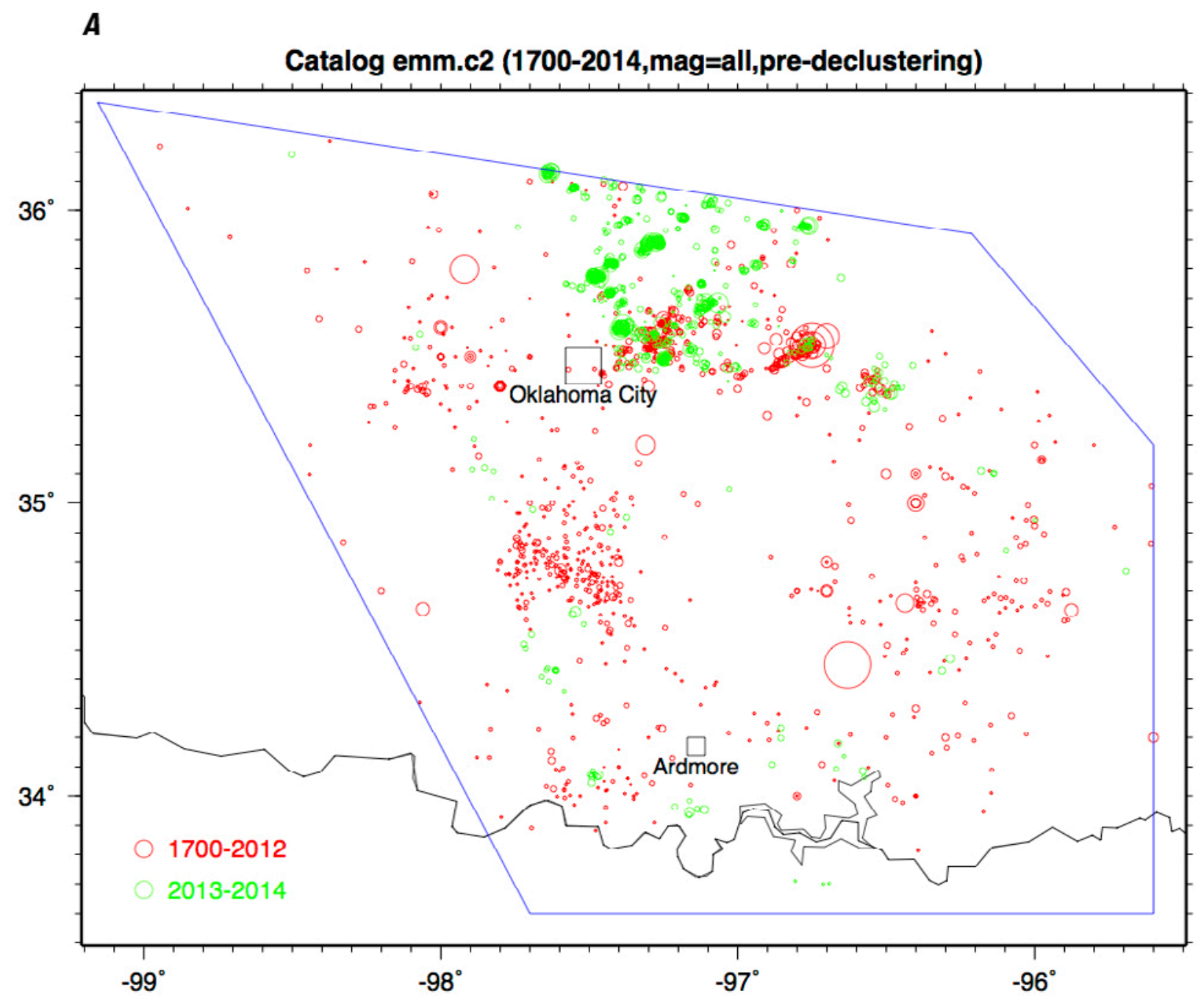

Figure 2-1. $A$, Seismicity in Oklahoma-south zone. The full (nondeclustered) earthquake catalog is shown with the years 1700-2012 as red, and 2013-2014 as green. B, b-value analysis for the Oklahoma-south full (nondeclustered) catalog. We assume completeness levels of M2.7 since 2013 and M4.7 since 2011. Eq/ Yr is the number of earthquakes in each 0.5-magnitude unit bin per year, and $\mathrm{Mw}$ is moment magnitude. 


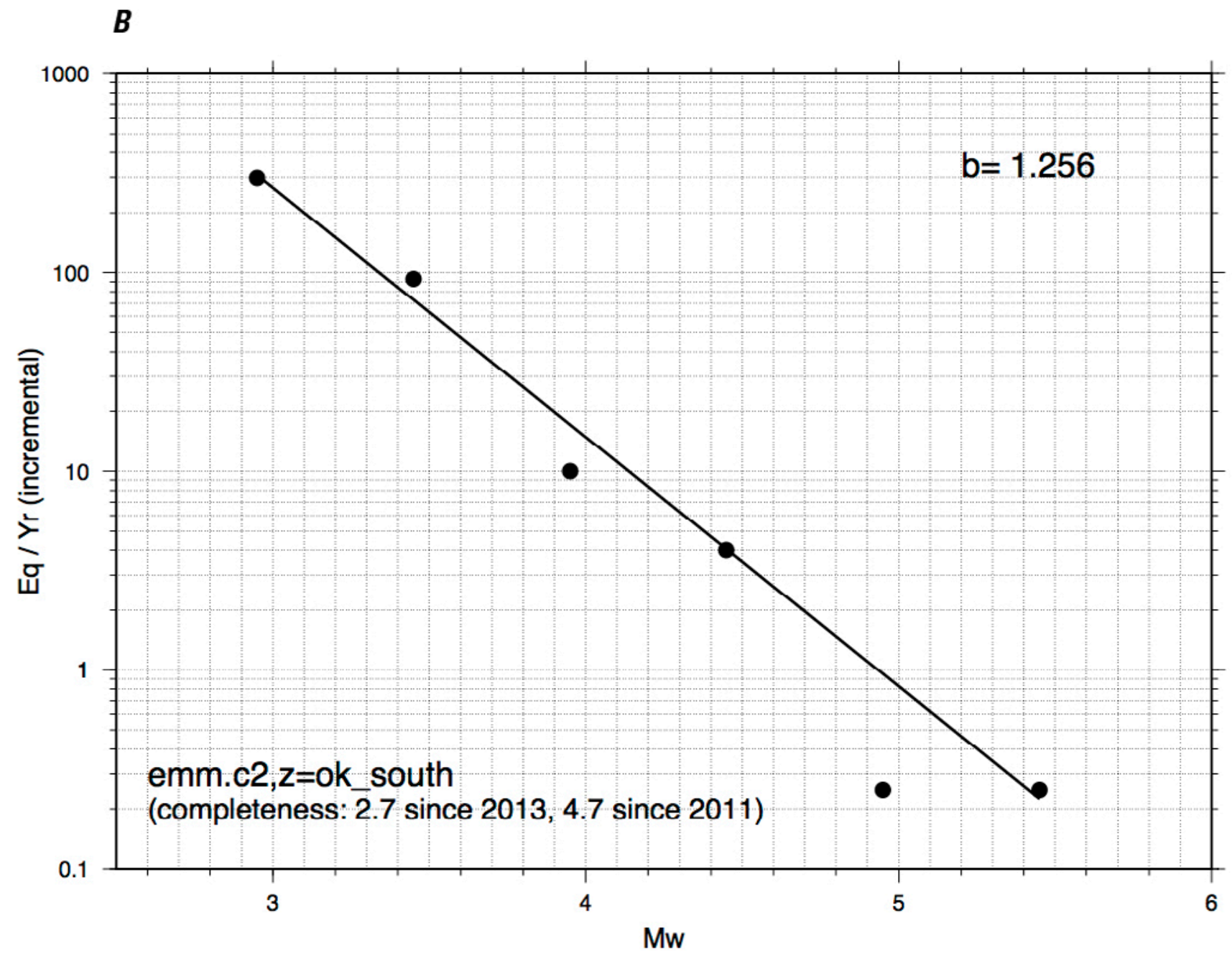

Figure 2-1. $A$, Seismicity in Oklahoma-south zone. The full (nondeclustered) earthquake catalog is shown with the years 1700-2012 as red, and 2013-2014 as green. B, b-value analysis for the Oklahoma-south full (nondeclustered) catalog. We assume completeness levels of M2.7 since 2013 and M4.7 since 2011. Eq/ $\mathrm{Yr}$ is the number of earthquakes in each 0.5 -magnitude unit bin per year, and $\mathrm{Mw}$ is moment magnitude.-Continued

Table 2-1. Earthquake counts in magnitude-time bins for Oklahoma-south nondeclustered catalog.

\begin{tabular}{cccccccc}
\hline & $\mathbf{2 . 7 - 3 . 2}$ & $\mathbf{3 . 2 - 3 . 7}$ & $\mathbf{3 . 7 - 4 . 2}$ & $\mathbf{4 . 2 - 4 . 7}$ & $\mathbf{4 . 7 - 5 . 2}$ & $\mathbf{5 . 2 - 5 . 7}$ & $\mathbf{5 . 7 - 6 . 2}$ \\
\hline $2001-2002$ & 3 & 0 & 0 & 0 & 0 & 0 & 0 \\
$2003-2004$ & 6 & 0 & 0 & 0 & 0 & 0 & 0 \\
$2005-2006$ & 8 & 0 & 0 & 0 & 0 & 0 & 0 \\
$2007-2008$ & 14 & 3 & 0 & 0 & 0 & 0 & 0 \\
$2009-2010$ & 115 & 10 & 3 & 1 & 0 & 0 & 0 \\
$2011-2012$ & 148 & 56 & 6 & 1 & 1 & 1 & 0 \\
$2013-2014$ & 598 & 186 & 20 & 8 & 0 & 0 & 0 \\
\hline
\end{tabular}


The Oklahoma-north catalog is mapped in figure 2-2A, and earthquake counts in 0.5-magnitude unit and 2-year bins are listed in table 2-2. For the analysis we assume a completeness level of M2.7 since 2013. Binned, incremental, annual earthquake rates and the b-value estimate of $1.44+/-0.05$ are plotted in figure $2-2 B$.

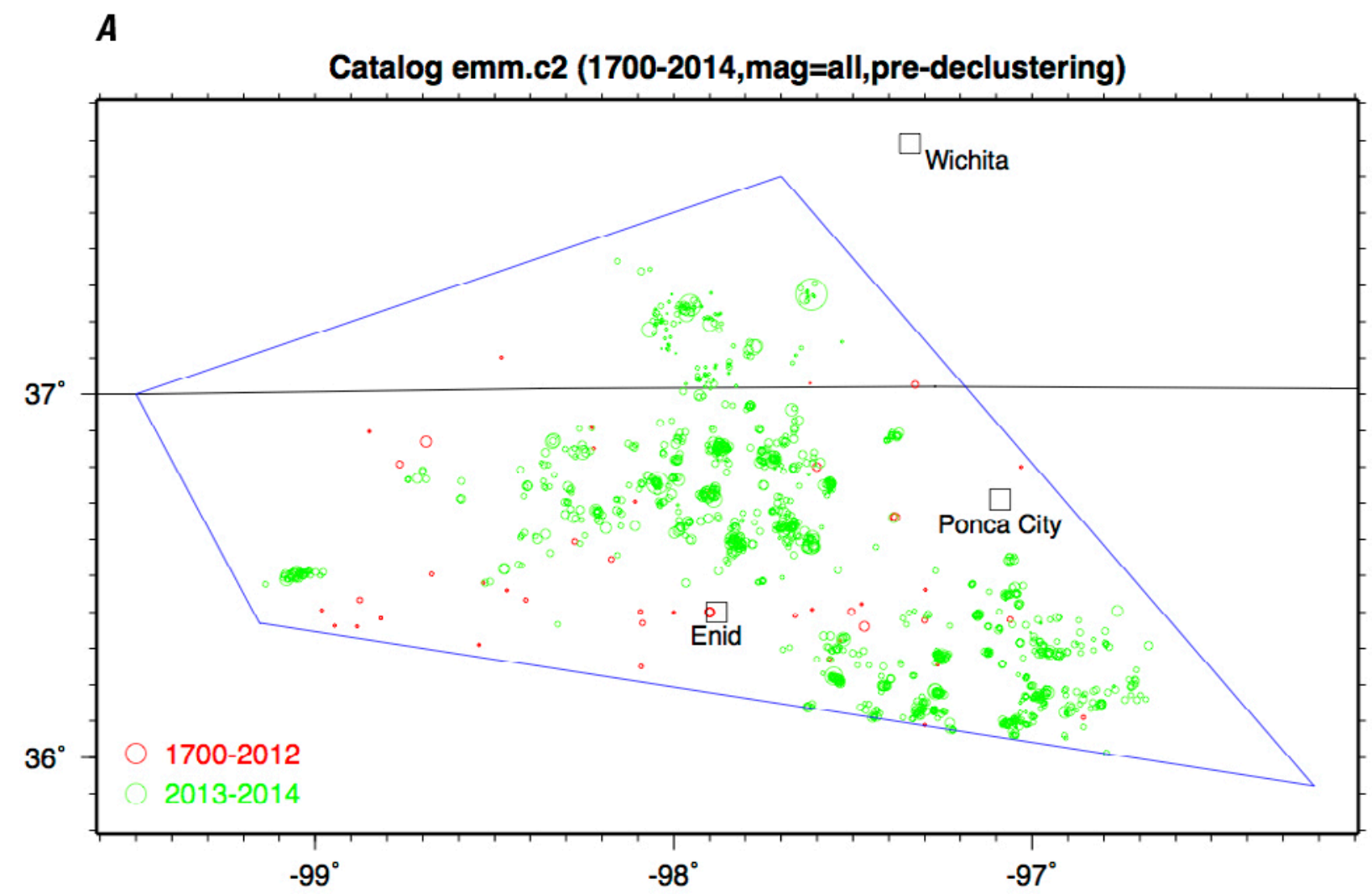

Figure 2-2. $A$, Seismicity in Oklahoma-north zone. The full (nondeclustered) earthquake catalog is shown with the years 1700-2012 as red, and 2013-2014 as green. B, b-value analysis for the Oklahoma-north full (nondeclustered) catalog. We assume completeness levels of M2.7 since 2013. Eq/ Yr is the number of earthquakes in each 0.5-magnitude unit bin per year, and $\mathrm{Mw}$ is moment magnitude. $C$, Comparison of the model and observed annual rate of earthquakes for Oklahoma-north full (nondeclustered) catalog. M is moment magnitude. 


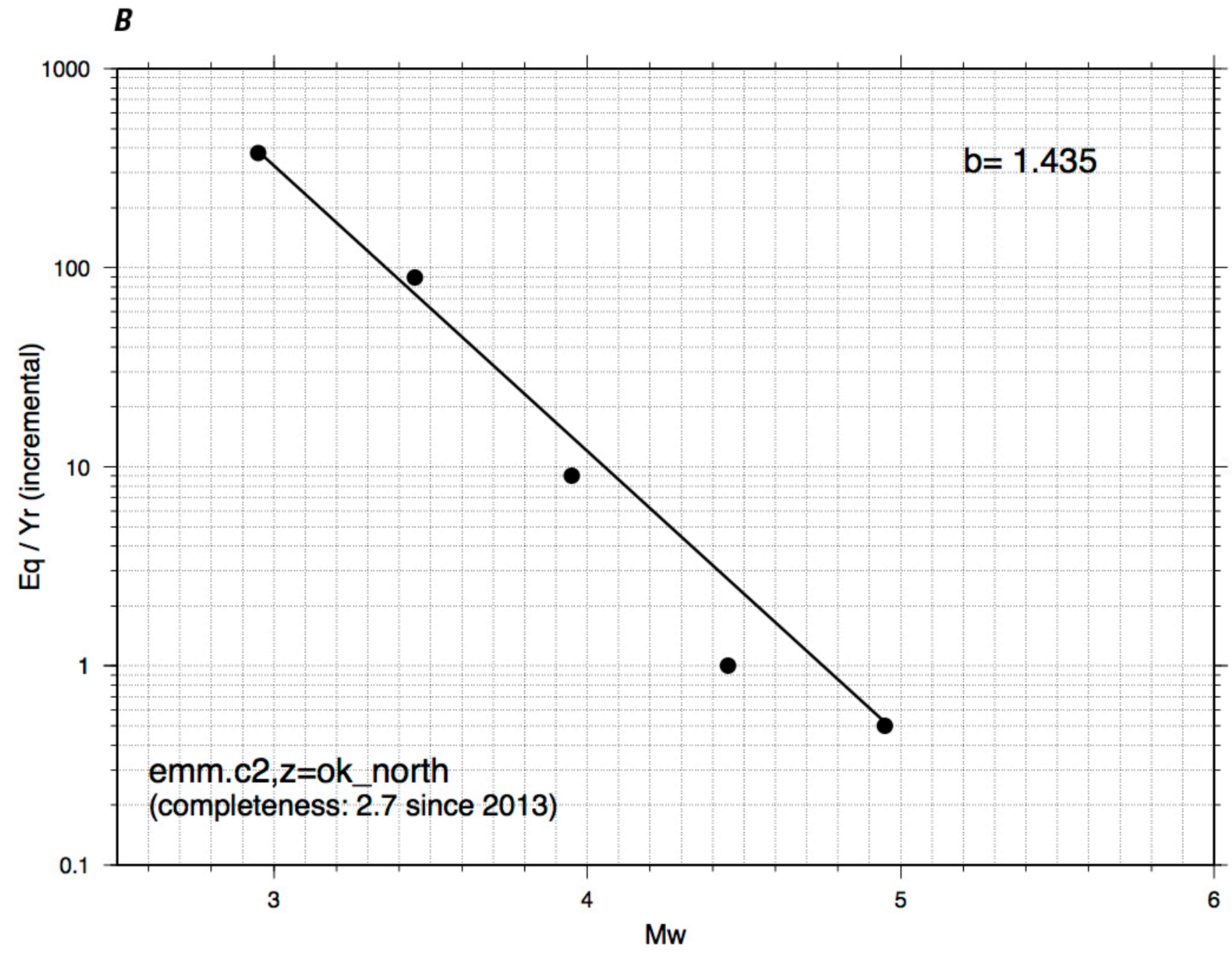

Figure 2-2. $A$, Seismicity in Oklahoma-north zone. The full (nondeclustered) earthquake catalog is shown with the years 1700-2012 as red, and 2013-2014 as green. B, b-value analysis for the Oklahoma-north full (nondeclustered) catalog. We assume completeness levels of M2.7 since 2013. Eq/ Yr is the number of earthquakes in each 0.5-magnitude unit bin per year, and $\mathrm{Mw}$ is moment magnitude. $C$, Comparison of the model and observed annual rate of earthquakes for Oklahoma-north full (nondeclustered) catalog. $\mathrm{M}$ is moment magnitude.-Continued 


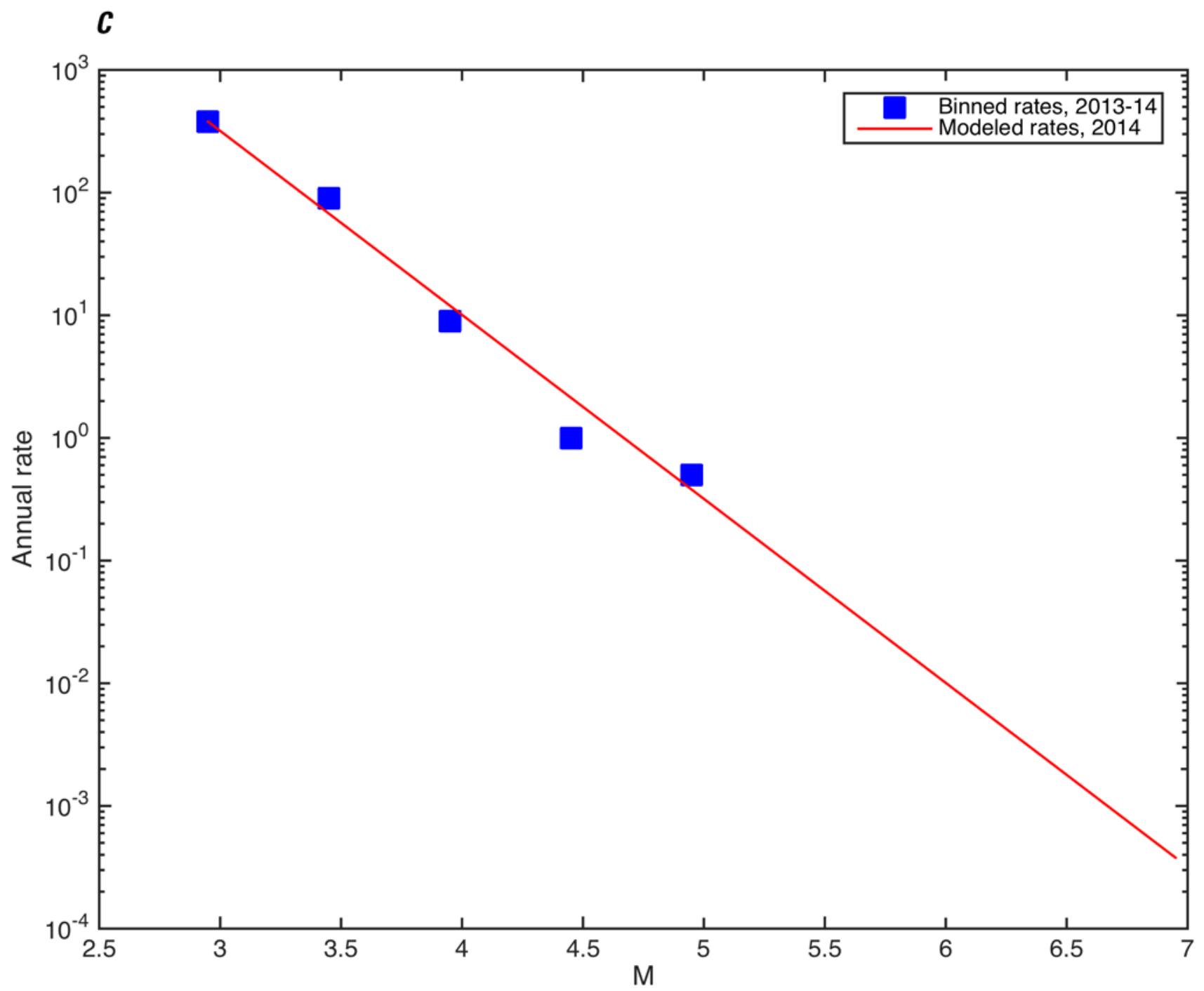

Figure 2-2. A, Seismicity in Oklahoma-north zone. The full (nondeclustered) earthquake catalog is shown with the years 1700-2012 as red, and 2013-2014 as green. B, b-value analysis for the Oklahoma-north full (nondeclustered) catalog. We assume completeness levels of M2.7 since 2013. Eq/ $\mathrm{Yr}$ is the number of earthquakes in each 0.5-magnitude unit bin per year, and $\mathrm{Mw}$ is moment magnitude. $C$, Comparison of the model and observed annual rate of earthquakes for Oklahoma-north full (nondeclustered) catalog. $\mathrm{M}$ is moment magnitude.-Continued 
Table 2-2. Earthquake counts in magnitude-time bins for Oklahoma-north nondeclustered catalog.

\begin{tabular}{lccccccc}
\hline & $\mathbf{2 . 7 - 3 . 2}$ & $\mathbf{3 . 2 - 3 . 7}$ & $\mathbf{3 . 7 - 4 . 2}$ & $\mathbf{4 . 2 - 4 . 7}$ & $\mathbf{4 . 7 - 5 . 2}$ & $\mathbf{5 . 2 - 5 . 7}$ & $\mathbf{5 . 7 - 6 . 2}$ \\
\hline $2001-2002$ & 0 & 0 & 0 & 0 & 0 & 0 & 0 \\
$2003-2004$ & 0 & 0 & 0 & 0 & 0 & 0 & 0 \\
$2005-2006$ & 1 & 0 & 0 & 0 & 0 & 0 & 0 \\
$2007-2008$ & 1 & 0 & 0 & 0 & 0 & 0 & 0 \\
$2009-2010$ & 1 & 1 & 0 & 0 & 0 & 0 & 0 \\
$2011-2012$ & 2 & 0 & 0 & 0 & 0 & 0 & 0 \\
$2013-2014$ & 754 & 179 & 18 & 2 & 1 & 0 & 0 \\
\hline
\end{tabular}

The analysis shows that b-values in the range 1.2-1.5 may be appropriate for recurrence models for recent (2001-14) seismicity in Oklahoma, using the full (nondeclustered) catalogs and depending on completeness assumptions. The Oklahoma-south and Oklahoma-north subcatalogs show evidence of incompleteness for magnitudes smaller than 2.7. Analysis of magnitudes 3.0 and greater with the full (nondeclustered) catalogs yields even larger b-values, in the range 1.5-2.0. Declustered Oklahoma catalogs yield $b$-values close to 1.0 for magnitudes 3.0 and greater, but uncertainties are large because of the smaller earthquake counts. A similar analysis for the full (nondeclustered) catalog for potentially induced earthquakes associated with the Raton Basin (as described in the main text and table 1 of this open-file report) yields a b-value close to 1.0, so it may not be appropriate to simply project the Oklahoma recurrence results into other cases of potential injection-related seismicity. A comparison of the model (using a b-value of 1.5) and observed rate of earthquakes in the Oklahoma-north zone is shown in figure 2-2C. The model is comparable to the observed rates for this zone. Magnitude 7 earthquakes recur about once every 3,300 years in this model.

\section{References Cited}

Petersen, M.D., Moschetti, M.P., Powers, P.M., Mueller, C.S., Haller, K.M., Frankel, A.D., Zeng, Yuehua, Rezaeian, Sanaz, Harmsen, S.C., Boyd, O.S., Field, Ned, Chen, Rui, Rukstales, K.S., Luco, Nico, Wheeler, R.L., Williams, R.A., and Olsen, A.H., 2014, Documentation for the 2014 update of the United States national seismic hazard maps: U.S. Geological Survey Open-File Report 2014$1091,210 \mathrm{p}$.

Weichert, D.H., 1980, Estimation of the earthquake recurrence parameters for unequal observation periods for different magnitudes: Bulletin of the Seismological Society of America, v. 70, no. 4, p. 1337-1346. 


\section{Appendix 3: Ratio Maps for Figures 13 through 17}

In this appendix, we show the ratios of the sensitivity study maps (report figs. 13-17) and the 2014 National Seismic Hazard Models (Petersen and others, 2014). The 2014 map for 5-Hz spectral acceleration and a 2-percent probability of exceedance in 50 years (equivalent to a 0.04 percent per year) on a firm rock (shear wave velocity [time-average] in the upper 30 meters [ $\left.\mathrm{V}_{\mathrm{S} 30}\right]$ of 760 meters per second $[\mathrm{m} / \mathrm{s}]$ ) uniform site condition is shown in figure 3-1. In the following figures (figs. 3-2-3-6), the ratio maps are generated for $5-\mathrm{Hz}$ spectral acceleration at a 0.04 -percent annual probability of exceedance on a firm rock site condition. The ratios are calculated by combining the induced seismicity hazard layer with the 2014 hazard (that excludes the induced seismicity), and then dividing this combined hazard by the 2014 hazard. Figure 3-2 shows the ratio of the base case **sensitivity study. Figure 3-3 shows the ratios for the base case but using a catalog with the minimum magnitude of moment magnitude (M) 3.0 rather than M2.5. Figure 3-4 shows the ratio for the base case but using a declustered catalog rather than the full (nondeclustered) catalog. Figure 3-5 shows the ratio of the base case but applies a b-value (the slope of the curve that relates the numbers of small and large earthquakes) of 1.5 rather than a b-value of 1.0 in the seismicity model. Figure 3-6 shows the base case but applies a declustered catalog and uses a 50-kilometer $(\mathrm{km})$ smoothing length rather than the $5-\mathrm{km}$ smoothing length applied in the base case. These maps all show ratios exceeding a factor of 3.0 over a broad region of Kansas, Oklahoma, and Texas and in smaller regions across portions of other states. On the plots, some ground motions may exceed ratios of 3.0 but are not distinguished in these figures.
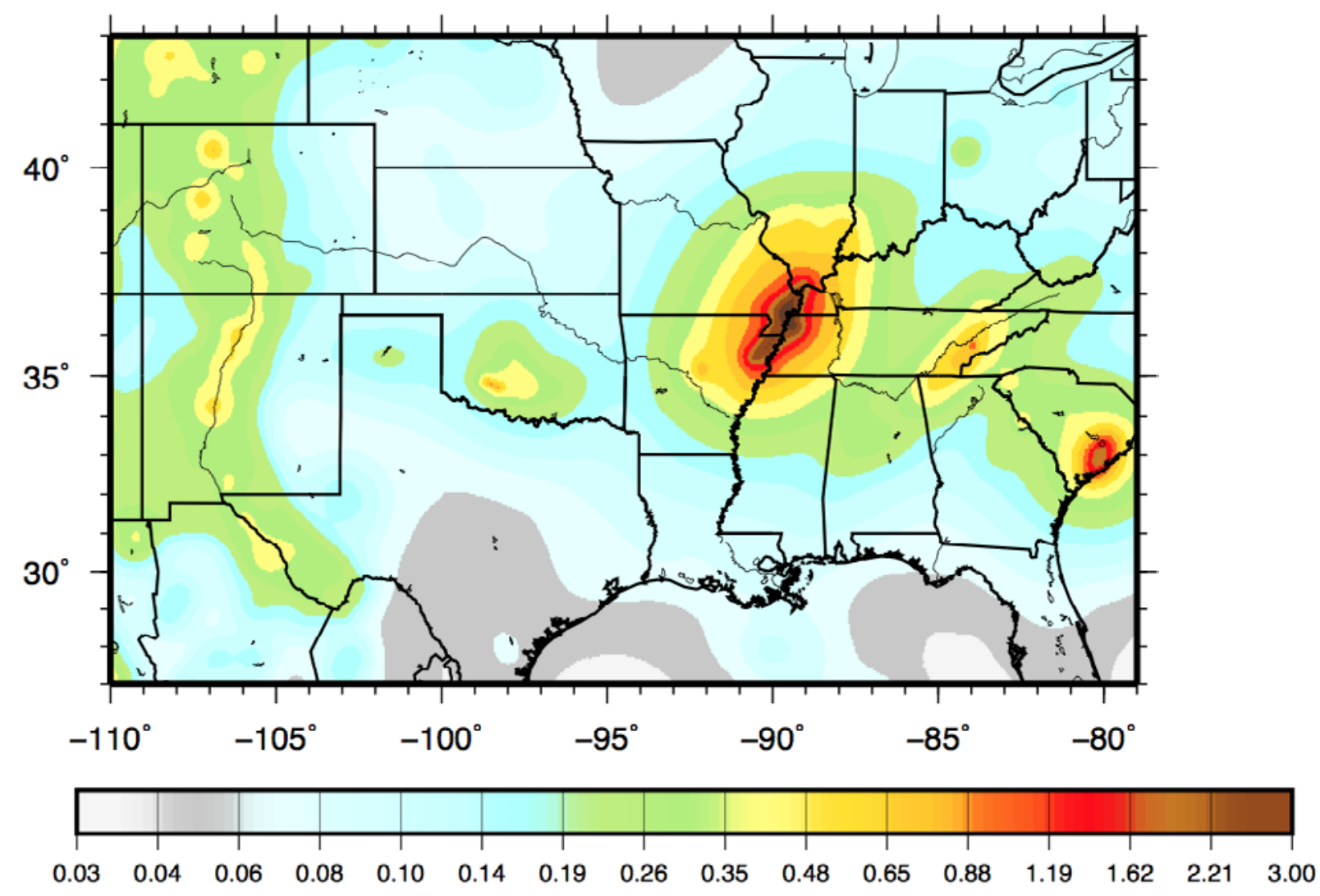

$5 \mathrm{~Hz}$ spectral acceleration for $0.04 \%$ probability of exceedance in one year

Figure 3-1. 2014 NSHM provided for reference. 


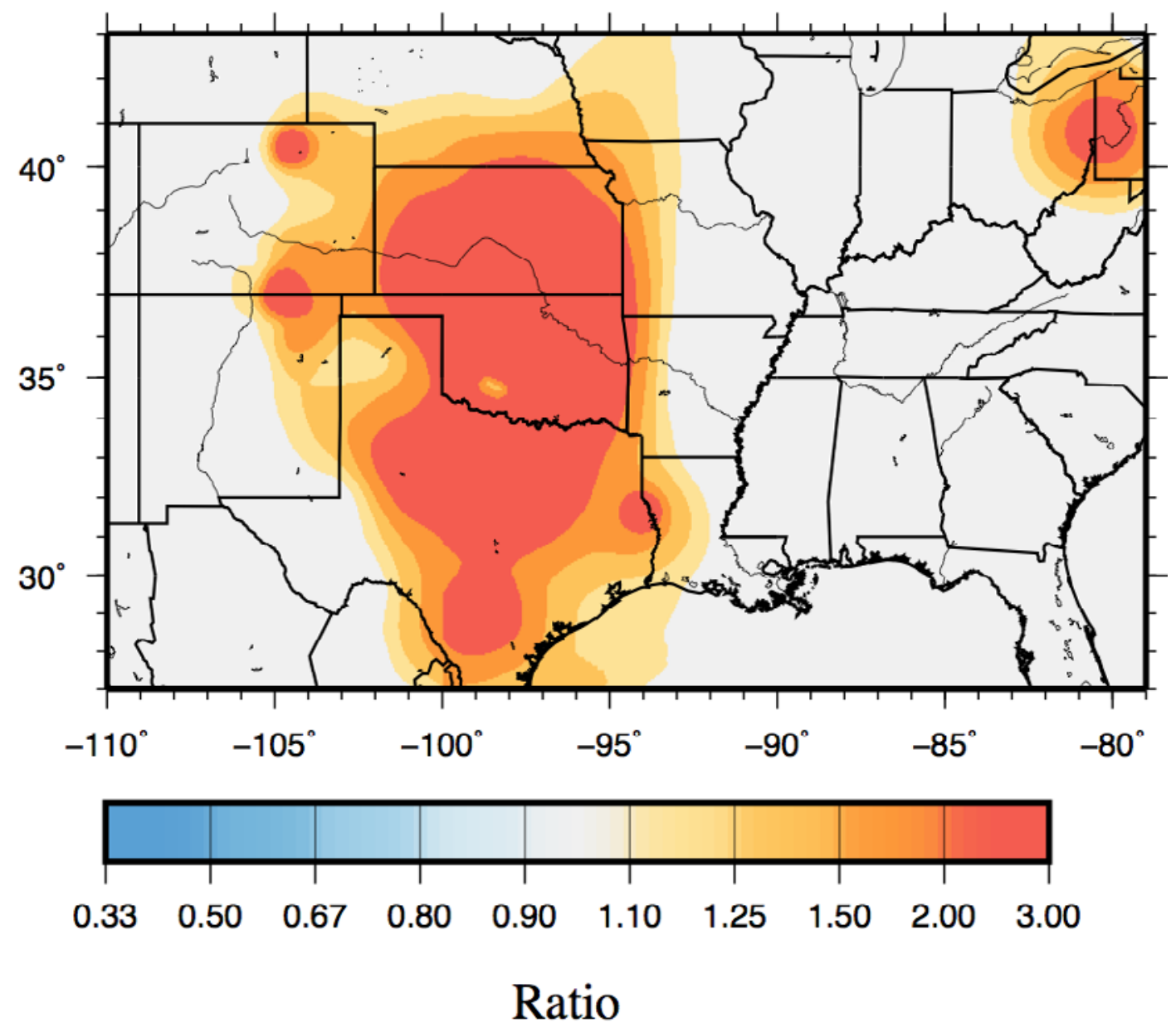

Figure 3-2. The base case combined with the 2014 NSHM (fig. 13) divided by the 2014 NSHM. 


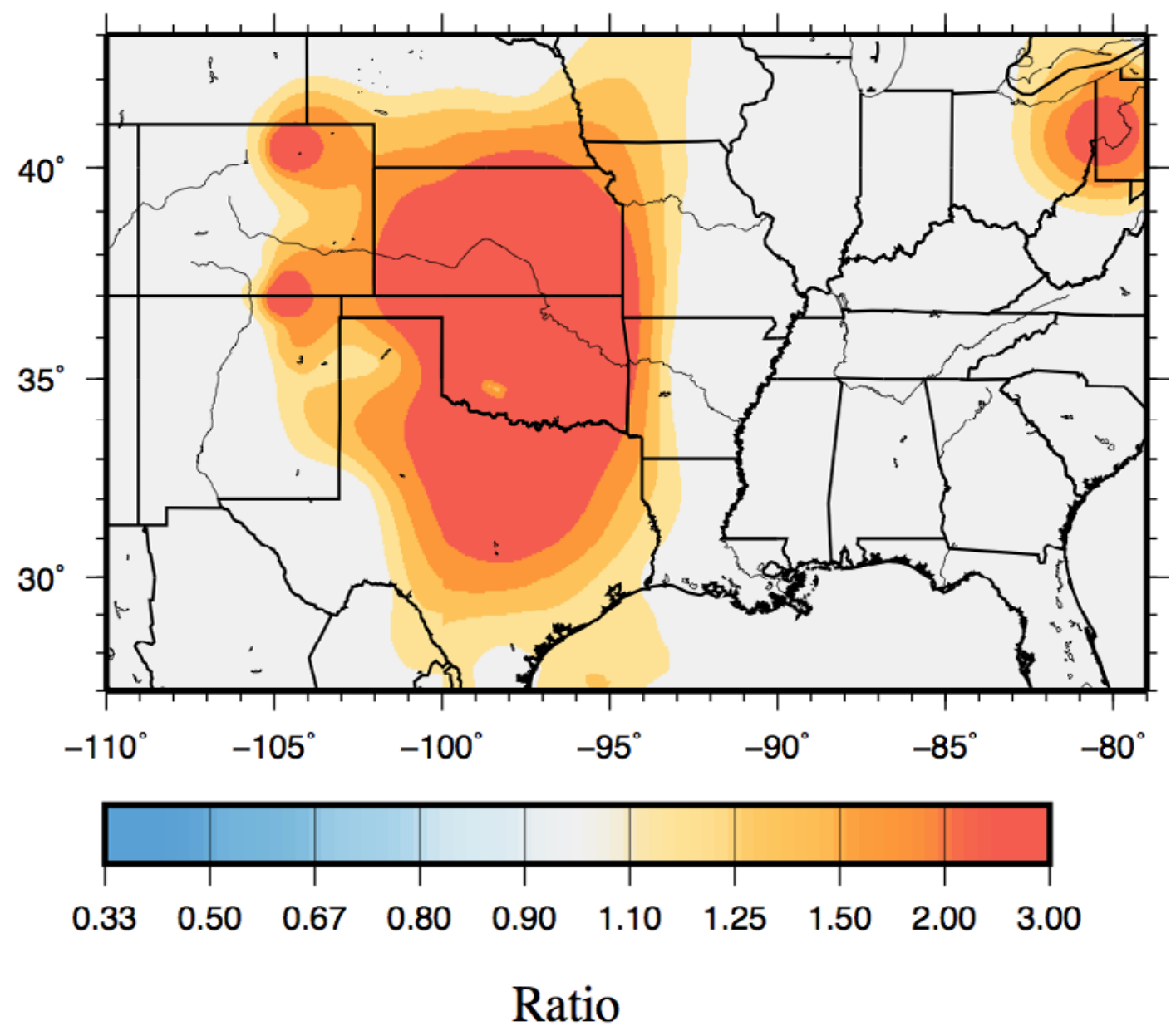

Figure 3-3. The base case modified by using moment magnitude (M) 3 minimum magnitude (Mmin) combined with the 2014 NSHM (fig. 14) divided by the 2014 NSHM. 


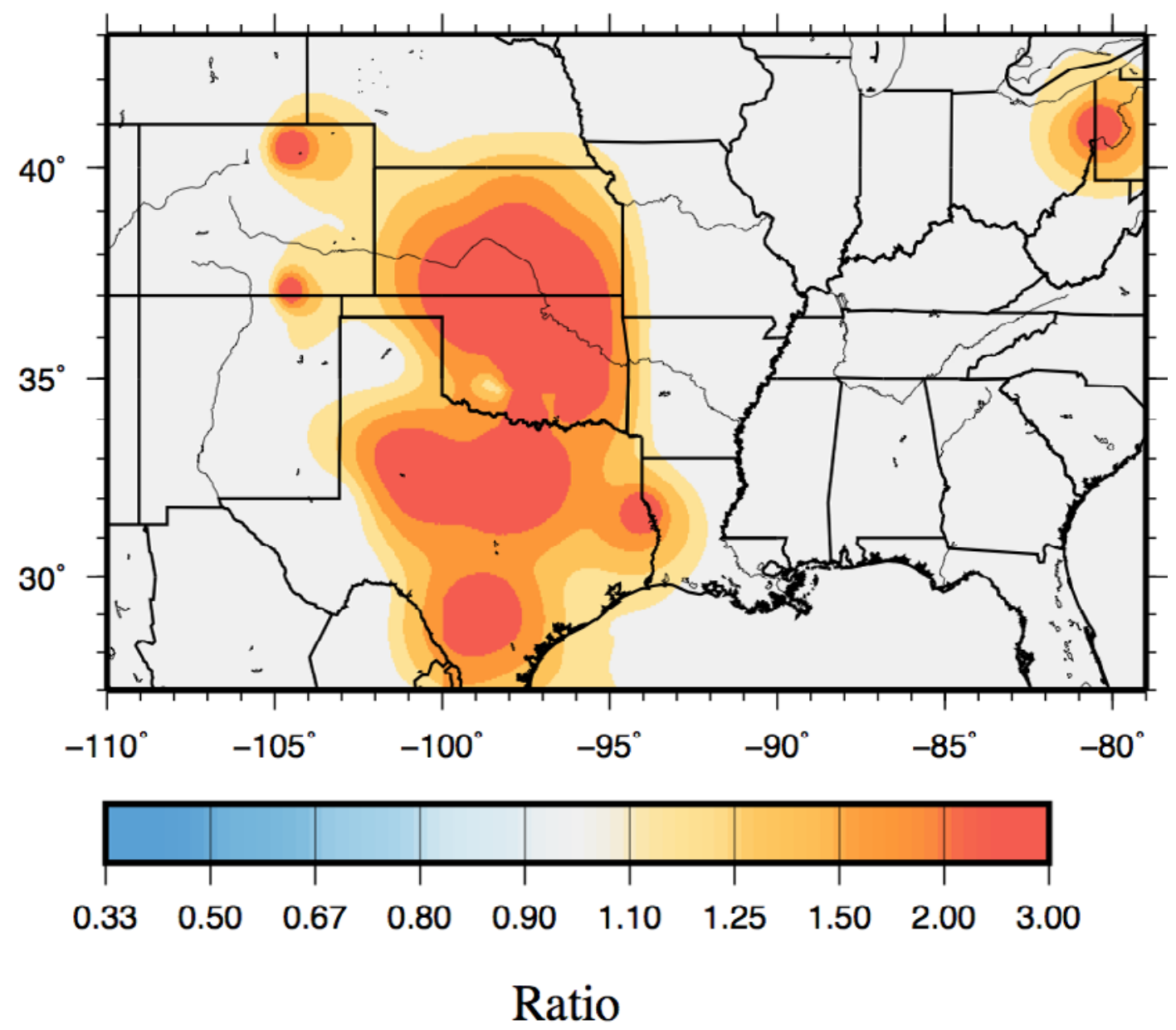

Figure 3-4. The base case modified by using the declustered catalog combined with the 2014 NSHM (fig. 15) divided by the 2014 NSHM. 


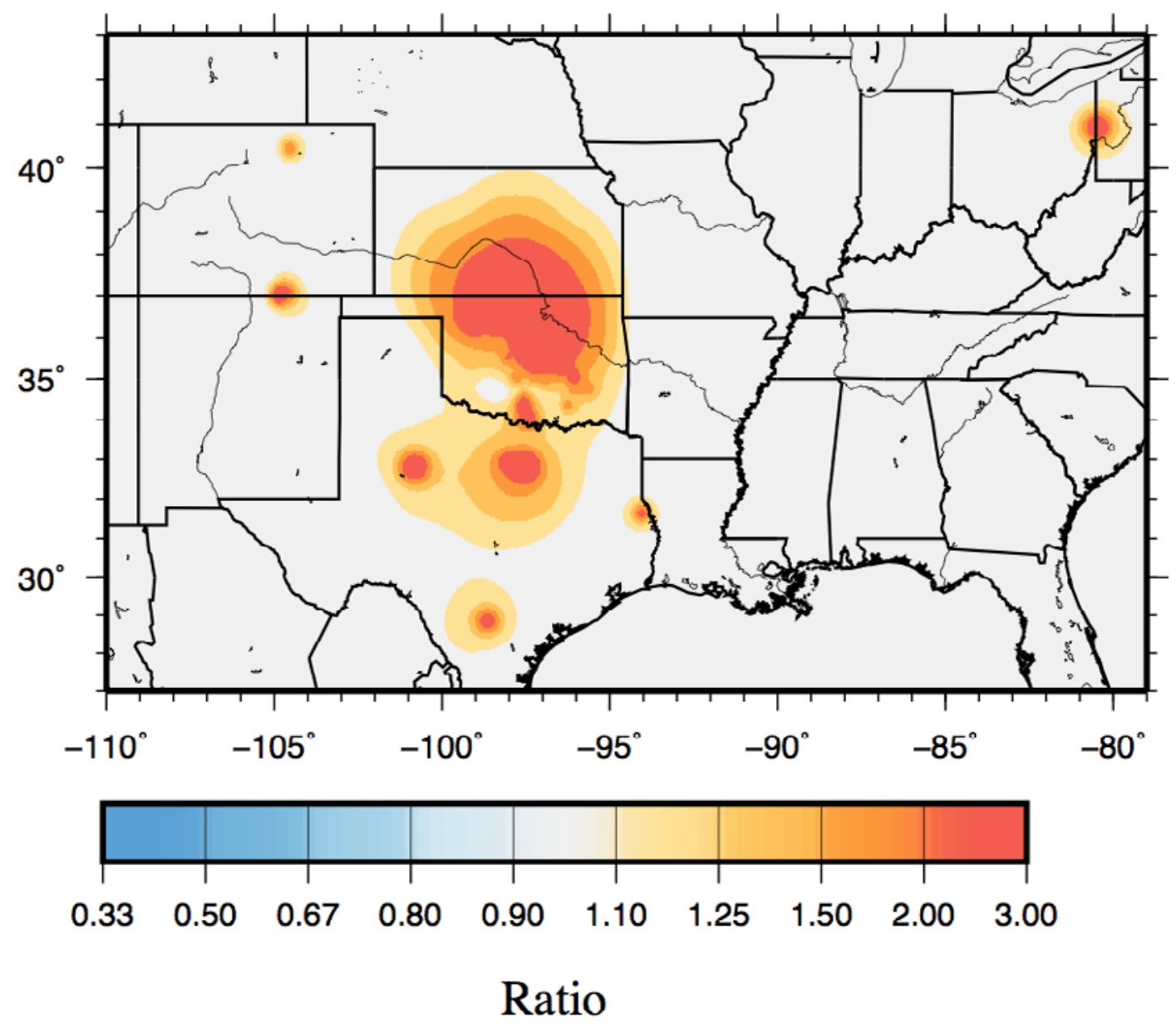

Figure 3-5. The base case modified by using b-value (the slope of the curve that relates the numbers of small and large earthquakes) equal to 1.5 combined with the 2014 NSHM (fig. 15) divided by the 2014 NSHM. 


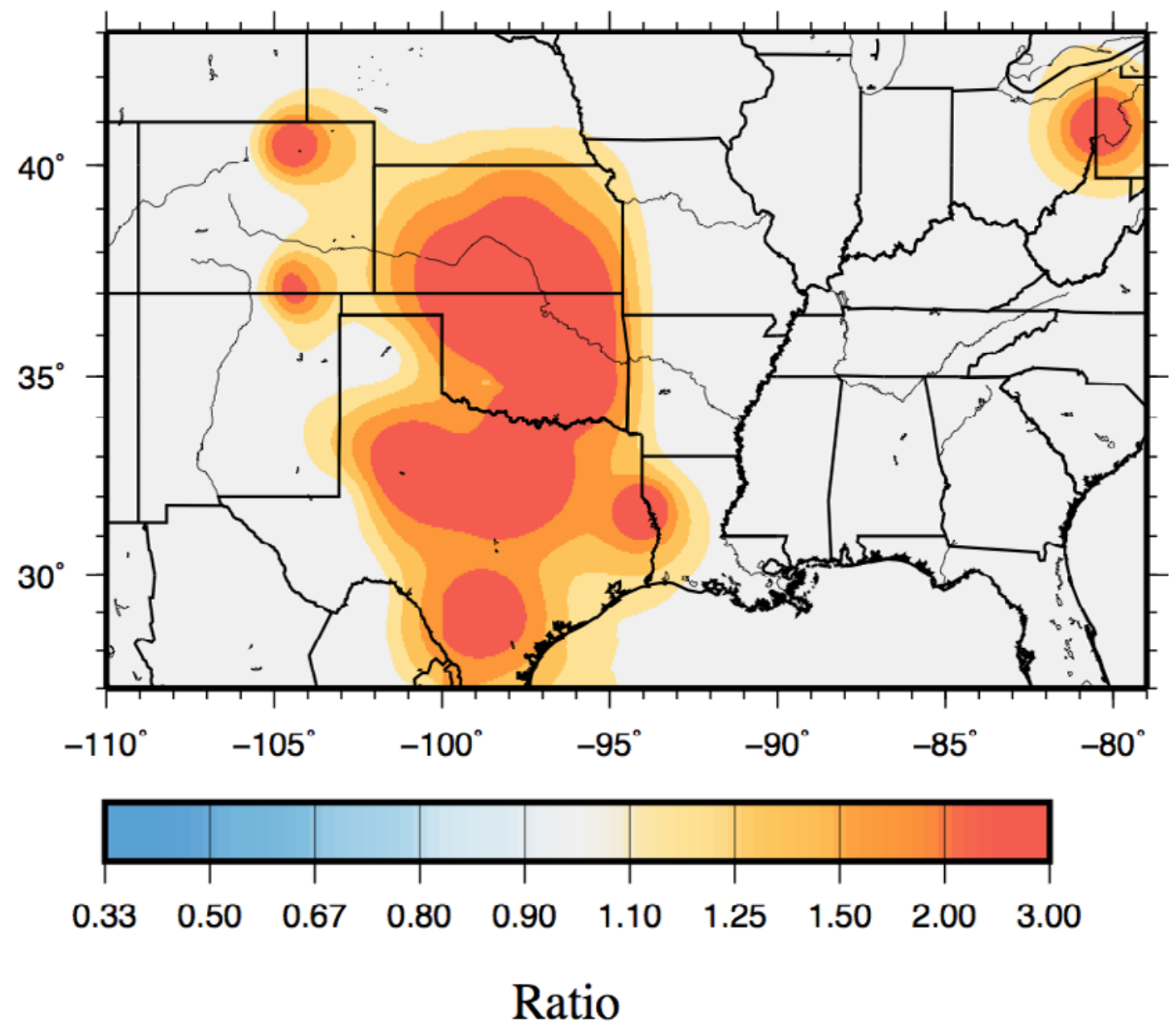

Figure 3-6. The base case modified by using the declustered catalog and 50-kilometer $(\mathrm{km})$ smoothing combined with the 2014 NSHM (fig. 15) divided by the 2014 NSHM.

\section{References Cited}

Petersen, M.D., Moschetti, M.P., Powers, P.M., Mueller, C.S., Haller, K.M., Frankel, A.D., Zeng, Yuehua, Rezaeian, Sanaz, Harmsen, S.C., Boyd, O.S., Field, Ned, Chen, Rui, Rukstales, K.S., Luco, Nico, Wheeler, R.L., Williams, R.A., and Olsen, A.H., 2014, Documentation for the 2014 update of the United States national seismic hazard maps: U.S. Geological Survey Open-File Report 2014$1091,210 \mathrm{p}$. 